Ricardo Palamar MENGHini

ECOLOGIA DE MANGUEZAIS: GRAU DE PERTURBAÇÃO E PROCESSOS REGENERATIVOS EM BOSQUES DE MANGUE DA ILHA BARNABÉ, BAIXADA SANTISTA, SÃO PAULO, BRASIL

Dissertação apresentada ao Instituto Oceanográfico da Universidade de São Paulo, como parte dos requisitos para obtenção do título de Mestre em Ciências, área de Oceanografia Biológica.

Orientadora:

Profa. Dra. Yara Schaeffer-Novelli 
Universidade de São Paulo

Instituto Oceanográfico

\title{
Ecologia de Manguezais: Grau de perturbação e processos regenerativos em bosques de mangue da Ilha Barnabé, Baixada Santista, São Paulo, Brasil
}

\author{
Ricardo Palamar Menghini
}

Dissertação apresentada ao Instituto Oceanográfico da Universidade de São Paulo, como parte dos requisitos para obtenção do título de Mestre em Ciências, área de Oceanografia Biológica.

Aprovado em

Prof $^{\mathrm{a}}$ Dr $^{\mathrm{a}}$ Berta Lange de Morretes

Professora Doutora no Departamento de Botânica do Instituto de Biociências da Universidade de São Paulo.

$\operatorname{Prof}^{\circ} \operatorname{Dr}^{\circ}$ Clemente Coelho-Júnior

Professor Doutor no Departamento de Biologia da Universidade Federal Rural de Pernambuco.

Prof $^{\text {a }} \operatorname{Dr}^{\mathrm{a}}$ Yara Schaeffer-Novelli

Professora Doutora no Departamento de Oceanografia Biológica do Instituto Oceanográfico da Universidade de São Paulo. 


\section{Manguetown}

Estou enfiado na lama

É um bairro sujo

Onde os urubus têm casas

E eu nâo tenho asas

Mas estou aqui em minha casa

Onde os urubus têm asas

vou pintando, segurando as paredes do mangue do meu quintal

Manguetown

andando por entre os becos

andando em coletivos

ninguém foge ao cheiro sujo

da lama da Manguetown

andando por entre becos

andando em coletivos

ninguém foge ao cheiro sujo

da lama da Manguetown

andando por entre becos

andando em coletivos

ninguém foge à vida suja dos dias da Manguetown

esta noite sairei

vou beber com meus amigos

e com as asas que os urubus me deram ao dia

eu voarei por toda a periferia

vou sonhando com a mulher

que talvez eu possa encontrar

ela também vai andar

na lama do meu quintal

Manguetown

andando... 


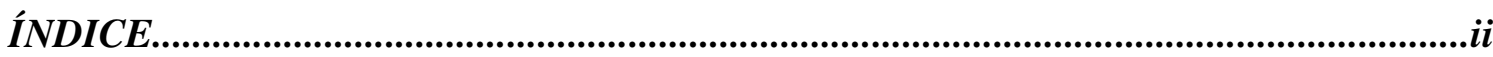

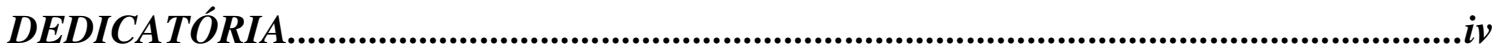

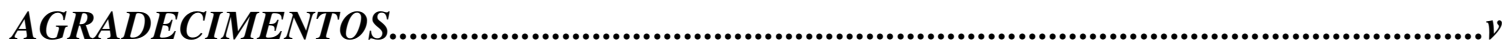

RESUMO

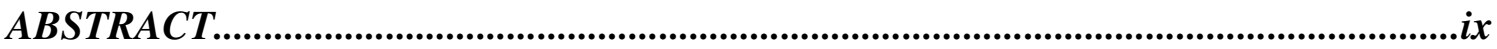

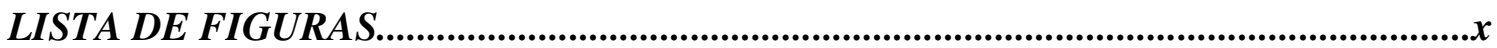

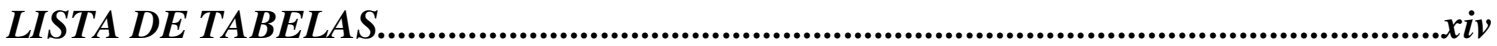

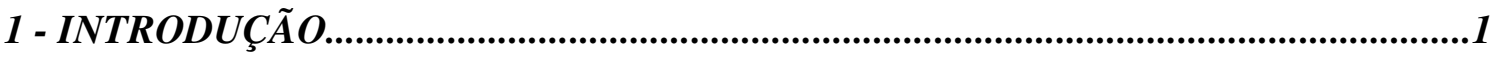

1.1 - Consideraç̃̃es Gerais................................................................................................1

1.2 - Funcionamento do ecossistema manguezal...........................................................2

1.3 - Ação de tensores no ecossistema manguezal..........................................................3

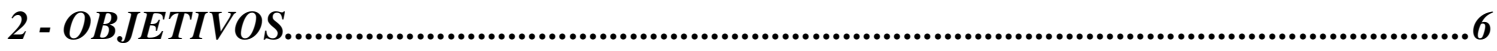

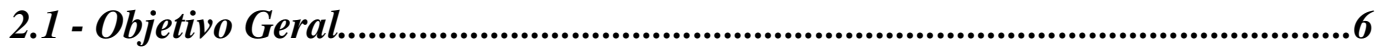

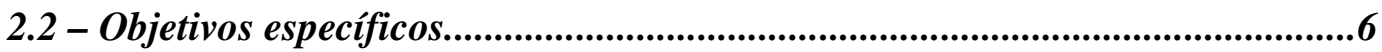

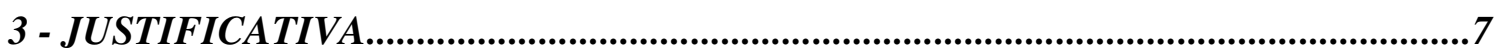

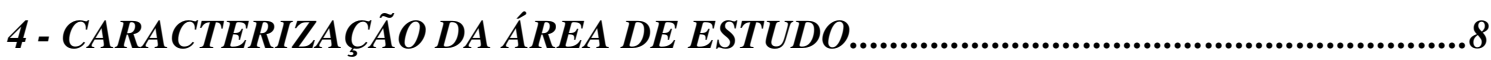

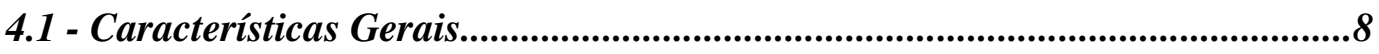

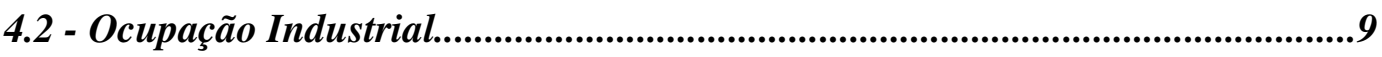

4.3 - Breve histórico do Porto de Santos..................................................................11

4.4 - Caracterização dos manguezais da região...................................................12

4.5 - Principais eventos ocorridos na Ilha Barnabé...................................................13

4.6 - Localização dos bosques de mangue estudados na Ilha Barnabé...................14 


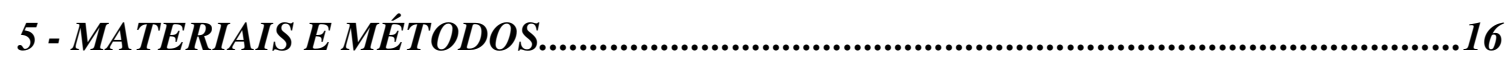

5.1 - Caracterização Estrutural....................................................................................16

5.1.1 - Tratamento dos Dados Estruturais...................................................17

5.2 - Caracterização da regeneração da cobertura vegetal........................................18

5.3 - Produção de serapilheira......................................................................................18

5.4 - Medidas Foliares........................................................................................19

5.4.1 - Análises Estatísticas..............................................................................20

5.5 - Microtopografia ...............................................................................................20

6 - RESULTADOS

6.1 - Características Estruturais..................................................................................22

6.2 - Regeneração da Cobertura Vegetal......................................................................23

6.3 - Produção de Serapilheira....................................................................................25

6.4 - Medidas Foliares....................................................................................................26

6.5 - Microtopografia do Entremarés...........................................................................28

7- DISCUSSÃO

7.1 - Estrutura da Cobertura Vegetal do Manguezal..................................................29

7.2 - Regeneração no Manguezal..................................................................................31

7.3 - Produção de Serapilheira do Bosque de Mangue...............................................35

7.4 - Folhas: "Locus" da Fotossíntese.....................................................................38

7.5 - Microtopografia do Entremarés............................................................................41

7.6 - Síntese do Funcionamento do Manguezal da Ilha Barnabé:.............................43

8 - CONCLUSÕES

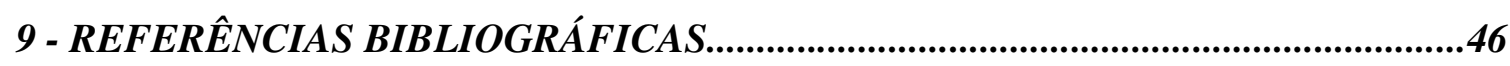


DEDICATÓRIA

Dedico este trabalho a minha Família (meus pais, Lupércio e Mahilde, aos meus avós, Vó Maria, Vô Güido "Dom Masca" e Vó Emília, e aos meus irmãos, Emerson e Daniel), amo muito todos vocês, Obrigado!!! 


\section{AGRADECIMENTOS}

À Professora Doutora Yara Schaeffer-Novelli, pela orientação e acima de tudo pelos constantes ensinamentos de ética profissional e cidadania. Prof ${ }^{a}$ Yara, você é um exemplo a ser seguido, o mundo estaria muito melhor se ao menos poucas pessoas fossem iguais a senhora. Obrigado pela oportunidade única de realizar o mestrado, sinto muito orgulho em fazer parte do BIOMA.

Ao grande amigo, Prof. Dr. Clemente Coelho-Júnior, sem a sua ajuda no início da caminhada, tudo seria mais difícil. Nunca vou me esquecer das idas para Cananéia, aprendi muito com você em campo, saber observar as pegadas, escutar os sons dos animais, reparar em mínimos detalhes, ou seja, trabalhar em campo com o satélite na cabeça !!!! Pois é.....você também me ensinou a valorizar profundamente o laboratório a céu aberto que temos a honra de estudar (Grané), e ele já está dando os seus primeiros frutos....as idas para o final de tarde regado a Itaipava, na praia do Tombo, depois das coletas já virou tradição, e muitas teorias interessantes também. Suarão, Juréia, Camburi (lembra aquela ressaca em Camburizinho?), até "Valapilheira" junto com as tainhas nós surfamos. Ó Grande Carunga, serei eternamente grato !!!!

Ao irmão André. Pangaré....acho que estamos indo na direção certa, da mesma forma que sonhávamos na época da faculdade, aliás, a melhor fase da minha vida. Quantas já passamos juntos, até fogo no meu apartamento de Santos você já colocou, e os forrózinhos no Barbatana? "malandro não cai, nem escorrega, malandro não dorme nem cochila, malandro não carrega embrulho, e tumem não entra em fila!!!! Precisamos ir visitar o Bacalhau, lembra dele? E a capoeira dentro do mangue em Bertioga? Sem falar nas inúmeras saídas para o litoral para pegar onda, fazer churrasco e tomar cerveja. Quando o Seu Roma estava lá então, era melhor ainda. É....existem coisas que passam, mas as verdadeiras amizades não. Valeu pelas inúmeras conversas na Granel, ida para campo com você é sempre mais divertido. Um grande abraço Fhaísca!!!!

Ao meu irmão mais velho Renatão....é capixaba, Cananéia não será mais a mesma sem você, aprendemos muitas coisas juntos por lá e curtimos outras tantas. Poder acompanhar o seu doutorado de perto foi um aprendizado enorme para mim. Cadeira na calçada no Jajú, teorias no Seu João, Gaivota depois das coletas (Sam's time), discussões 
dentro do mangue chovendo, densidade de tocas no cajueiro com sol a pino, e a felicidade de quando estalamos as torres de observação dentro do mangue? Obrigado também pela cansativa coleta de topografia, fomos guerreiros naquela ocasião!!! Sua visão Abarebebê é o seu diferencial, continue assim mano velho. Um grande abraço e boa sorte na sua empreitada pelo nordeste!!!!

Maryland, te considero minha irmã, você sempre esteve me mostrando como se comportar em situações difíceis. Também curtimos muito suas saídas a campo, até testemunho dentro do manguezal conseguimos fazer!!! Obrigado por todas as ajudas nos momentos em que eu estava mais no sufoco, principalmente pelas inúmeras ajudas na reta final.

À Gilberto Cintrón, um exemplo a ser seguido de simplicidade e sabedoria, a sua presença no BIOMA é inquestionável, e nos faz muito bem.

Aos sábios conselhos da Prof $^{a}$ Dr $^{a}$ Berta Lange de Morretes, espero poder continuar aprendendo com a senhora. Acredito que o "estágio" no seu laboratório será muito valioso para minha formação profissional.

À Prof ${ }^{\mathrm{a}} \operatorname{Dr}^{\mathrm{a}}$ Beatriz Beck Eichler, do Instituto Oceanográfico da USP, pelo apoio fundamental nos primeiros meses de mestrado.

Ao grande biólogo e profundo conhecedor dos manguezais da Baixada Santista, Renato Kiko. Espero continuar sendo seu parceiro em cursos, palestras, saídas a campo e tubos em Paúba, aprendi muito com você sobre a Baixada, valeu bodyboarder!!!

Aos meus bons amigos Koiti, Fabrício e Pelicano, as baladinhas nos finais de semana e nos feriados em São Pedro foram fundamentais para esfriar a cabeça e descontrair. Um grande abraço também, a todos os amigos de vocês, que acabaram virando meus amigos (Carol, Silvia, Fabí, Fernando, Bam-bam, Ricardo, Betão, Seu Durval e família e tantos outros). As cervejas tomadas no Henrique, Pepa, Enios, Mamães, etc...valem ouro e a amizade de vocês também.

Aos meus grandes camaradas de Santos (Arápa, Cauê, Marquinhos e Alvinho) por todos os momentos de alegrias, altas ondas, risadas e companheirismo. $\mathrm{O}$ pior de morar em São Paulo é ficar longe de vocês, das praias e das molecagens, mas dias melhores virão.....

Ao Sandrão, por todos os almoços, lanches, baladas e principalmente pelos rituais mineiros de sexta-feira à noite, que abrem o final de semana. 
Aos amigos do Instituto Oceanográfico (Cacá, Carol, Cintia capixaba, Cintia, Evelin, Fernanda, Francine, Gabriela, Mariana, Betinho, Gominha, Felipe, Marquinhos, Roni, Carlão, Pisetta) e a todos os outros amigos e amigas de corredores e festinhas!!!!

À todos os funcionários da empresa Granel Química que sempre nos apoiaram quando precisamos.

Aos funcionários da Base Sul do IOUSP de Cananéia (Irene, Fátima, Mara, Heloísa, Apolinário, Humberto, João, Clóvinho, Joãozinho, Chico, Zeca, Amauri, Gilson, João e Ricardo) por todo apoio nas coletas realizadas pelo laboratório BIOMA na região, embora os manguezais de Cananéia não terem sido o foco do meu estudo, o conhecimento adquirido por aí me ajudou muito no estudo dos manguezais da Baixada.

À todos funcionários do Instituto Oceanográfico e todas outras pessoas que de alguma forma contribuíram para a realização deste trabalho, muito obrigado!!!!

À CAPES (Coordenadoria de Aperfeiçoamento de Pessoal de Nível Superior) pela concessão da bolsa de mestrado.

À Vovó-do-mangue, Nanã e Iemanjá que estão sempre olhando pelos manguezais e me protegeram nas coletas de campo.

E a Deus, por me dar saúde e capacidade de continuar fazendo uma das coisas que eu mais gosto na vida.....pisar na lama!!!!! 


\section{RESUMO}

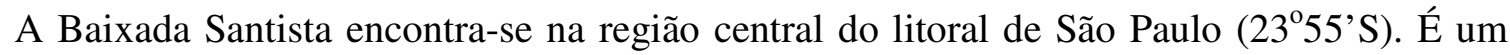
típico ambiente costeiro tropical dominado por extensos manguezais. Entretanto, o sistema vem sofrendo intenso processo de alteração ambiental devido a atividades industriais e portuárias, além da ausência de planejamento urbano. O presente estudo foi realizado em bosques de mangue na Ilha Barnabé, onde ocorreu derramamento e combustão de produto químico (diciclopentadieno - DCPD), em 1998. A fim de avaliar o grau de perturbação e os processos regenerativos dos bosques de mangue foram caracterizadas a estrutural vegetal, área foliar, microtopografia e produção de serapilheira, durante 25 meses, entre fevereiro de 2002 e a fevereiro de 2004. As características estruturais mostraram mortalidade e formação de clareiras seguidas de regeneração. Também foram observadas deformidades foliares e erosão como conseqüência do evento. A produção de serapilheira sugere certa desordem funcional no sistema. A metodologia utilizada mostrou-se adequada como ferramenta para avaliação de impactos em bosques de mangue. Sugere-se monitoramento de longo prazo nas áreas de manguezal impactadas para melhor compreensão dos efeitos de tensores naturais e/ou induzidos pelo homem.

Palavras-chave: manguezal, Baixada Santista, dinâmica de clareiras, regeneração, degradação. 


\section{ABSTRACT}

"Mangrove ecology: levels of responses and regenerative processes in mangrove stands at Barnabé Island, Baixada Santista, São Paulo, Brazil."

The Baixada Santista and Santos Estuary are located in the central portion of the São Paulo State coastline $\left(23^{\circ} 55^{\prime} \mathrm{S}\right)$. It is a typical tropical coastal environment dominated by extensive mangroves areas despite the intensive harbor and heavy industrial activities, and their location within a continually evolving human landscape. The present study was developed in a mangrove area at Barnabé Island (Santos Estuary), a site impacted in 1998 by a DCPD (dicyclopentadiene) spill that was followed by a fire. In order to assess residual impacts, and to describe natural restoration processes, leaf area, microtopography, and litter fall during the 25 months period from February 2002 to February 2004 was monitored. Structural changes included gap formation due to mangrove tree mortality and partial regeneration. Leaf deformities were observed as well as accelerated coastal erosion due to the loss of the mangrove fringe. Litter fall production suggests a systemic level functional impairment. The methodology used appears adequate to describe and assess the level of impact and recovery pattern of a mangrove stand affected by a chemical spill. It is suggested that more extensive (long-term) monitoring studies on impacted mangroves must be developed as effective tools helping to understand the response of systems exposed to natural or human-induced stressors.

Key words: mangroves, Baixada Santista, gap dynamics, regeneration, degradation. 


\section{LISTA DE FIGURAS}

Figura 1 - Diagrama proposto por Lugo (1978) e modificado por Lugo et al. (1981), ilustrando os diferentes pontos de atuação dos tensores no ecossistema manguezal.

Figura 2 - Localização das áreas de estudo, com bosques de mangue situando-se na porção leste da Ilha Barnabé (Foto aérea obtida no site www.agem.sp.gov.br).

Figura 3 - Localização das principais fontes de contaminantes químicos para a região da Baixada Santista.

Figura 4 - Visão do evento ocorrido na área de estudo, 3 de setembro de 1998, com derramamento e combustão de produto químico (DCPD - diciclopentadieno).

Figura 5 - Detalhe de plântula de Avicennia schaueriana com manchas de óleo sobre as folhas, durante evento ocorrido no dia 27 de abril de 2004.

Figura 6 - Cesta coletora de serapilheira instalada no bosque de mangue da Ilha Barnabé.

Figura 7 - Detalhe da cesta coletora de serapilheira.

Figura 8 - Detalhe do início do processo de regeneração da cobertura vegetal no bosque de mangue da Ilha Barnabé, no ano de 2000.

Figura 9 - Detalhe do processo de regeneração da cobertura vegetal no bosque de mangue da Ilha Barnabé, no ano de 2002.

Figura 10 - Detalhe do processo de regeneração da cobertura vegetal no bosque de mangue da Ilha Barnabé, no ano de 2004.

Figura 11 - Taxa de sobrevivência por espécie, na parcela em regeneração (R2), ao longo dos dois anos de monitoramento no bosque de mangue da Ilha Barnabé.

Figura 12 - Taxa de sobrevivência por espécie, na parcela em regeneração (R3), ao longo dos dois anos de monitoramento no bosque de mangue da Ilha Barnabé.

Figura 13 - Incremento na altura média dos indivíduos e dos indivíduos emergentes da parcela em regeneração (R2), ao longo dos dois anos de monitoramento no bosque de mangue da Ilha Barnabé.

Figura 14 - Incremento na altura média dos indivíduos e dos indivíduos emergentes da parcela em regeneração (R3), ao longo dos dois anos de monitoramento no bosque de mangue da Ilha Barnabé.

Figura 15 - Distribuição da frequiência de indivíduos, por classe de altura, na parcela em regeneração (R2), ao longo dos dois anos de monitoramento no bosque de mangue da Ilha Barnabé. 
Figura 16 - Distribuição da frequiência de indivíduos, por classe de altura, na parcela em regeneração (R3), ao longo dos dois anos de monitoramento no bosque de mangue da Ilha Barnabé.

Figura 17- Médias mensais da queda de serapilheira, no bosque de mangue da Ilha Barnabé.

Figura 18 - Médias mensais de cada compartimento na queda de serapilheira, no bosque de mangue da Ilha Barnabé.

Figura 19 - Contribuição em porcentagem de cada compartimento na queda anual de serapilheira do bosque de mangue da Ilha Barnabé.

Figura 20 - Contribuição em porcentagem de cada espécie na queda anual de folhas na serapilheira do bosque de mangue da Ilha Barnabé.

Figura 21 - Médias mensais da queda de folhas da serapilheira, no bosque de mangue da Ilha Barnabé.

Figura 22 - Médias mensais da queda de frutos da serapilheira, no bosque de mangue da Ilha Barnabé.

Figura 23 - Contribuição em porcentagem de cada espécie na queda anual de frutos na serapilheira do bosque de mangue da Ilha Barnabé.

Figura 24 - Propágulos deformados e abortados de Rhizophora mangle coletados pelas cestas de serapilheira no bosque de mangue da Ilha Barnabé.

Figura 25 - Médias mensais da queda de flores da serapilheira, no bosque de mangue da Ilha Barnabé.

Figura 26 - Contribuição em porcentagem de cada espécie na queda anual de flores na serapilheira do bosque de mangue da Ilha Barnabé.

Figura 27 - Médias mensais da queda de estípulas da serapilheira, no bosque de mangue da Ilha Barnabé.

Figura 28 - Médias mensais da queda de detritos da serapilheira, no bosque de mangue da Ilha Barnabé.

Figura 29 - Médias mensais da queda de madeira da serapilheira, no bosque de mangue da Ilha Barnabé.

Figura 30 - Prancha com os padrões de folhas de Avicennia schaueriana coletadas nos bosques de mangue da Ilha Barnabé. 
Figura 31 - Prancha com os padrões de folhas de Laguncularia racemosa coletadas nos bosques de mangue da Ilha Barnabé.

Figura 32 - Prancha com os padrões de folhas de Rhizophora mangle coletadas nos bosques de mangue da Ilha Barnabé.

Figura 33 - Áreas foliares de Avicennia schaueriana dos bosques de mangue da Ilha Barnabé.

Figura 34 - Áreas foliares de Laguncularia racemosa dos bosques de mangue da Ilha Barnabé.

Figura 35 - Modelo de terreno com curvas de nível (superior) e modelo de superfície (inferior) para a área de estudo onde se localiza o bosque remanescente.

Figura 36 - Modelo de terreno com curvas de nível (superior) e modelo de superfície (inferior) para a área de estudo onde se localiza o bosque remanescente, assinalando a localização do bosque remanescente (área verde, projetada no modelo de superfície como linha contínua), área em que ocupava a antiga franja do bosque (área vermelha, projetada no modelo de superfície como linha tracejada), além das parcelas de regeneração (R2 e R3) e cestas coletoras de serapilheira (pontos brancos).

Figura 37 - Modelo de superfície para a área onde se localiza o bosque remanescente, onde as setas bidirecionais indicam as áreas com presença de "sulcos de escoamento" de drenagem terrestre e de fluxo de maré vazante e enchente no terreno. A seta direcional indica a localização do desnível no terreno.

Figura 38 - Medidas foliares de Avicennia schaueriana dos bosques de mangue da Ilha Barnabé: controle $(\mathrm{O})$; remanescente $(\times)$ e regeneração $(+)$, comparados com dados de outros bosques da Baixada Santista $(\bullet)$ (Cetesb, 1988; Rodriguez et al., 1989).

Figura 39 - Medidas foliares de Laguncularia racemosa dos bosques de mangue da Ilha Barnabé: controle $(\mathrm{O})$; remanescente $(\times)$ e regeneração $(+)$, comparados com dados de outros bosques da Baixada Santista $(\bullet)$ (Cetesb, 1988; Rodriguez et al., 1989).

Figura 40 - Medidas foliares de Rhizophora mangle dos bosques de mangue da Ilha Barnabé: controle $(\mathrm{O})$; remanescente $(\times)$ e regeneração $(+)$, comparados com dados de outros bosques da Baixada Santista $(\bullet)$ (Cetesb, 1988; Rodriguez et al., 1989).

Figura 41 - Detalhe do constante embate de ondas que ocorre na franja do bosque de mangue às margens do Canal de Santos.

Figura 42 - Detalhe dos restos das raízes das árvores que morreram na franja do bosque no evento ocorrido em 1998.

Figura 43 - Detalhe do processo erosivo expondo o sistema radicial das árvores. 
Figura 44 - Detalhe de árvores mortas ainda em pé, devido a erosão.

Figura 45 - Modelo proposto por Duke (2001), onde A: processo ocorrido na franja do bosque, após perda da cobertura vegetal; B: processos regenerativos ocorrido nas partes internas do bosque, após abertura de clareiras no dossel e C: "vias de acesso" aos estágios iniciais de desenvolvimento.

Figura 46: Perfil esquemático dos processos ocorridos no bosque de mangue da Ilha Barnabé, onde: $\mathbf{A}=$ bosque antes do evento em 1998 (derramamento e combustão de produto químico); $\mathbf{B}=$ bosque após o evento, com as árvores da franja e alguns indivíduos do interior do bosque queimados, decorrentes do incêndio; $\mathbf{C}=$ após a morte das árvores da franja, a erosão começou e/ou se intensificou no local; $\mathbf{D}=$ perfil do bosque atualmente, com raízes expostas decorrentes da erosão e ausência de recrutamento de novos indivíduos na franja. Nota-se que as áreas internas do bosque, onde se formaram clareiras decorrentes da morte de alguns indivíduos, ocorreu o recrutamento de novos indivíduos, possibilitando desta forma a regeneração destas áreas. 


\section{LISTA DE TABELAS}

Tabela I - Principais fontes de poluição industrial na Baixada Santista (adaptado de CETESB, 2001).

Tabela II - Principais fontes de poluição nos terminais portuários da Baixada Santista (adaptado de CETESB, 2001).

Tabela III - Principais fontes de poluição relacionadas às áreas contaminadas da Baixada Santista (adaptado de CETESB, 2001).

Tabela IV - Dados populacionais dos municípios da Baixada Santista para os anos de 1996 e 2003.

Tabela V - Movimentação anual de cargas do Porto de Santos (em toneladas).

Tabela VI - Número de troncos vivos amostrados $(\mathrm{N})$, altura média e DAP médio dos bosques de mangue da Ilha Barnabé.

Tabela VII - Densidade relativa (\%) de troncos vivos e mortos, por espécie e por classe de DAP, nos bosques de mangue da Ilha Barnabé.

Tabela VIII - Área basal $\left(\mathrm{m}^{2} / \mathrm{ha}\right)$ viva e morta, por classe de DAP dos bosques de mangue da Ilha Barnabé.

Tabela IX - Dominância em área basal (\%) viva e morta, por espécie, nos bosques de mangue da Ilha Barnabé.

Tabela X - Número de indivíduos vivos e taxa de sobrevivência por espécie e total, altura média e taxa de crescimento da parcela em processo de regeneração (R2), do bosque de mangue da Ilha Barnabé.

Tabela XI - Número de indivíduos vivos e taxa de sobrevivência por espécie e total, altura média e taxa de crescimento da parcela em processo de regeneração (R3), do bosque de mangue da Ilha Barnabé.

Tabela XII - Número de troncos vivos amostrados (N), altura média e DAP médio das parcelas em processo de regeneração (R2 e R3) do bosque de mangue da Ilha Barnabé, nos anos de 2002 e 2004.

Tabela XIII - Densidade relativa (\%) de troncos vivos e mortos, por espécie e por classe de DAP, das parcelas em processo de regeneração (R2 e R3) do bosque de mangue da Ilha Barnabé, nos anos de 2002 e 2004.

Tabela XIV - Área basal $\left(\mathrm{m}^{2} / \mathrm{ha}\right)$ viva e morta, por classe de DAP das parcelas em processo de regeneração (R2 e R3) do bosque de mangue da Ilha Barnabé, nos anos de 2002 e 2004. 
Tabela XV - Dominância em área basal (\%) viva e morta, por espécie, das parcelas em processo de regeneração (R2 e R3) do bosque de mangue da Ilha Barnabé, nos anos de 2002 e 2004.

Tabela XVI - Resultados das análises estatísticas (Teste de Kruskal-Wallis e Tukey), com os respectivos valores médios, desvio padrão (DP), valor máximo e valor mínimo das medidas foliares dos bosques de mangue da Ilha Barnabé

Tabela XVII - Porcentagem (\%) das folhas de mangue coletadas na Ilha Barnabé que apresentaram deformações (anômalas), e para cada padrão de deformação encontrado por espécie. 


\section{1 - INTRODUÇ̃̃O}

\section{1 - Considerações Gerais}

Manguezal, ecossistema costeiro tropical cuja cobertura vegetal coloniza depósitos sedimentares formados por vasas lamosas, argilosas ou arenosas, ocupando a faixa do entremarés até o limite superior das preamares equinociais. A esse ambiente halófilo associa-se cobertura vegetal típica, com desenvolvimento de flora especializada, caracterizada por espécies arbóreas que lhe conferem fisionomia peculiar. Essas formações estão associadas a costas de baixa energia ou a ambientes estuarinos, lagunares, baías e enseadas, sendo considerado como importante zona úmida costeira tropical, onde as marés permitem um constante intercâmbio de água, nutrientes, sedimentos e organismos com as regiões costeiras adjacentes, sendo de grande valor ecológico para as áreas que extrapolam a do próprio ecossistema, providenciando diversos bens e serviços que atendem diretamente e indiretamente seres humanos e organismos costeiros (Lugo \& Snedaker, 1974; SchaefferNovelli, 1989; Twilley et al., 1996; Schaeffer-Novelli, 2002).

Costanza et al. (1997), estimaram um valor econômico para os bens e os serviços prestados à humanidade por 16 diferentes biomas da biosfera, sendo o valor médio estimado em US\$33 trilhões por ano. Os manguezais encontram-se entre os que mais fornecem bens e serviços, cerca de US $\$ 10$ mil por hectare por ano, totalizando uma quantia global superior a US\$1.6 bilhões/ano.

Nos últimos anos, tem sido dado maior atenção à conservação dos manguezais devido a esses atributos. No entanto, uma característica até então pouco considerada e, que também merece atenção especial, diz respeito ao papel dos manguezais na manutenção da alta diversidade biológica, estrutural e funcional da zona costeira, a despeito da reduzida diversidade de espécies vegetais típicas, quando comparada a outros ecossistemas (Soares, 1999).

Reunindo algumas características que pudessem evidenciar o maior desenvolvimento do ecossistema manguezal, Walsh (1974) propôs que este se daria nas seguintes condições: (a) temperatura média do mês mais frio superior a $20^{\circ} \mathrm{C}$ e amplitude térmica anual maior que $5^{\circ} \mathrm{C}$; (b) sedimentos predominantemente lodosos, ricos em matéria orgânica; (c) áreas abrigadas contra tormentas; (d) presença de água salgada, pois as espécies vegetais são halófitas facultativas e assim ganhariam na competição com 
espécies terrestres não adaptadas a presença do sal no sedimento; (e) grande amplitude de maré com reduzida declividade, o que permitiria a penetração de águas marinhas a grandes distâncias.

No Brasil o ecossistema manguezal é encontrado praticamente ao longo de todo litoral, do Oiapoque ( $\left.04^{\circ} 30^{\prime} \mathrm{N}\right)$ no Amapá até Laguna (2830’S) em Santa Catarina, limite austral de ocorrência desse ecossistema no Atlântico Sul. A área total ocupada varia entre $10.000 \mathrm{~km}^{2}$ (Herz, 1987) e $25.000 \mathrm{~km}^{2}$ (Saenger et al. 1983), em função das diferentes metodologias empregadas.

Os manguezais brasileiros apresentam formação vegetal típica constituída por 3 gêneros (Rhizophora, Avicennia e Laguncularia) sendo 6 as espécies (R. mangle L; $R$. racemosa G. F. Mayer; $R$. harrisonii Leechman; A. schaueriana Stapf. e Leech.; A. germinans (L.) Stearn; L. racemosa (L.) Gaetern. f.), além de espécies características de áreas de transição com outros ecossistemas. Para a região da Baixada Santista encontramos 3 espécies de mangue, $R$. mangle L., A. schaueriana Stapf. e Leech. e L. racemosa (L.) Gaetern. f. (Schaeffer-Novelli, 1987).

\section{2 - Funcionamento do ecossistema manguezal}

O conceito da "assinatura energética" foi introduzido por Odum (1967) para descrever os compartimentos de energia que operam sobre os ecossistemas, influenciando suas funções, sendo o ecossistema manguezal altamente subsidiado por energias externas, podendo ser destacadas a disponibilidade de correntes de água fluvial ou marinha, aporte de nutrientes trazidos pelos rios, marés, drenagem superficial e características do substrato. $\mathrm{O}$ aproveitamento máximo dessas fontes energéticas, permite alto grau de desenvolvimento estrutural e elevada produtividade, porém tensores naturais ou induzidos pelo homem podem drenar energia, removendo estrutura e/ou limitando o desenvolvimento (Cintrón \& Schaeffer-Novelli, 1985; Schaeffer-Novelli et al., 1990).

A ação dos tensores induzidos pelo homem somada a dos naturais que atuam sobre o ecossistema limita o desenvolvimento do bosque interferindo tanto nas características estruturais como na diversidade funcional do ecossistema manguezal (Cintrón \& SchaefferNovelli, 1984). 
Manguezais podem ser considerados ecossistemas naturalmente estressados, devido às condições ambientais em que se desenvolvem, tais como a salinidade do sedimento que dificulta a obtenção de água doce, fluxos das marés que removem energia potencial armazenada na forma de detritos orgânicos, processos geomorfológicos costeiros que podem causar erosão e/ou deposição de sedimentos e tempestades, furacões ou tsunamis que podem causar perdas de componentes estruturais do sistema (Lugo, 1980).

\section{3 - Ação de tensores no ecossistema manguezal}

Segundo Lugo (1978), o custo energético de um tensor a um sistema ocorre em função de: (1) intensidade do tensor, ou seja, quanto de energia é drenada por unidade de área e tempo; (2) efeito multiplicativo ou aditivo deste dreno de energia em todas as funções e na homeostase do sistema; (3) freqüência em que ocorre; (4) compartimento do ecossistema atingido; (5) condição do sistema durante o impacto; (6) intensidade de outros tensores durante o impacto; (7) efeito residual de outros tensores no sistema; e (8) freqüência de retorno deste tensor em particular.

Este custo energético varia de intensidade, conforme o ponto de ataque do tensor no ecossistema, sendo que Lugo (op. cit.), classificou em 5 tipos os tensores que podem atuar nos ecossistemas:

(1) Alterando a natureza da fonte principal de energia;

(2) Desviando uma porção da fonte principal de energia, antes da mesma ser incorporada ao sistema;

(3) Removendo energia potencial antes desta ser estocada, mas depois de ter sido transformada pelo processo fotossintético;

(4) Removendo estoques de fatores limitantes à fotossíntese (a) ou removendo porções da estrutura do sistema (b) à (d),

(5) Aumentando a taxa de respiração.

$\mathrm{O}$ mesmo autor cita ainda algumas propriedades que podem ser observadas em ecossistemas estressados:

- Sucessão da vegetação interrompida ou retornando periodicamente a estágios iniciais;

- Poucos estágios entre o pioneiro e o clímax; 
- Vegetação demonstrando estado de estresse, como aberrações ou deformações foliares em resposta aos tensores;

- Variações na intensidade do tensor podem mudar a composição das espécies (geralmente quando se aumenta a intensidade ocorre decréscimo na diversidade);

- Velocidade da sucessão ocorrendo em função do ambiente físico e dependendo do compartimento do sistema onde a desordem energética atua;

- Espécies apresentando zonação que reflete gradiente de estresse (não podendo ser confundidas com estágios sucessionais).

Lugo \& Snedaker (1974), sugeriram um modelo de funcionamento dos manguezais em função do ponto de ataque de tensores, onde: drenagens e canalizações atuariam sobre a ciclagem de materiais, reduzindo a entrada de nutrientes, água doce e matéria orgânica para o bosque; aumento de temperatura da água causando um incremento nas taxas de respiração nos organismos; deposição excessiva de sedimentos interferindo na ciclagem de nutrientes e trocas gasosas; cortes, herbicidas e furacões, removendo estrutura do sistema, incluindo a cobertura vegetal.

Odum \& Johannes (1975) revisaram a literatura que trata das respostas dos manguezais a tensores, tais como flutuações de salinidade, herbicidas, poluição por petróleo, inundação prolongada e estresse térmico, concluindo que as trocas gasosas entre raízes e sedimento são o "Calcanhar de Aquiles" dos manguezais, portanto os tensores que interferissem nesses processos seriam os mais prejudiciais aos manguezais.

Lugo et al. (1981), incorporaram aos manguezais a classificação proposta por Lugo (1978) sobre a atuação de tensores em sistemas naturais (Figura 1), concluindo que tensores como barragens, diques, canalizações e construções de estradas (que venham a alterar cursos d'água ao sistema) possuem capacidade de causar impactos mais severos aos manguezais quando comparados aos causados por fogo, corte de madeira ou herbivoria moderada, sendo que outros impactos seriam classificados em categorias intermediárias de severidade.

A nível global as perturbações induzidas pelo homem, principalmente à conversão de áreas de manguezal em fazendas de carcinocultura, áreas para agricultura, usos urbanos, industriais (e seus respectivos efluentes), desvios e/ou aprisionamento de leitos de rios e os 
grandes derramamentos de óleo, estariam entre as mais importantes formas de perturbação para este ecossistema.

Segundo Odum (1981), ecossistemas naturais possuem estratégias de crescimento e adaptações que os fazem aptos a se recompor após perturbações (atuações de tensores) naturais periódicas. $\mathrm{Na}$ ausência de efeitos residuais causados por tensores, o ecossistema pode voltar a um estado muito similar às condições pretéritas ao distúrbio. Porém, sofrendo a influência de tensores residuais e/ou eventos agudos, o sistema poderá eventualmente alcançar níveis simples de organização.

Há um limiar em que o ecossistema pode adaptar-se naturalmente sobre a ação de tensores naturais, entretanto, tensores induzidos pelo homem tendem a ser não seletivos, aleatórios e de grande intensidade, com periodicidade diferente daquela dos eventos naturais, sendo que a capacidade de um sistema regenerar depende da disponibilidade de energia suficiente para reorganizar a estrutura, dependendo ainda das condições ambientais em que o sistema encontra-se inserido (Lugo \& Snedaker, 1974; Lugo, 1978).

Duke (2001) concluiu que os processos de regeneração dos bosques de mangue podem ocorrer inteiramente via formação de clareiras (gaps), e cita como fatores que influenciam esta dinâmica de regeneração das espécies arbóreas: (a) estratégia reprodutiva envolvendo produção de propágulos; estabelecimento e desenvolvimento de plântulas e competição com plântulas vizinhas; (b) estratégias combinadas de reprodução e desenvolvimento vegetativo. 


\section{1 - Objetivo Geral}

Caracterizar o grau de perturbação e os processos regenerativos em bosques de mangue localizados na Ilha Barnabé (Baixada Santista), em decorrência dos diversos tensores atuantes na área, com ênfase especial ao evento ocorrido em 1998, com derramamento e combustão de produto químico (DCPD - diciclopentadieno).

\section{2 - Objetivos Específicos}

- Caracterizar a estrutura do bosque de mangue da Ilha Barnabé, visando quantificar o grau de perturbação da cobertura vegetal;

- Monitorar a capacidade de regeneração da cobertura vegetal, nas áreas onde foram registradas clareiras (gaps) no dossel do bosque remanescente, decorrentes da queima da vegetação;

- Avaliar a produção de serapilheira do bosque, no período de um ano (agosto de 2002 a agosto de 2003), visando analisar o funcionamento do ecossistema;

- Efetuar estudo das medidas foliares das espécies vegetais típicas de mangue, a fim de quantificar as perdas de área foliar decorrentes das deformações presentes nas folhas deste bosque;

- Estudar a microtopografia da área amostral, englobando o bosque remanescente e seu entorno, com o intuito de elucidar os processos erosivos presentes na área decorrentes da perda de cobertura vegetal na franja do bosque. 


\section{3 - JUSTIFICATIVA}

Manguezais são ecossistemas que apresentam condições propícias para alimentação, proteção e reprodução de muitas espécies animais, sendo considerado importante transformador de nutrientes em matéria orgânica, assim como gerador de bens e de serviços que pelo fato de não serem adequadamente quantificados e valorados, acabam tendo pouco peso nas decisões políticas, sendo que esta negligência tem comprometido seriamente a sustentabilidade dos seres humanos na biosfera (Schaeffer-Novelli, 1991; Costanza et al., 1997).

Lugo (1999), revisando os estudos realizados no ecossistema manguezal, identificou áreas que merecem maior atenção por parte dos pesquisadores, destacando as respostas do ecossistema a tensores e estudos sobre a capacidade de restauração do ecossistema. Como cada região possui tipos característicos de tensores, estes requerem uma avaliação apropriada com foco na sua intensidade, duração e tempo de retorno. Cada um destes aspectos é necessário para o entendimento da resposta das espécies envolvidas e do ecossistema como um todo. Comparações com a resposta de outros manguezais em diferentes partes do mundo são úteis, pois as respostas deste ecossistema são razoavelmente parecidas de acordo com o tipo de tensor e ponto de atuação no sistema (Lugo et al. 1981).

Lugo (op cit.) cita ainda a importância de se realizar estudos em manguezais alterados, visto que este foco de pesquisa tem sido ignorado pelos pesquisadores, e são estes estudos que irão determinar quais os atributos mais resilientes a ação de tensores. Tais resultados são imprescindíveis à formulação e implantação de projetos de recuperação de manguezais.

O presente trabalho apresenta como diferencial, o estudo do grau de perturbação e a capacidade de regeneração de bosque de mangue localizado em área impactada por derramamento e combustão de produto químico, sendo tal acontecimento ainda não descrito na literatura pertinente. Assim, configura-se o caráter inédito do presente estudo. 


\section{4 - CARACTERIZAÇÃO DA ÁREA DE ESTUDO:}

\section{1 - Características Gerais:}

A Baixada Santista encontra-se localizada no litoral do Estado de São Paulo ( $24^{\circ} 50^{\prime} \mathrm{S}, 46^{\circ} 45^{\prime} \mathrm{W}$ e $23^{\circ} 45^{\prime} \mathrm{S}, 45^{\circ} 50^{\prime} \mathrm{W}$ ), ocupando posição central na costa, ao entremear o Litoral Norte, caracterizado por costas altas, extremamente recortadas, com inúmeras enseadas, ilhas e cabos, e o Litoral Sul, dominantemente retilíneo com costas baixas, extensas e monótonas (Penteado, 1965). A região metropolitana da Baixada Santista engloba os municípios de Praia Grande, São Vicente, Cubatão, Santos, Guarujá e Bertioga (Figura 2).

Este setor do litoral de São Paulo apresenta, basicamente, duas formações geológicas principais: a área da escarpa da Serra do Mar e a planície sedimentar litorânea. Em frente à serra e circundando os morros e maciços isolados, desenvolve-se a planície sedimentar formada originalmente por aluviões, material de mangues atuais e antigos e por sedimentos de praias em geral (Rodrigues, 1965).

A proximidade com a Serra do Mar responde pelas características dos rios que deságuam na região, cujos fluxos são rápidos e intensos. Esta energia é perdida quando os cursos de água chegam à planície costeira com pouca ou nenhuma declividade, diminuindo sensivelmente este fluxo. Como resultado, córregos e canais são formados gerando uma complexa rede hidrológica, transformando vastas regiões em áreas úmidas sob influência de efetivo aporte de água doce e de águas salgadas trazidas pelas marés. Esse ambiente costeiro tropical torna-se propício ao desenvolvimento de extensos manguezais (Goldentein, 1972).

A região apresenta características climáticas bastante individualizadas, sob domínio alternado dos sistemas tropical e polar atlântico, podendo ser classificado como clima quente e úmido, com temperaturas máxima absoluta de $39^{\circ} \mathrm{C}$ e mínima absoluta de $10^{\circ} \mathrm{C}$, com temperatura média anual de $22^{\circ} \mathrm{C}$. A temperatura média no mês mais quente (fevereiro) é superior a $25^{\circ} \mathrm{C}$ e a média no mês mais frio (julho) é acima de $18^{\circ} \mathrm{C}$. Trata-se de região chuvosa, com valores mensais de precipitação acima de $100 \mathrm{~mm}$, durante todo o ano. A precipitação é maior no verão (janeiro-março) decrescendo no inverno (julhoagosto). A região não apresenta estação seca definida, com precipitação média anual entre 
2000 e $2500 \mathrm{~mm}$. A umidade relativa do ar é alta, alcançando cerca de $80 \%$ durante o ano. Quanto ao regime de ventos, há predomínio da situação de calmas, sem vento, em 51,8\% do período, seguidos do vento Sul $(11,6 \%)$ e do quadrante Leste $(7,9 \%)$, oriundos respectivamente do anticiclone polar e do anticiclone atlântico. Como ocorre em todo o litoral sudeste do Brasil, a região está sujeita à constante ação das massas de ar e das perturbações frontais que, freqüentemente, atuam na região (Santos, 1965; SchaefferNovelli, 1986).

A região é caracterizada por marés semi-diurnas, com alturas máximas de 1,6 m acima do nível médio que é de 0,77 m (DHN, 1984). A amplitude média de maré é de 0,926 $\mathrm{m}$, sendo que nas marés de quadratura é de 0,290 m e nas marés de sizígia é de 1,400 m (Hidroconsult, 1974).

Quanto a circulação das águas, existe um regime de circulação de água que caracteriza os braços dos Portos de Santos e de São Vicente, como parcialmente misturados. A fração de água doce que chega ao braço do Porto de Santos diminui das cabeceiras (63\%) para a boca da entrada do canal (21\%), sendo que o tempo médio de renovação de 99\% das águas, varia entre cinco (na região que corresponde à desembocadura do canal) e dois dias (na região que corresponde às cabeceiras), admitindose um modelo de estuário parcialmente misturado, sendo necessários dez ciclos de maré de sizígia para renovar essa quantidade de água. A vazão média efluente que escoa pela boca do canal do porto é de $690 \mathrm{~m}^{3} / \mathrm{s}$, sendo $130 \mathrm{~m}^{3} / \mathrm{s}$ aproximadamente de água doce, e 560 $\mathrm{m}^{3} / \mathrm{s}$ de água salgada provenientes do oceano (CETESB, 1978).

Tommasi (1979) aponta a existência de uma área de assoreamento em frente ao cais do Valongo e de Paquetá e, entre o primeiro e a Ilha Barnabé, contribuindo à formação de um giro de água no largo, em frente ao Canal de Bertioga, Ilha Barnabé, Ilha de São Vicente e Ilha de Santo Amaro. Este grande giro, neste ponto do estuário, já havia sido descrito por Kutner (1976), a partir de análises granulométricas dos sedimentos de fundo da região.

\section{2 - Ocupação Industrial}

A Baixada Santista apresenta importância socioeconômica nos contextos nacionalregional-metropolitano, devido ao parque poli-industrial de Cubatão, aos terminais 
marítimos em Cubatão, Santos e Vicente de Carvalho (Guarujá). A facilidade de escoamento da produção pelo Porto de Santos trouxe para a Baixada Santista um complexo de indústrias de base, transformando a região em pólo siderúrgico, petroquímico e energético, incluindo industrias de fertilizantes (Schaeffer-Novelli et al., 2003).

As principais razões que favoreceram a escolha da Baixada Santista como sede do primeiro complexo industrial nacional, foram: (1) a pré-existência de redes ferroviárias e rodoviárias e de um porto marítimo, fundamentais para o recebimento e escoamento de matérias-primas e produtos; (2) a proximidade de um grande centro consumidor (a cidade de São Paulo) e (3) a disponibilidade de água e presença da Usina de Henry Borden, gerando energia local (Azevedo, 1965).

A poluição de origem industrial constitui a principal fonte de contaminantes químicos para a região, não só pela diversidade dos poluentes envolvidos como também pelo volume lançado (CETESB, 2001). A Tabela I relaciona as principais fontes industriais de contaminação existentes na Baixada Santista. Dentre as principais fontes de contaminantes podemos destacar o complexo industrial de Cubatão e o canal da Cosipa, além das indústrias Dow Química situada no estuário de Santos (próxima ao Rio Santo Amaro) e Ciel situada no estuário de São Vicente (próxima ao Rio Santana).

Fontes de origem portuária (Tabela II) são, também, bastante diversificadas em virtude da ampla pauta de produtos manipulados pelos terminais, especialmente os de granéis líquidos (CETESB, op. cit.). Cabe ressaltar que acidentes ocorridos nestes terminais acabam despejando grandes quantidades de produtos químicos no ambiente, comprometendo seriamente as regiões envolvidas. Outro agravante é a drenagem que ocorre nos pátios destas empresas, principalmente em dias de chuva, tendo como destino final as águas do estuário.

As áreas com solos contaminados, descritas na Tabela III, constituem fontes de alto risco, devido à alta toxicidade, persistência e potencial de bioacumulação de alguns dos resíduos industriais depositados de forma irregular em diversos pontos da região (CETESB, op. cit.), sendo comum o afloramento destes resíduos no entorno das áreas de deposição, demonstrando a contaminação do lençol freático. Outro fator de risco nestas áreas deve-se a grande parte delas terem sido recobertas por vegetação naturalmente e não apresentarem 
nenhum aviso à população de serem áreas contaminadas, sendo comum à presença de pessoas nestas áreas com o intuito de lazer.

A contribuição de esgoto doméstico pelos assentamentos humanos às margens do estuário (palafitas) que carecem de saneamento básico é grande, e pelo fato de estarem localizados em áreas confinadas (dentro de estuário), a sua dispersão torna-se comprometida.

Na Figura 3 estão assinalados a localização das principais fontes de contaminantes químicos acima citados para a região da Baixada Santista.

Dados recentes revelam o crescimento populacional dos municípios da Baixada Santista entre os anos de 1996 e 2003 (Tabela IV), fato este que acarreta um maior aporte de esgotos domésticos e outras formas de poluição para a região.

A forma de ocupação industrial e portuária, juntamente com a falta de planejamento no que tange ao crescimento das áreas urbanas, são os principais meios de contaminação, além das constantes dragagens e aterros do complexo portuário, constituindo os principais agentes de perturbação do equilíbrio natural da região, afetando direta e indiretamente várias espécies de organismos aquáticos, com consequiências diretas às populações ribeirinhas tradicionais que subsistem da pesca.

\section{3 - Breve histórico do Porto de Santos}

O marco oficial da inauguração do Porto de Santos é 2 de fevereiro de 1892, após sua inauguração, o porto não parou de se expandir, atravessando todos os ciclos de crescimento econômico do país, até chegar ao período atual de amplo uso dos contêineres. Açúcar, café, laranja, algodão, adubo, carvão, trigo, sucos cítricos, soja, veículos, granéis líquidos diversos, em milhões de quilos, têm feito o cotidiano do porto, que já movimentou mais de 1 bilhão de toneladas de cargas diversas, desde 1892, até hoje. Atualmente, o Porto de Santos, movimenta anualmente mais de 42 milhões de toneladas de cargas diversas, número inimaginável em 1892, quando operou 125 mil toneladas. Com $12 \mathrm{~km}$ de cais, entre as duas margens do estuário de Santos, o porto entrou em nova fase de exploração, conseqüência da Lei 8.630/93, com arrendamento de áreas e instalações à iniciativa privada, mediante licitações públicas (CODESP, 2003). 
Com a atual demanda de crescimento econômico no país a movimentação de cargas dentro do Porto de Santos encontra-se em contínuo crescimento, como pode ser observado na Tabela V. Tanto o crescimento populacional quanto a demanda exercida pelo crescimento da atividade portuária, levou a construção da $2^{\circ}$ pista da Rodovia dos Imigrantes em 2002, interligando as regiões metropolitanas de São Paulo e da Baixada Santista.

\section{4 - Caracterização dos Manguezais da Baixada Santista}

A área total da Baixada Santista é de $1.329 \mathrm{~km}^{2}$, sendo que $10 \%\left(133 \mathrm{~km}^{2}\right)$ foram ocupados originalmente por manguezais (CETESB, 1991). Segundo Herz (1987), os manguezais da Baixada Santista representam cerca de $43 \%$ dos $231 \mathrm{~km}^{2}$ de manguezais do litoral paulista. Levantamento do estado de conservação dos manguezais nesta região, baseado em fotografias aéreas do período compreendido entre 1958 e 1989 demonstrou que $16 \%\left(21 \mathrm{~km}^{2}\right)$ haviam sido aterrados para ocupação urbana e industrial, $31 \%\left(42 \mathrm{~km}^{2}\right)$ estão ocupados por manguezais degradados e $13 \%\left(17 \mathrm{~km}^{2}\right)$ por manguezais altamente degradados, localizados principalmente no estuário de Santos. Apenas $40 \%\left(53 \mathrm{~km}^{2}\right)$ destes manguezais encontram-se razoavelmente bem conservados, principalmente em Bertioga e São Vicente (CETESB, 1990, 1991).

A partir dos dados de estrutura dos bosques de mangue e do nível de contaminação por metais pesados (levantados no período entre 1982 e 1984, em 33 pontos da Baixada Santista), foram identificados locais altamente contaminados e bosques de mangue bastante alterados pela poluição (CETESB, 1988).

Alguns trabalhos descreveram aspectos dos bosques de mangue da região da Baixada Santista: CETESB (1983; 1985; 1988; 1994); Lamparelli (1995); Comelli et al. (1996); Soares (1997); Menezes (2000); Pozzi-Neto (2001). Referências às respostas da cobertura vegetal aos diversos tensores que incidem sobre o ecossistema foram registrados pelos estudos de Ponte et al. $(1987$; 1990) e Rodrigues et al. (1990), especificamente como respostas a impactos causados por derramamentos de óleo. Não existem relatos de trabalhos realizados em bosque de mangue localizados em áreas impactadas por produtos químicos na região. 


\section{5 - Principais eventos ocorridos na Ilha Barnabé}

A Ilha Barnabé encontra-se localizada, na parte central do estuário de Santos, reunindo o maior volume de produtos químicos do Brasil em uma mesma área (cerca de 170 milhões de litros). Atualmente operam na ilha as empresas Vopak Brasterminais e Odfjell Terminals Granel Química Ltda.

O primeiro grande evento na Ilha Barnabé ocorreu em 24 de janeiro de 1954, onde o petroleiro "Cerro Gordo", durante manobra de descarga de combustíveis (óleo diesel, petróleo bruto, querosene e gasolina de aviação) incendiou-se a poucos metros da ilha. Aos 2 de setembro de 1969 o petroleiro "Guaporé" incendiou enquanto atracado no píer da ilha. Em 29 de julho de 1974, evento envolvendo explosão na ilha, ocasionou vazamento de 3.150 litros de tolueno nas águas do Estuário de Santos, além de causar a morte de um funcionário e ferimento em outros. Em 10 de outubro de 1991, dois tanques da empresa Granel Química, contendo acetato de vinila e acrilonitrila pegaram fogo após serem atingidos por um raio (Jornal A Tribuna, 4 de setembro de 1998, caderno Região, p.A9A14).

No dia 3 de setembro de 1998, incendiou-se caminhão-tanque ao ser carregado com 80 toneladas do líquido inflamável diciclopentadieno (DCPD). O incêndio foi provocado por vazamento na casa de bombas da empresa Vopak Brasterminais, instalada ao lado dos 66 tanques desta empresa. O líquido alcançou a área de manguezal fronteiriça à empresa, espalhando-se em direção ao bosque de mangue às margens do estuário (Figura 4), provocando graves danos, não somente à vegetação, pela queima dos troncos, galhos e folhas de indivíduos jovens e adultos, como também a fauna associada (CETESB, 1998; 1999).

Cabe destacar que o diciclopentadieno é obtido como subproduto na produção de etileno, possuindo fórmula estrutural $\mathrm{C}_{10} \mathrm{H}_{12}$, apresentando como rotas principais de contaminação o contato com a pele, olhos, inalação e ingestão. A exposição aguda pode provocar entre outras reações, depressão do sistema nervoso central, podendo ser fatal se ingerido em grandes quantidades, e o contato prolongado pode ser depressor do sistema nervoso central, além de comprometer pulmões e rins, sendo que pessoas que já tiveram problemas nestes órgãos têm maior predisposição a eventuais danos à saúde. O 
diciclopentadieno pode ser classificado como substância possivelmente carcinogênica para seres humanos (Equistar, 2003; Texmark, 2003).

Quanto às propriedades ecotoxicológicas é moderadamente tóxica para peixes, sendo possível a ocorrência de grande mortandade se alcançado o ambiente aquático. Sua adsorsão em matéria orgânica e no sedimento pode ser significante, sendo que quando esta última ocorre, pode tornar lento o processo de volatização. A biodegradação e a hidrólise não são esperadas como fatores importantes. Possui fator de bioacumulação de 93.2, indicando que o diciclopentadieno pode se bioacumular em peixes e outros organismos aquáticos (Equistar op cit.; Texmark op cit.).

O evento ocorrido na Ilha Barnabé em 1998 foi o de maior proporção, entretanto, aos 19 de abril de 1999 ocorreu novo acidente no interior da empresa Brasterminais seguido de explosão e incêndio durante operação de carregamento com coperaf I (hidrocarboneto halifático, obtido da industria petroquímica). Como o produto vazado foi consumido pelo incêndio, o volume que atingiu as águas do estuário não pôde ser estimado, porém observou-se grandes danos à vegetação de Hibiscus sp., espécie característica da transição entre o ecossistema manguezal e os ecossistemas terrestres (CETESB, 1999).

Altas concentrações de vapores do produto vazado (coperaf I), causam irritação ao trato respiratório, à pele e aos olhos, podendo provocar tonturas e dores de cabeça, além de depressor do sistema nervoso central, entretanto, sendo um hexano, não apresenta potencial de concentração na cadeia alimentar (CETESB, op cit.).

Cabe destacar ainda a entrada esporádica de pequenas quantidades de produtos químicos na área, aportadas pelas águas do estuário que inundam o bosque diariamente nas marés enchentes, como foi presenciado na área de estudo no dia 27/04/04, onde uma pequena quantidade de óleo atingiu parte do bosque (Figura 5), provavelmente oriundo das embarcações que trafegam no canal.

\section{6 - Localização dos bosques de mangue estudados na Ilha Barnabé}

Os bosques de mangue estudados situam-se na porção leste da Ilha Barnabé, em frente ao Canal de Santos (Figura 2). Neste estudo os bosques foram separados em três classes, intitulados: bosque remanescente, regeneração e controle.

O bosque atingido pelo derramamento e combustão do diciclopentadieno encontrase em área adjacente à empresa Odfjell Terminals Granel Química Ltda., e possuía uma 
área aproximada de $1650 \mathrm{~m}^{2}$, com 55 metros de frente e 30 metros de fundo, sendo que o bosque remanescente, possui área aproximada de $600 \mathrm{~m}^{2}$, localizado na parte central desta área e representa o bosque que permaneceu no local após o evento de 1998. O bosque regeneração representa a vegetação que está em processo regenerativo, decorrentes da formação das clareiras no dossel do bosque remanescente. O bosque escolhido como controle localiza-se do outro lado da desembocadura do Rio Diana e não foi afetado diretamente pelo evento de 1998. 


\section{5 - MATERIAIS E MÉTODOS}

\section{1 - Caracterização Estrutural}

Para realizar a caracterização estrutural do bosque remanescente, adotou-se metodologia padronizada por Cintrón \& Schaeffer-Novelli (1984) e Schaeffer-Novelli \& Cintrón (1986). Delimitaram-se parcelas que variaram de $10 \mathrm{~m}$ x $15 \mathrm{~m}$ à $3 \mathrm{~m}$ x $2 \mathrm{~m}$, cobrindo grande parte do bosque, sendo denominadas IB1, IB2 e IB3 (bosque remanescente) e R1, R2, R3 (regeneração). O estudo foi realizado em novembro de 2001, portanto, 36 meses após o evento com produto químico em 1998. Com o intuito de comparar os dados estruturais obtidos no bosque remanescente, em novembro de 2003 foi feita a caracterização estrutural da vegetação em bosque localizado na mesma ilha, porém não afetado diretamente pelo evento de 1998, sendo esta denominada parcela controle (C1) (Figura 2).

Apenas na parcela IB1 o número de indivíduos foi menor que o proposto pela metodologia. Tal fato justifica-se por ser a área do bosque remanescente mais afetada pelo impacto, com grande número de troncos mortos. Contudo, em função da alta taxa de recrutamento de novos indivíduos, optou-se por plotar duas parcelas, R1 e R2, dentro da parcela IB1. Posteriormente foram tratadas separadamente para uma melhor descrição dos processos de recomposição natural decorrentes na área de estudo.

Foram medidos os diâmetros à altura do peito (DAP) e altura total, da base da árvore à extremidade superior da copa, dos indivíduos com altura superior a $1 \mathrm{~m}$. No caso dos indivíduos menores das parcelas R1, R2 e R3, substituiu-se o DAP pelo diâmetro do tronco abaixo da primeira ramificação, doravante referidos também como DAP para efeito prático.

Com base nos dados obtidos em campo, foram calculadas para cada parcela: densidades de troncos vivos e mortos de cada espécie, área basal viva e morta, dominância em área basal de troncos vivos e mortos, DAP médio e altura média do bosque. 


\subsection{1 - Tratamento dos Dados Estruturais}

As medidas obtidas in situ foram registradas em fichas de campo e posteriormente transferidas para planilha Excel para tratamento de dados estruturais de manguezal. Para cálculo de área basal, utilizou-se a seguinte fórmula:

\section{$\mathrm{AB}=0,00007854(\mathrm{DAP})^{2}$}

Onde: $\mathrm{AB}=$ área basal $\left(\mathrm{m}^{2}\right)$

$\mathrm{DAP}=$ diâmetro à altura do peito $(\mathrm{cm})$

A área basal do bosque é a soma das áreas basais de todos os troncos medidos por unidade de área. A área total da parcela $\left(\mathrm{em} \mathrm{m}^{2}\right)$ é convertida em 1 hectare (ha). Esta medida é um ótimo índice do grau de desenvolvimento estrutural do bosque, pois está relacionada ao volume de madeira e biomassa, assim como indicadora de eventuais impactos ocorridos na estrutura, neste caso refletindo nos valores de área basal morta.

A área basal média $(\overline{\mathrm{AB}})$ é obtida dividindo-se o valor da área basal pelo número de troncos medidos:

$$
(\mathbf{A B})=\frac{\overline{\mathbf{A B}}}{\mathbf{n}}
$$

O diâmetro médio $(\overline{\mathrm{DA}})$ de um bosque considera o diâmetro da árvore de área basal média. $\mathrm{O}$ valor do diâmetro médio é sempre maior do que a média dos diâmetros. $\mathrm{O}$ diâmetro médio é uma medida descritiva, permitindo comparações entre bosques de mangue. Calcula-se o diâmetro médio pela expressão:

$$
\overline{\mathrm{DAP}}=\underline{(\mathrm{AB})(\mathbf{1 2 7 3 2 , 3 9 )}}
$$

Onde: $\mathrm{AB}=$ área basal;

n

$\mathrm{n}=$ número de indivíduos por hectare. 
A comunidade pode ser descrita ainda, pela contribuição do número de espécies para o bosque, registrada em densidade:

\section{Densidade relativa $=\underline{\text { número de indivíduos de uma espécie }} \times 100$ número total de indivíduos}

\section{Dominância relativa $=\underline{\text { dominância de uma espécie }} \times 100$ dominância total $(\mathrm{AB})$}

O cálculo para a altura média é obtida a partir da média aritmética de todas as árvores vivas de cada parcela.

\section{2 - Caracterização da Regeneração da Cobertura Vegetal}

Durante a realização da caracterização estrutural do bosque de mangue remanescente aos eventos, foram selecionadas três parcelas com a finalidade de caracterizar a regeneração do bosque, denominadas R1, R2 e R3. Das três parcelas, foram escolhidas as parcelas R2 e R3 para monitoramento da dinâmica do bosque em regeneração, onde os indivíduos foram devidamente lacrados e feitas as medições da altura, segundo metodologia proposta pelo pesquisador Coelho-Jr (2003). Foram realizados monitoramentos nas seguintes datas: 27/03/02 para a parcela R2, e 28/02/02 para a parcela R3, e em 04/06/02, 28/10/02, 05/02/03, 25/06/03, 09/10/03 e 18/02/04 para ambas parcelas. Com base nesses dados foi possível observar a taxa de sobrevivência por espécie, o incremento na altura média e as taxas de crescimento, que estão relacionadas ao incremento da altura média. A fim de ampliar os dados da regeneração natural foi realizada em fevereiro de 2004, nova caracterização estrutural das mesmas parcelas conforme metodologia descrita acima.

\section{3 - Produção de Serapilheira}

No intuito de monitorar os possíveis impactos na produção primária do bosque, foram dispostas nove cestas coletoras, de acordo com às características fisiográficas do bosque de mangue. Devido cuidado foi tomado durante a instalação das cestas coletoras para que não ficassem expostas à ação das preamares. As cestas possuem estrutura em PVC 
$\left(0,25 \mathrm{~m}^{2}\right.$ de área) e tela de náilon com $2 \times 2 \mathrm{~mm}$ de malha (Cintrón \& Schaeffer-Novelli, 1984 e Schaeffer-Novelli \& Cintrón, 1986) (Figuras 6 e 7).

Cada cesta teve o material recolhido mensalmente (agosto de 2002 à agosto de 2003) e transportados em sacos de papel até o laboratório, onde as frações folhas, flores e propágulos (frutos) foram separados por espécie, além de madeiras, estípulas e detritos não identificáveis. Também foram contados o número de propágulos viáveis e o número de estípulas.

Posteriormente todo material foi seco em estufa com circulação forçada QUÍMIS (Mod. Q-314D) à $70^{\circ} \mathrm{C}$, até atingir peso constante. A pesagem foi feita em balança digital QUÍMIS (Mod. BG 400, precisão 0,001 g).

Após a pesagem, com auxílio de planilha Excel, os dados foram convertidos em $\mathrm{g} / \mathrm{m}^{2} /$ dia e ton/ha/ano quando necessários.

\section{4 - Medidas Foliares}

Durante as coletas de serapilheira pôde-se observar deformações foliares, principalmente em folhas de Laguncularia racemosa e Avicennia schaueriana. Visando quantificar estas deformações foi feito estudo de medidas foliares (comprimento, largura e área foliar), empregando metodologia padronizada por Cintrón \& Schaeffer-Novelli (1984) e Schaeffer-Novelli \& Cintrón (1986). Nas áreas em processo de regeneração, pelo fato dos indivíduos serem jovens e de pequeno porte, foram realizadas coletas manuais, e nos bosques de maior estatura (remanescentes e controle), as coletas foram feitas com o auxílio de um podão. Foram coletadas aleatoriamente entre 40 e 50 folhas verdes, adultas e expostas ao sol das três espécies vegetais típicas de mangue existentes na área (Rhizophora mangle, L. racemosa e A. schaueriana) nos bosques remanescente, regeneração e controle O comprimento foi medido entre o ápice e a base da lâmina da folha, e a largura na porção mais larga da folha (Cintrón \& Schaeffer-Novelli, 1984 e Schaeffer-Novelli \& Cintrón, 1986). Ambas as medidas foram feitas com régua milimetrada.

Para determinar a porcentagem de área foliar total, foram decalcados os contornos das folhas sobre papel sulfite, restaurando as áreas pastoreadas quando necessário. A utilização de um digitalizador de imagens (scanner) e de um programa específico (ImageJ 1.23 - Sun Inc.) se mostrou mais eficiente na determinação das áreas foliares (intacta e 
pastoreada), dispensando o uso de um planímetro ou outros métodos empregados para estimativa da área foliar.

Wilcken et al. (1998) concluíram não existir diferenças nas medições de área foliar quando comparados os métodos tradicionais (planímetro e pesagem) e o da digitalização de imagens. Os mesmos autores afirmam ainda, que a técnica de medição de área foliar por meio da digitalização de imagens reduz o tempo de avaliação em até 87\%, sendo plenamente adequada sua utilização nesse tipo de estudo.

Juntamente com as medidas foliares, as folhas foram separadas de acordo com o padrão de deformação encontrado, estes padrões foram descritos sucintamente e foram contabilizados o percentual de folhas coletadas por espécie que apresentaram estes padrões. Foram consideradas folhas deformadas aquelas que apresentassem formato ou características morfológicas que diferissem dos padrões de uma folha da mesma espécie sadia. Esta metodologia foi utilizada por Lugo et al. (1981) para folhas de $R$. mangle deformadas após derramamento de óleo.

\subsection{1 - Análises Estatísticas}

Inicialmente com o auxílio do programa Excel, foram realizadas estatísticas descritivas, adotando-se a média como tendência central e o desvio padrão como medida de dispersão. Os testes estatísticos foram aplicados mediante o programa Statistica 6.0. Para cada espécie vegetal, as médias de comprimento, largura e área foliar foram testadas entre os diferentes bosques (remanescente, regeneração e controle) utilizando o teste não paramétrico Kruskal-Wallis, sendo considerados significativos valores de $p \leq 0,05$. A seguir, havendo encontrado diferença estatística, adotou-se o teste de Tukey para comparações múltiplas.

\section{5 - Microtopografia}

$\mathrm{O}$ estudo da microtopografia foi realizado com equipamento fundamentado no princípio físico dos vasos comunicantes. Esse método tem sido empregado pelo BIOMA Centro de Ensino e Informação sobre Zonas Úmidas Costeiras Tropicais, com ênfase no Ecossistema Manguezal, do Instituto Oceanográfico da Universidade de São Paulo (IOUSP) e pelo Núcleo de Estudos em Manguezais (NEMA), do Departamento de 
Oceanografia, da Universidade do Estado do Rio de Janeiro (UERJ). Foi descrito por Pellegrini (2000) e utilizado por Cunha-Lignon (2001).

Para o presente levantamento foram utilizadas duas réguas de alumínio, graduadas a cada centímetro, de 0 (zero) a $200 \mathrm{~cm}$, e uma mangueira de borracha flexível e transparente, com diâmetro de $5 \mathrm{~mm}$ e comprimento de $25 \mathrm{~m}$. A partir de um valor e de um ponto de referência, fixou-se a régua base, pela leitura do nível da água na mangueira, associado a um valor na régua, em seguida fixou-se a outra régua no local a ter seu nível determinado. $\mathrm{O}$ valor de referência na régua-base é restabelecido, e é feita a leitura na segunda régua, com precisão de $0,1 \mathrm{~cm}$. A variação dos valores na segunda régua corresponde, em ordem inversa, à elevações ou depressões do terreno.

Métodos convencionais de medição de topografia são pouco práticos em bosques de mangue devido à consistência "pouco consolidada" do terreno. O manuseio de equipamentos convencionais é dificultado, ainda, devido à grande densidade de árvores de determinados bosques.

A topografia foi caracterizada com rede amostral abrangendo a totalidade do bosque, além das áreas ao redor do bosque, incluindo a antiga franja onde ocorreu a grande mortandade de árvores devido ao incêndio, sendo que as medidas foram feitas a cada 2 metros. Após determinado o rumo, utilizou-se trena de $50 \mathrm{~m}$, esticada na direção a ser seguida.

Para o processamento dos dados levantados foi utilizado o software SURFER 6.01, da Golden Software, Inc., que consiste num sistema para mapeamento de superfície de fácil manuseio. O objetivo foi a elaboração de um modelo numérico do terreno, visando a determinação do processo erosivo ocorrido na área após a supressão da vegetação da franja do bosque (área atingida pelo incêndio). 


\section{6 - RESULTADOS}

\section{1 - Características Estruturais}

Analisando os dados de altura do bosque e diâmetro a altura do peito (DAP) na Tabela VI, nota-se que o bosque remanescente obteve valores médios de altura total de 4,23, 4,59 e 5,13 m e DAP de 8,74, 5,83 e 6,49 $\mathrm{cm}$ para as parcelas IB1, IB2 e IB3, respectivamente, enquanto que o bosque controle $(\mathrm{C} 1)$ obteve altura média total de 2,97 $\mathrm{m}$ e DAP de $4,48 \mathrm{~cm}$.

Para o bosque em recomposição os valores médios de altura foram de 1,37, 1,59 e $1,93 \mathrm{~m}$ e os valores de DAP de 1,31, 1,59 e 0,88 cm para as parcelas R1, R2 e R3, respectivamente.

Os dados das Tabelas VII refletem a grande dominância de troncos vivos de Laguncularia racemosa nas parcelas do bosque remanescente (IB1 IB2 e IB3), assim como na parcela controle $(\mathrm{C} 1)$, porém com grande contribuição de troncos mortos no bosque remanescente, sendo $65,39 \%$ e $48,97 \%$ do total das parcelas IB1 e IB3. A maior contribuição de troncos vivos de $L$. racemosa no bosque remanescente foi da parcela IB2 com $64,44 \%$ do total, sendo que a parcela controle (C1) apresentou $51,00 \%$ de troncos vivos desta espécie. As parcelas R1 e R2 também apresentaram dominância de L. racemosa com 85,00 e $51,72 \%$ do total de troncos vivos, somente a parcela R3 apresentou dominância de Avicennia schaueriana, sendo a contribuição de troncos vivos desta espécie de $89,09 \%$.

As parcelas que apresentaram maior desenvolvimento estrutural relacionado a área basal de troncos vivos e mortos foram as parcela C1 e IB1 com 16,90 e 16,68 $\mathrm{m}^{2} / \mathrm{ha}$ de área basal, seguida das parcelas, IB3 e IB2, com 13,68 e 12,72 $\mathrm{m}^{2} /$ ha, respectivamente (Tabela VIII). Podemos verificar a grande contribuição em área basal de troncos mortos das parcelas IB1, IB2 e IB3, de acordo com o mencionado acima, onde as parcelas IB1 e IB3 obtiveram os maiores valores 9,88 e $8,39 \mathrm{~m}^{2} / \mathrm{ha}$, seguidas das parcelas IB2 com $3,62 \mathrm{~m}^{2} / \mathrm{ha}$, e da $\mathrm{C} 1$ que obteve o menor valor com $2,88 \mathrm{~m}^{2} / \mathrm{ha}$. As áreas basais totais das parcelas $\mathrm{R} 1$, R2 e R3 foram de $9,07 \mathrm{~m}^{2} / \mathrm{ha}, 9,60 \mathrm{~m}^{2} /$ ha e $5,57 \mathrm{~m}^{2} /$ ha, respectivamente.

Tais dados refletem os valores de dominância em área basal (\%), apresentados na Tabela IX, onde as parcelas IB3 e IB1 obtiveram maior dominância em área basal morta 
61,30 e 59,22 \% respectivamente e as parcelas C1 e IB2 apresentaram as maiores dominâncias de áreas basais vivas, com 82,97 e 71,53 \%. Todas as parcelas localizadas na recomposição apresentaram maior dominância de área basal viva, chegando a 100\% para as parcelas R1 e R2 e 99,79\% para a parcela R3.

\section{2 - Regeneração da Cobertura Vegetal}

Nas Tabelas X e XI encontram-se compilados os resultados do monitoramento das parcelas R2 e R3, no período de 27 de março de 2002 a 18 de fevereiro de 2004 e 28 de fevereiro de 2002 a 18 de fevereiro de 2004, respectivamente. Optou-se por apresentar o número total de indivíduos vivos (marcados com lacre) dentro das parcelas, sem extrapolar os valores por unidade de área. Nas Figuras 8, 9 e 10 são apresentadas fotografias com detalhes do processo regenerativo do bosque de mangue de 2000 a 2004.

Os resultados mostram que durante o período de monitoramento, houve decréscimo no número total de indivíduos em ambas parcelas, sendo esta mortandade mais acentuada na parcela R2, dominada por L. racemosa.

Analisando as taxas de sobrevivência por espécie nas parcelas (Figuras 11 e 12), nota-se que as duas espécies mais representativas, L. racemosa e A. schaueriana, apresentaram taxas de sobrevivência ao final do monitoramento na parcela R2 de 28,3\% e $78,6 \%$, e na parcela R3 de $40 \%$ e $89,2 \%$, respectivamente. Sendo que a taxa de sobrevivência total para a parcela R2 foi de $38,8 \%$ e na R3 foi de $83,7 \%$. Destacando a baixa taxa de sobrevivência da primeira espécie, comparada a segunda.

A parcela R2 apresentou um maior incremento na altura média dos indivíduos (Figura 13), de 1,56 metros na primeira medição (27/03/2002), para 2,51 metros na última medição (18/02/2004), sendo que na parcela R3 este incremento foi menor, de 1,90 para 2,13 metros entre a primeira (28/02/2002) e última (18/02/2004) medição (Figura 14). Porém analisando os dados de incremento na altura média dos indivíduos emergentes (cinco indivíduos mais altos da parcela) pode-se notar que os indivíduos emergentes da parcela R2 mantiveram um incremento na altura média de acordo com os demais indivíduos da parcela, enquanto os indivíduos emergentes da parcela R3 registraram um crescimento mais acelerado comparados com os demais indivíduos. 
Durante o período estudado os indivíduos da parcela R2 apresentaram expressiva variação na taxa anual de crescimento entre os dois anos de monitoramento, onde no primeiro ano as taxas de crescimento foram maiores que as do segundo. A parcela R3 manteve reduzida taxa de crescimento durante os dois anos, com pequeno aumento nos meses de inverno (Tabelas X e XI).

As Figuras 15 e 16 mostram a freqüência dos indivíduos por classe de altura nas parcelas R2 e R3 ao longo dos dois anos de monitoramento. Nota-se que o conjunto de indivíduos, de todas classes de altura da parcela R2 manteve crescimento mais uniforme no período. $\mathrm{Na}$ parcela $\mathrm{R} 3$, os indivíduos das maiores classes de altura (emergentes) apresentaram crescimento acelerado, despontando os emergentes de A. schaueriana, enquanto que a maioria apresentou baixa taxa de crescimento no período. Tais figuras também apontam a maior mortalidade de L. racemosa em ambas as parcelas.

Com o objetivo de reforçar os resultados descritos anteriormente, nas Tabelas XII, XIII, XIV e XV estão representados os dados estruturais comparativos, feitos nas duas parcelas de regeneração (R2 e R3) em dois períodos, o primeiro junto com o estudo estrutural do bosque remanescente (fevereiro de 2002) e após 2 anos (fevereiro de 2004), conforme descrito na metodologia.

Analisando a Tabela XII podemos notar que o aumento da altura média das parcelas seguiu o padrão encontrado pelo monitoramento, e o DAP médio da parcela R2 teve uma pequena queda de 1,59 para $1,36 \mathrm{~cm}$, enquanto que na parcela R3 o DAP médio apresentou um incremento, de 0,88 para $1,57 \mathrm{~cm}$.

A Tabela XIII mostra que a parcela R2 apresentou queda na contribuição de troncos vivos $<2,5 \mathrm{~cm}$ de DAP, principalmente de L. racemosa, com pequeno incremento nos troncos vivos $>2,5 \mathrm{~cm}$ de DAP, gerando queda na contribuição de troncos vivos na parcela R2, sendo de 100,00\% para 79,37\% de troncos/ha e, consequentemente, aumento na contribuição de trocos mortos, de $0 \%$ para $20,63 \%$ de troncos/ha.

A parcela R3 apresentou queda na contribuição de troncos $<2,5 \mathrm{~cm}$ de DAP, com incremento nos troncos vivos $>2,5 \mathrm{~cm}$ de DAP de A. schaueriana, porém a densidade de troncos mortos e vivos se manteve praticamente constante no período (Tabela XIII).

A Tabela XIV mostra que na parcela R2, a área basal viva teve queda de 9,60 para $8,10 \mathrm{~m}^{2} /$ ha e a área basal morta incremento de 0,00 para $2,46 \mathrm{~m}^{2} / \mathrm{ha}$, gerando pequeno 
aumento na área basal total de 9,60 para $10,56 \mathrm{~m}^{2} / \mathrm{ha}$. A parcela $\mathrm{R} 3$ apresentou aumento significativo na área basal viva, de 5,56 para $18,75 \mathrm{~m}^{2} /$ ha e pequeno na área basal morta, de 0,01 para $0,38 \mathrm{~m}^{2} /$ ha, ocasionando sensível aumento na área basal total, de 5,57 para 19,13 $\mathrm{m}^{2} / \mathrm{ha}$.

Tais dados refletem a dominância (\%) na área basal viva e morta que estão na Tabela XV, onde na parcela R2 a área basal viva caiu de 100,00 para 76,72\% e a morta aumentou de 0,00 para 23,28 \%, e na parcela R3 ocorreu pequena queda na área basal viva, de 99,79 para $98,02 \%$ e conseqüente aumento na morta, de 0,21 para $1,98 \%$.

\section{3 - Produção de Serapilheira}

A taxa anual de produção de serapilheira na Ilha Barnabé foi de 8,96 ton/ha/ano, sendo a produção média anual de $2,52 \mathrm{~g} / \mathrm{m}^{2} / \mathrm{dia}$, apresentando-se de forma sazonal com dois picos distintos, sendo dezembro o pico na queda de folhas e março na queda de propágulos (Figuras 17 e 18). O mês de março apresentou o maior valor (7,36 g/m $/ 2$ dia), com o menor no mês de outubro $\left(0,62 \mathrm{~g} / \mathrm{m}^{2} / \mathrm{dia}\right)$.

A serapilheira apresenta composição média, em termos das frações: folhas (43\%), propágulos (43\%) e madeiras (10\%). As demais frações (miscelânea, composta por flores, estípulas e detritos) contribuíram com apenas 4\% (Figura 19).

A queda de folhas ocorre durante todos os meses, apresentando média de 1,19 $\mathrm{g} / \mathrm{m}^{2} /$ dia, com maiores valores no mês de dezembro $\left(2,41 \mathrm{~g} / \mathrm{m}^{2} /\right.$ dia). L. racemosa apresentou picos de queda nos meses de dezembro, janeiro e fevereiro, sendo ainda a principal constituinte da fração folhas na maioria dos meses, contribuindo desta forma com (65\%) do material foliar durante o período de amostragem (Figura 20). R. mangle foi mais representativa nos meses de fevereiro, março e abril. A. schaueriana não apresentou sazonalidade marcada (Figura 21).

Março foi o mês com maior contribuição de propágulos (Figura 22), representando $76 \%\left(5,54 \mathrm{~g} / \mathrm{m}^{2} / \mathrm{dia}\right)$ da produção mensal, sendo que a contribuição anual de cada espécie foi de $58 \%$ de $R$. mangle, $28 \%$ de L. racemosa e $14 \%$ de A. schaueriana (Figura 23). O número de propágulos maduros de $R$. mangle, L. racemosa e A. schaueriana foram 114,3; 4171,4 e 280 unidades $/ \mathrm{m}^{2} / a n o$, respectivamente. Cabe ressaltar a presença de abortos de 
propágulos deformados de $R$. mangle (Figura 24), principalmente nos meses de novembro e dezembro.

Picos da fração flores foram observados entre os meses de dezembro e fevereiro, com os maiores valores no mês de janeiro, com as flores de L. racemosa contribuindo com $11 \%$ da produção mensal da serapilheira $\left(0,28 \mathrm{~g} / \mathrm{m}^{2} /\right.$ dia) (Figura 25$)$, sendo a espécie que mais contribuiu com a queda anual de flores, com $78 \%$ do total (Figura 26).

A queda de estípulas não apresentou um padrão estacional definido, somente foi observado um pequeno acréscimo nas taxas nos meses de novembro e maio (Figura 27). Os detritos apresentaram picos de queda entre os meses de novembro à fevereiro, com exceção de janeiro, acompanhando as altas taxas de folhas, flores e frutos nestes meses (Figura 28).

A fração madeira apresentou picos, porém sem um padrão estacional definido, tendo registrado para o mês de junho a maior contribuição (figura 29), com $43 \%$ da produção mensal $\left(0,92 \mathrm{~g} / \mathrm{m}^{2} / \mathrm{dia}\right)$.

\section{4 - Medidas Foliares}

Analisando os dados da Tabela XVI, observamos que as folhas de A. schaueriana no bosque em regeneração apresentaram os menores valores médios de comprimento, largura e área foliar $\left(5,83 \mathrm{~cm}, 2,54 \mathrm{~cm}\right.$ e $\left.10,16 \mathrm{~cm}^{2}\right)$, respectivamente, sendo significativamente diferentes dos demais bosques $(\mathrm{p} \leq 0,01)$.

As folhas de L. racemosa não apresentaram diferenças significativas ( $>0,05)$ quanto aos valores médios de comprimento e área foliar. Porém os bosques remanescente e regeneração apresentaram iguais valores médios de largura $(3,12 \mathrm{~cm})$, sendo significativamente diferentes $(\mathrm{p} \leq 0,01)$ do bosque controle, que apresentou valor médio de $3,66 \mathrm{~cm}$.

Para $R$. mangle os menores valores médios de comprimento, largura e área foliar foram registrados no bosque remanescente $\left(6,91 \mathrm{~cm}, 3,46 \mathrm{~cm} \mathrm{e} 16,33 \mathrm{~cm}^{2}\right)$, apresentando diferenças significativas $(p \leq 0,01)$ quando comparadas aos demais bosques.

Para o estudo das deformações foliares, utilizou-se como padrão de folhas normais, aquelas que apresentassem as seguintes características, segundo (Schaeffer-Novelli \& Cintrón, 1986): 
- A. schaueriana: Folhas peninérvias com extremidade da lâmina obtusa ou arredondada e base aguda atenuada no pecíolo, bordos inteiros e coriáceas;

- L. racemosa: Folhas pecioladas, espessas e coriáceas, oblongas ou elípticas ou obovadas, com ápice arredondado e emarginado;

- R. mangle: Folhas coriáceas, ovaladas e ovado-lanceoladas, obtusas no ápice e glabras.

O percentual de folhas coletadas que apresentaram algum tipo de deformação está expresso na Tabela XVII, sendo que as fotos dos padrões das folhas coletadas de $A$. schaueriana, L. racemosa e $R$. mangle, estão nas figuras 30, 31 e 32 respectivamente.

As duas espécies que apresentaram as maiores taxas de folhas deformadas foram $A$. schaueriana e L. racemosa, sendo que o padrão de deformação encontrado diferenciou entre os bosques remanescente e em regeneração, para as duas espécies. Para a espécie $R$. mangle não foram observadas folhas que apresentassem algum tipo de deformação.

Das folhas de A. schaueriana coletadas no bosque remanescente, 58,1\% apresentaram algum tipo de deformação, sendo 41,9 \% classificadas como padrão A, apresentando tamanho reduzido, deformação da lâmina foliar que assume a forma de concha $^{1}$ com grande parte apresentando sulcos laterais e $16,3 \%$ classificadas como padrão B, com deformação da lâmina foliar que assume a forma de concha e enrolamento.

No bosque em processo de regeneração, $58,0 \%$ das folhas de A. schaueriana apresentaram deformações, sendo que 20,0 \% apresentaram pequeno encrespamento da lâmina foliar, sendo mais coriáceas e de tamanho reduzido, classificadas desta forma como padrão C, e 38,0 \% apresentaram as maiores deformações desta espécie, sendo extremamente delgadas na base, apresentando grande encrespamento no ápice da lâmina foliar e mais coriáceas que o padrão normal, sendo considerado padrão D. No bosque controle nenhuma folha apresentou as deformações acima descritas, sendo, portanto consideradas normais.

Todas as folhas de L. racemosa coletadas no bosque remanescente apresentaram um padrão diferenciado do normal, com um comprimento mais acentuado da lâmina foliar, apresentando um formato lanceolado com ápice agudo, denominado padrão E.

\footnotetext{
${ }^{1}$ (com. pess. Prof ${ }^{\mathrm{a}}$ Dr $^{\mathrm{a}}$ Berta Lange de Morretes do Departamento de Botânica do Instituto de Biociências da Universidade de São Paulo, em 02.08.2004).
} 
Já no bosque em regeneração, 56,5 \% das folhas de L. racemosa apresentaram alguma deformação, sendo que $26,1 \%$ apresentaram enrolamento apenas no ápice (padrão F), 8,7 \% enrolamento em toda porção da lâmina foliar (padrão F') e 21,7 \% apresentaram tamanho reduzido (padrão $\mathrm{G}$ ).

Para esta espécie $61,5 \%$ das folhas do bosque controle também apresentaram algum tipo de deformação, sendo $25 \%$ em formato lanceolado e ápice agudo (padrão E) e 36,5 \% com tamanho reduzido (padrão G).

Esta diminuição nos valores médios de comprimento e largura nas áreas em regeneração indica que está havendo uma redução na área foliar, sendo que para $A$. schaueriana esta perda de área foliar do bosque em regeneração comparado com o bosque controle foi de $30 \%$ (Figura 33) e para L. racemosa de $21 \%$ (Figura 34).

\section{5 - Microtopografia do Entremarés}

A partir do levantamento microtopográfico realizado, foi gerado modelo de terreno com curvas de nível e um modelo de superfície para a área de estudo (Figura 35). Sobre os modelos de terreno e superfície foram plotadas a localização do bosque remanescente, a área onde se encontram os resquícios das árvores que se localizavam na franja e foram queimadas no evento de 1998, além das parcelas de regeneração e as cestas coletoras de serapilheira (Figura 36).

Pode-se observar na Figura 37 "sulcos de escoamento" modelados pela drenagem terrestre e pelo fluxo das marés (enchentes e vazantes) no terreno, além um "desnível" entre a franja do bosque remanescente e a área localizada a sua frente, preteritamente ocupada pela franja do bosque de mangue, sugerindo processo intenso de transporte de sedimento, que a nível local pode ser considerado como processo de erosão, possivelmente iniciado e/ou intensificado pela perda da cobertura vegetal que se encontrava na franja do bosque de mangue. 


\section{7 - DISCUSSÃO}

\section{1 - Estrutura da Cobertura Vegetal do Manguezal}

A caracterização estrutural da vegetação dos manguezais constitui valiosa ferramenta no que concerne à resposta desse ecossistema às condições ambientais existentes, bem como aos processos de alteração do meio ambiente, auxiliando assim, nos estudos e ações que objetivam a conservação desse ecossistema (Cintrón \& SchaefferNovelli, 1985).

Descrições a respeito da estrutura vegetal dos manguezais podem incluir medidas da composição das espécies, diversidade, altura do bosque, diâmetro dos troncos, área basal, densidade de árvores, distribuição por classe etária e padrões de distribuição espacial das espécies que compõe o bosque de mangue (Smith III, 1992). A estrutura dos bosques de mangue é resultado da combinação de diversas forças subsidiárias, tais como, energia solar, aporte de água doce e nutrientes e energia das marés, como também por tensores naturais ou antrópicos (Lugo et al. 1981, 1990; Brown \& Lugo, 1982; Cintrón \& Schaeffer-Novelli, 1985).

Analisando-se os dados estruturais do bosque remanescente comprova-se a grande mortalidade ocorrida, com densidade de troncos mortos e área basal morta superando a densidade de troncos vivos e a área basal viva, nas parcelas IB1 e IB3, sendo que segundo Jiménez et al. (1985) a densidade de árvores mortas pode alcançar cerca de 19\% do total das árvores do bosque, parâmetro altamente variável, que depende de fatores locais, como taxas de crescimento, intensidade e freqüência de períodos de estresse, estabilidade geomorfológica, taxas de decomposição do material lenhoso morto e diâmetro inicial das árvores.

Outros indicativos da mortalidade ocorrida são refletidos pelos dados estruturais obtidos na parcela controle $(\mathrm{C} 1)$ que está localizada em área próxima, porém não afetada diretamente pelo derramamento do produto químico (DCPD) diciclopentadieno, que apresentou valores inferiores de troncos mortos e área basal morta comparados com as parcelas do bosque remanescente. Tais fatos corroboram com o proposto por Jiménez et al. (op. cit.), caracterizando mortalidade massiva como sendo aquela que envolve grande 
número de indivíduos e afeta todas as classes de tamanho em relativo curto período de tempo.

Cabe destacar a importância de se realizar estudos em bosques de mangue afetados por incêndios, sendo escassos os relatos sobre os efeitos deste tipo de tensor sobre o ecossistema. Merece destaque o trabalho de Robertson (1962), onde o autor cita que bosques de mangue geralmente não toleram fogo, e tendem a serem excluídos de locais onde ocorreu incêndio, ou retornam a estágios sucessionais iniciais.

Podemos considerar o tensor na ocasião do evento de 1998 como agudo, estando o bosque remanescente submetido a vários outros tensores (crônicos) que atuam sobre a região, como efluentes industriais e urbanos, além das atividades portuárias que comprometem seriamente a qualidade dos recursos ambientais disponíveis. A ação do tensor agudo somado aos vários tensores crônicos atuantes sobre o bosque de mangue, pode ter gerado um efeito sinérgico dos tensores, ou seja, a ação somada destes tensores resultou efeito superior ao obtido por cada tensor atuando separadamente sobre o sistema.

Lugo et al. (1981), propõem que os efeitos sobre um ecossistema podem ser acentuados caso este esteja sob estresse. Mesmo estando o ecossistema adaptado a certos graus de perturbação, isto não significa que não ocorra perda de energia que seria empregada para a manutenção do próprio sistema (Lugo, 1978).

Peria et al. (1990) observaram valores reduzidos de diâmetro e altura média de bosque de mangue em Bertioga, concluindo que os diversos tensores induzidos pelo homem na região, vão aos poucos drenando energia do sistema e reduzindo o vigor estrutural desses bosques. Tal conclusão pode ser aplicada a área de estudo, onde mesmo antes dos eventos, o bosque encontrava-se submetido a ação de outros tensores. Soares (1999), também encontrou valores reduzidos de diâmetro e altura em bosques de mangue da Lagoa da Tijuca, sujeitos a perturbações naturais e/ou induzidas pelo homem.

Devemos considerar ainda que a perda de biomassa causada pelos diferentes tensores atuantes no bosque pode estar causando uma perda das funções desempenhada pelo ecossistema manguezal. Entre as funções afetadas, podemos destacar a produção de serapilheira, que subsidia uma grande cadeia trófica estuarina e a retenção de sedimentos finos pelo sistema radicial das árvores dentro do estuário. 
Outro fato que nos leva a sugerir que estes bosques de mangue foram alterados e continuam sofrendo diferentes graus de perturbação é a dominância de indivíduos de $L$. racemosa, com reduzido número de indivíduos de $R$. mangle. Segundo Schaeffer-Novelli et al. (1990), os bosques de franja da Baixada Santista, geralmente, apresentam dominância de mangue-vermelho (R. mangle). Smith III (1992), afirma que em bosques sujeitos a maiores freqüências de distúrbios, ocorre menor representatividade de indivíduos do gênero Rhizophora, em comparação às espécies dos demais gênero, por exemplo, Laguncularia e Avicennia, que no presente estudo são dominantes nas parcelas em recomposição. A reduzida representatividade de $R$. mangle tanto no bosque remanescente como na área em recomposição, pode sugerir mudança nas características ambientais após os últimos eventos.

Outra característica que pode explicar a grande representatividade de $L$. racemosa nas parcelas em recomposição, é o fato desta espécie requerer consideravelmente menos tempo para germinação e estabelecimento de raízes que as demais espécies típicas de mangue (Rabinowitz 1975, 1978).

A recomposição, em manchas, no interior do bosque remanescente, provavelmente é resposta às clareiras (gaps) deixadas pelas árvores adultas mortas, permitindo deste modo recrutamento de plântulas. Porém, Jimenéz et al. (1985) sugerem que a recuperação natural de um bosque de mangue, após perturbação antrópica, torna-se mais demorada que após uma perturbação natural, pois altera as condições naturais do ambiente.

A caracterização estrutural do bosque de mangue mostrou sua adequação como ferramenta para análise dos impactos na região da Baixada Santista, caracterizando áreas alteradas por tensores naturais e/ou induzidos pelo homem.

\section{2 - Regeneração no Manguezal}

Assim como muitas florestas, os manguezais são dinâmicos, possuem crescimento contínuo e constantemente se restabelecem e se renovam. Diferem das florestas terrestres, principalmente, pelas adaptações requerentes a sobrevivência no ambiente do entremarés. Tais adaptações fazem com que o ecossistema manguezal seja apto a ocupar, dominar e se estabilizar nestes ambientes com severas condições hidrológicas e físico-químicas, sendo 
essencial desta forma a presença de processos regenerativos adaptáveis, progressivos e principalmente eficientes neste ecossistema (Duke, 2001).

O mesmo autor afirma que os manguezais possuem uma combinação de atributos e estratégias de crescimento que promovem sua sobrevivência, estabelecimento e regeneração em clareiras (gaps) dentro do bosque, incluindo: 1) abundância de propágulos com capacidade de flutuar; 2) estratégias de "autoplantio" devido ao formato e ao peso dos propágulos; 3) propágulos possuem grandes reservas nutritivas auxiliando a sua dispersão e estabelecimento; 4) rápido crescimento de raízes e folhas pelo propágulo fixado (plântula); 5) habilidade de sustentar crescimento por cerca de 2 ou 3 anos sobre dossel fechado em um "banco de plântulas"; 6) intolerância à sombra, reduzindo os recursos exigidos por competidores de crescimento lento; 7) forte ligação trófica com a fauna bentônica, promovendo grande crescimento em altura e ganho de biomassa. Esta dinâmica pode diferir em resposta, dependendo de fatores internos (espécies envolvidas) e externos (exposição a ventos e ondas).

Os dados obtidos durante os dois anos de monitoramento, apontam para uma maior taxa de crescimento médio dos indivíduos na parcela $\mathrm{R} 2$, dominada pela espécie $L$. racemosa, quando comparada à parcela $\mathrm{R} 3$, onde A. schaueriana representa a espécie dominante apresentando também as maiores taxas de crescimento (emergentes) em ambas parcelas.

O fato das espécies estudadas apresentarem diferenças nas características inerentes ao crescimento é esperado. Segundo Tomlinson (1986), as espécies típicas de mangue representam diversos grupos taxonômicos, podendo desta forma diferenciar na sua morfologia, fenologia, fisiologia e grau de adaptação ao ambiente.

Fatores como salinidade (Ball, 1988; Krauss \& Allen, 2003a), baixos teores de oxigênio e freqüência de inundação (Smith, 1987; McKee \& Mendessohn, 1987; Jimenez \& Sauter, 1991; McKee, 1993; Ellison \& Farnsworth, 1993; Delgado et al., 2001; Kitaya et al., 2002); competição interespecífica (Jimenez \& Sauter, op cit.; Clark \& Myerscough, 1993; Patterson et al.,1993); condições físico-químicas do sedimento (McKee, op cit.); luminosidade (Smith, op cit; Ellison \& Farnsworth, 1996; Krauss \& Allen, op cit. e 2003b), e distúrbios (Ellison \& Farnsworth, op cit.; Duke et al., 1999) tem sido demonstrados que influenciam o crescimento e a dinâmica das plantas típicas de mangue. 
Comparando plântulas de $R$. mangle, A. germinans e L. racemosa crescendo na ausência dos seus tensores naturais (inundação, salinidade e herbívoros), McKee (1995) demostrou que estas espécies não apenas diferem em termos de crescimento potencial, mas também exibem diferentes padrões de compartimentação de biomassa, diferindo de acordo com a disponibilidade dos recursos (nutrientes e luz) no ambiente.

McKee (op. cit.) concluiu ainda que L. racemosa apresenta padrão de crescimento e compartimentação de biomassa que sugere que a espécie se beneficia quando os níveis de luminosidade e nutrientes são altos e a intensidade de tensores é baixa, porém quando as condições ambientais são desfavoráveis (baixo teor de nutrientes, luz solar intensa e condições redutoras no sedimento) apresenta as menores taxas de crescimento entre as três espécies.

Esta afirmação pode explicar o fato de L. racemosa ter apresentado as maiores taxas de mortalidade no presente estudo, pelo fato do bosque estar sobre a influência de diversos tensores atuantes na região. Embora o presente estudo não tenha abordado os níveis de contaminação no sedimento do bosque, trabalhos recentes (Cetesb, 2001; Abessa, 2002) apontam para altos níveis de contaminação nos sedimentos da Baixada Santista, entre os quais metais pesados, que segundo Siedlecka (1995) podem inibir a absorção de nutrientes pelas plantas por competição ou interferindo em diversos metabolismos fisiológicos, principalmente nos tecidos das raízes.

Outra possibilidade é que algum poluente tenha aportado pelas águas do estuário, já que as maiores mortandades ocorreram na mesma época do ano em ambas parcelas (período entre as datas 05/02/03 à 25/06/03), sendo que observações de campo no dia 27 de abril de 2004, registraram pequena quantidade de óleo, provavelmente vindo pelas águas do estuário, atingindo parte do bosque. Sendo o óleo facilmente visível, podemos concluir que possivelmente outras substâncias podem estar chegando ao bosque oriundas das águas do estuário, comprometendo desta forma o crescimento destes indivíduos.

A competição entre L. racemosa e A. schaueriana pode estar agindo em favor da segunda espécie em ambas parcelas, pois Jimenez \& Sauter (1991) estudando manguezais da Costa Rica, encontraram menores taxas de mortalidades de A. bicolor em bosques mistos quando comparados com bosques monoespecíficos. 
Outro ponto que cabe ser destacado quanto às baixas taxas de crescimento da parcela R3, são devido à habilidade de indivíduos emergentes de A. schaueriana estarem com maiores capacidades de competição, em comparação aos restantes, ocasionando sombreamento sobre os demais, comprometendo o crescimento destes. O crescimento acelerado de poucos indivíduos, mais adaptados às condições ambientais, acaba inclinando os indivíduos menores mais próximos para seguirem competindo por espaço e luz, diminuindo desta forma a altura média da parcela.

Não podemos descartar a possibilidade de todos estes fatores estarem atuando em conjunto, e o efeito sinérgico de vários tensores conjugados pode estar interferindo nas taxas de crescimento. Os resultados até o presente apontam para um aparente sucesso da $A$. schaueriana, sugerindo que esta espécie esteja mais adaptada às condições ambientais locais.

O fato da parcela R2 não apresentar sazonalidade no crescimento e a R3 apresentar crescimento maior no inverno, discordam com outros trabalhos disponíveis na literatura, onde manguezais localizados em regiões tropicais apresentariam fraca sazonalidade e localizados em regiões subtropicais forte sazonalidade, com picos de desenvolvimento vegetativo nos meses de verão (Duke, 1990; Há et al., 2003), podendo desta forma estar refletindo uma possível desordem funcional no ecossistema.

Com os dados obtidos até o presente, não é possível afirmar se esta regeneração natural do bosque terá sucesso, cabendo destacar a importância de realizar monitoramentos de longo prazo em áreas impactadas, em vista da magnitude destes processos. Outro fator que deve ser considerado são as constantes perturbações que os manguezais da Baixada Santista sofrem, aumentando ainda mais as variáveis que podem interferir nestes processos regenerativos.

A continuidade do monitoramento de clareiras (gaps) formadas em bosques de mangue e as forças que as criam, é considerado tema prioritário de pesquisa com vistas ao melhor entendimento do papel da biodiversidade e da função do ecossistema manguezal nas zonas úmidas costeiras tropicais ao redor do mundo (Duke, 2001). Os dados levantados com a dinâmica das parcelas de regeneração permitirão subsidiar informações a respeito da capacidade de bosques de mangue se regenerarem (naturalmente) em áreas onde a incidência de tensores antrópicos pode ser considerada crônica. 


\section{3 - Produção de Serapilheira do Bosque de Mangue}

As características estruturais dos bosques de mangue exercem grande influência sobre as taxas de crescimento e na produção primária do bosque. Dentre os atributos estruturais, podemos destacar a densidade de troncos, área basal, índice de área foliar, além da distribuição e orientação das folhas no dossel (Clough, 1992).

A produção de serapilheira do bosque de mangue da Ilha Barnabé mostrou marcada sazonalidade nas frações folhas, flores e frutos, ocorrendo os maiores valores nos meses de verão (meses quentes e úmidos). Diversos autores encontraram este padrão sazonal, destacando-se os trabalhos clássicos feitos por Gill \& Tomlinson (1971), que apontaram inicialmente como fatores determinantes os maiores valores de temperatura do ar e luz incidente. Pool et al. (1975) acrescentaram a importância da maior disponibilidade de água doce nos meses de verão, propondo desta forma que os manguezais tenham desenvolvido uma estratégia de queda de serapilheira, onde as folhas caem continuamente ao longo do ano, com maiores taxas durante a estação úmida, e as menores taxas durante a estação seca, que normalmente coincide com as menores temperaturas.

No Brasil, os trabalhos realizados por Adaime (1985), Menezes (1994) e Almeida et al. (2003) em Cananéia e Ponte et al. (1990) e Lamparelli (1995) no Canal de Bertioga (Baixada Santista), também encontraram padrão sazonal na queda de serapilheira, estando ambas as regiões submetidas a características climáticas de precipitação e temperatura bastante semelhantes.

No aspecto quantitativo, as taxas totais de produção de serapilheira no bosque da Ilha Barnabé (8,96 ton/ha/ano), e a produção média anual de $2,52 \mathrm{~g} / \mathrm{m}^{2} /$ dia, foram altas quando comparados com outros bosques estudados na região da Baixada Santista.

Lamparelli (1995) estudou a produção de serapilheira em duas áreas do Canal de Bertioga (Rios Iriri e Itapanhaú), encontrando valores menores que os do presente estudo, variando de 4,17 a 6,55 ton/ha/ano, enquanto que Ponte et al. $(1984 ; 1990)$ analisando os efeitos de derramamento de óleo na serapilheira também no Canal de Bertioga (Rio Iriri) encontraram valores que variaram de 1,06 a $1,26 \mathrm{~g} / \mathrm{m}^{2} / \mathrm{dia}$. Ambos trabalhos fazem menção a reduzida contribuição de propágulos.

A dominância de L. racemosa no compartimento foliar, com pouca contribuição das demais espécies, reflete os dados estruturais da cobertura vegetal do bosque, onde esta 
espécie é dominante, tanto em área basal, como em número de troncos vivos, tanto no bosque remanescente, como nas áreas em processo de regeneração.

Cabe ressaltar a baixa contribuição de folhas na serapilheira (43\%), quando em condições normais, a queda de folhas representa de 70 a $80 \%$ dos componentes da serapilheira (Cintrón \& Schaeffer-Novelli, 1983).

A progressão dos eventos fenológicos encontrados, onde o pico de queda de folhas ocorreu em dezembro, de flores em janeiro e propágulos em março, também foi encontrado por Lamparelli (1995), para manguezais da região de Bertioga.

Para $R$. mangle, os meses de maior queda de propágulos (dezembro, janeiro e fevereiro) coincidem com os meses de maior queda de folhas. Gill \& Tomlinson (1971) concluíram que substâncias responsáveis pela queda dos propágulos são transportadas para os ramos, podendo causar a queda de folhas nos mesmos. Indivíduos de L racemosa e A. schaueriana não apresentaram padrão de queda de folhas e propágulos na mesma época.

A grande contribuição de flores $(2 \%)$ e propágulos $(45 \%)$ na produção de serapilheira, pode estar evidenciando uma resposta de estresse da cobertura vegetal, onde a maior parte da energia disponível é revertida para fins reprodutivos, visto a grande quantidade de tensores presentes na Baixada Santista, principalmente na área de estudo. A presença de frutos de $R$. mangle abortados e folhas deformadas de L. racemosa e $A$. schaueriana são outros indícios do estado atual de estresse em que o bosque se encontra.

A queda de flores de L. racemosa e A. schaueriana nos meses de verão, com pico em janeiro, pode estar apontando para a época de floração destas espécies, porém seria necessário acompanhar mensalmente as árvores e ramos, conforme sugerido por Gil \& Tomlinson (op cit.), a fim de se compreender o comportamento fenológico de cada espécie.

A contribuição de madeira (necromassa) está relacionada a eventos episódicos, onde grande quantidade de troncos mortos contribui como fonte de galhos e ramos mortos durante eventos de frentes frias ou tempestades. Cabe constatar que o pico da queda de madeira ocorreu em junho (inverno), época de maior incidência desses fenômenos metereológicos.

Poucos trabalhos utilizaram a produção de serapilheira como ferramenta para analisar possíveis respostas funcionais frente a perturbações em bosques de mangue, 
cabendo fazer referência aos trabalhos de Lugo et al. (1981), Ponte et al. (1984 e 1990); Tam et al. (1998) e Carmo et al. (1998).

Lugo et al. (1981), analisaram a queda de serapilheira em bosques de mangue atingidos por óleo em Porto Rico, sendo que concluíram como possível diferença no padrão da queda de serapilheira, apenas uma maior contribuição de folhas do bosque impactado na estação seca, quando comparado com o bosque controle, que manteve padrão sazonal com as maiores quedas na estação chuvosa. Cabe ressaltar que o trabalho foi realizado quatro anos após o evento (derramamento de óleo), não avaliando o efeito agudo inicial, que segundo os autores teria sido de desfolhamento total ou parcial do dossel.

No Canal de Bertioga (Baixada Santista) ocorreu em 1983, vazamento de óleo decorrente do rompimento de oleoduto. Estudos de serapilheira realizados na área antes e após o evento, não encontraram padrão atípico, relatando baixa produção anual que variou de 1,06 a $1,26 \mathrm{~g} / \mathrm{m}^{2} /$ dia. Também houve referência a presença de propágulos deformados e abortados após o derramamento de óleo (Ponte et al. 1984; 1990).

Estudos realizados na Reserva Natural de Futian, na República da China, por Tam et al. (1998), analisaram a influência da descarga de esgotos municipais na produtividade de bosques de mangue, não encontrando variações significativas entre os anos de estudo e entre os bosques que receberam esgoto e não (controle). Porém o estudo foi realizado com certo espaçamento entre o primeiro (1991-1992) e o segundo (1995-1996) ano, entre estes períodos não se realizaram coletas e não houve lançamento de esgoto no bosque. Este fato pode ter interferido nos resultados, além de ter sido insuficiente o tempo para o bosque responder funcionalmente ao aumento na descarga de esgotos sobre o sistema.

A extração da casca de $R$. mangle para obtenção de tanino para confecção de panelas de barro, pode ser considerado um dos impactos mais freqüentes sobre os manguezais da Baía de Vitória, Espírito Santo. Carmo et al. (1998) investigaram a influência desta extração sobre a produção de serapilheira, registrando inicialmente murchamento das folhas, seguido de senescência e intenso desfolhamento, ocasionando posteriormente, redução na produção de serapilheira, sendo que a parcela controle (sem extração da casca) apresentou produção em torno de $10 \mathrm{t} / \mathrm{ha} / \mathrm{ano}$, enquanto os valores da parcela teste (com extração da casca) foram de 7,53 t/ha/ano em 1995 e 5,83 t/ha/ano em 1996. 
A produção de serapilheira do bosque de mangue da Ilha Barnabé mostrou alguns padrões que podem estar sugerindo certa desordem funcional no sistema, tal como a pequena contribuição de folhas e a grande contribuição de partes reprodutivas (flores e propágulos), além de propágulos abortados e deformados.

Embora seja grande a quantidade de trabalhos de serapilheira feitos no mundo com duração de apenas um ano, estudos de longa duração apontam para grandes variações no padrão de queda da serapilheira (Twilley, et al. 1986, Clark, 1994; Day Jr. et al. 1996). Tal fato aponta novamente a importância de monitoramentos de longo prazo, nesse caso da produção de serapilheira, com o intuito de aprimorar os conhecimentos sobre os impactos dos tensores antrópicos sobre a funcionalidade dos bosques de mangue.

\section{4 - Folhas: "Locus" da Fotossíntese}

Deformações nas folhas podem afetar a capacidade fotossintética das plantas, que juntamente com a baixa contribuição das mesmas, diminuem o índice de área foliar (IAF), configurando-se em dreno de energia ao seu metabolismo. Lugo et al. (1981) concluíram que a condição das folhas é um ótimo indicador de estresse nas árvores de mangue, pois as folhas são "locus" de captura de energia do sistema, e a manutenção de um índice de área foliar ótimo é provavelmente determinado pela habilidade das árvores para concentrar e transportar nutrientes e água doce para as folhas. Segundo Clough (1992), o índice de área foliar exerce grande influência na produção primária e no crescimento das plantas de mangue.

A grande quantidade de folhas deformadas de L. racemosa e A. schaueriana, indica presença de tensores atuando nos processos metabólicos dessas espécies, podendo ser devido aos efeitos crônicos referentes ao vazamento de dicicloropentadieno (DCPD) ocorrido em 1998, onde o produto químico, ou algum subproduto de sua combustão podem ter contaminado o sedimento, persistindo até os dias atuais. Dados da CETESB (2001) também apontam a contaminação do sedimento do Estuário de Santos por diversas substâncias, destacando metais pesados, hidrocarbonetos policíclicos aromáticos e Alfa, Beta e Gama - BHC. Porém o menor número de folhas deformadas no bosque controle apontam como fatores locais os principais agentes destas deformações nos bosques remanescente e em regeneração, cabendo destacar ainda que as árvores mais susceptíveis as 
deformações foliares são aquelas que estão crescendo no ambiente após o evento de 1998 (bosque em regeneração).

Em Bertioga (Baixada Santista), Ponte et al. (1987 e 1990) e Rodrigues et al. (1989) também encontraram folhas de A. schaueriana e L. racemosa com deformações, após derramamento de óleo na região.

A deformação da lâmina foliar como indicadora de estresse do mangue, tem sido pouco utilizada em estudos de áreas impactadas. Entretanto cabe destacar alguns trabalhos que mencionaram esta metodologia em áreas que sofreram derramamento de óleo (Lugo et al. 1981; Rodrigues et al. 1989). Outros autores apontam propágulos com deficiência de clorofila como conseqüência de derramamentos de óleo (Klekowski et al. 1994; Duke \& Watkinson, 2002), ou raízes anômalas (Snedaker et al. 1981; Böer, 1993). Também constatou-se modificações em pneumatóforos (raízes respiratórias) em área impactada por esgoto doméstico (Mandura, 1997).

No estudo feito por Lugo et al. (op cit.) em bosques de mangue impactado por óleo em Porto Rico, os autores encontraram dois padrões de deformações foliares em R. mangle: encrespamento das folhas e mudanças na sua simetria. No bosque que eles escolheram como controle, ou seja, que não tinha sido atingido diretamente pelo óleo, tais deformações foram em menor número quando comparadas com os bosques atingidos por óleo.

Rodrigues et al. (1989) analisaram os efeitos do derramamento de óleo ocorrido em 1983, sobre as folhas de mangue no Canal da Bertioga (Baixada Santista), encontrando murchamento, manchas, perfurações, amarelecimento, enrolamento e clorose, sendo que as espécies mais atingidas foram A. schaueriana e L. racemosa, enquanto que $R$. mangle foi a que apresentou as menores deformações.

Segundo Tomlinson (1986), as espécies vegetais típicas de mangue possuem adaptações distintas para lidar com o sal do ambiente entremarés, sendo que $R$. mangle exclui parte desses sais e alguns solutos orgânicos pelo sistema radicial, sendo considerada espécie sal excludente. A. schaueriana e L. racemosa realizam sua osmorregulação por meio da eliminação dos sais por glândulas especializadas da superfície foliar, sendo, portanto sal excretoras.

Estas diferenças fisiológicas podem estar favorecendo os indivíduos de $R$. mangle da Ilha Barnabé, evitando o transporte de algum produto químico que se encontra no 
sedimento, das raízes para as folhas, não apresentando desta forma deformações foliares significativas. O mesmo não pode ser descrito para A. schaueriana e L. racemosa, que sendo sal excretoras podem estar favorecendo a entrada de substâncias químicas para as folhas, ocasionando desta forma as deformações foliares encontradas.

As medidas de comprimento e largura das folhas, e as respectivas áreas foliares refletem o grau de deformação foliar. As deformações descritas para as árvores do bosque em regeneração foram as que causaram as maiores reduções na média dos valores de comprimento, largura e área foliar.

No intuito de comparar o grau de perturbação em que se encontra o bosque de mangue da Ilha Barnabé com outros bosques da Baixada Santista, foram compilados nas Figuras 38, 39 e 40 os valores médios de comprimento e largura das folhas das três espécies do presente estudo, juntamente com dados de outros bosques de mangue da região (Cetesb, 1988; Rodrigues et al. 1989).

Nota-se que as folhas de A. schaueriana do bosque em regeneração, em decorrência da grande proporção de folhas deformadas, apresentam os menores valores de comprimento e largura entre os dados obtidos na literatura para a Baixada Santista. Os bosques remanescente e controle apresentaram valores também reduzidos, em comparação aos demais bosques da região, refletindo a magnitude dos tensores que atuam na Ilha Barnabé e a fragilidade da espécie perante tais tensores.

As folhas de L. racemosa do bosque controle apresentaram valores intermediários de comprimento médio e largura média diante de outros bosques da região. Entretanto as larguras médias das folhas desta espécie, nos bosques remanescente e em regeneração, ficaram entre as menores para a região, provavelmente devido aos padrões de deformação encontrados nesta folhas. O comprimento médio das folhas do bosque em regeneração também se apresentou reduzido em relação aos demais, porém com alguns bosques apresentando valores ainda menores.

As folhas de $R$. mangle do bosque remanescente apresentaram os menores valores de largura média e comprimento médio em relação aos demais bosques. O bosque controle apresentou folhas com valores um pouco acima, porém também encontra-se entre os menores valores para a região, e as folhas do bosque em regeneração apresentaram valores medianos em relação aos demais. Isto se deve possivelmente ao fato de serem escassos os 
indivíduos desta espécie nas áreas em regeneração, sendo que os poucos indivíduos encontram-se ao redor do bosque, o que pode ter levado a uma coleta de folhas de sombra, que apresentam valores de comprimento e largura maiores que de folhas de sol.

A diminuição nos valores médios de área foliar, tanto de A. schaueriana (30\%) quanto de $L$. racemosa de (21\%) dos bosques em regeneração comparado com os bosques controle podem ser considerados como drenos de energia, já que podem estar interferindo nos processos fotossintéticos destas plantas. Lugo et al. (1981) encontraram um decréscimo de $63 \%$ na área foliar de $R$. mangle, ocasionado pela diminuição do seu comprimento e largura, em bosques de mangue impactados por derramamento de óleo em Porto Rico.

Cabe mencionar ainda a necessidade de realizar estudos de anatomia vegetal nestas folhas deformadas, a fim de se avaliar quais os tecidos mais atingidos pelas deformações, se existe a presença de alguma substância química e quais os possíveis processos metabólicos que estão sendo atingidos.

\section{5 - Microtopografia do Entremarés}

Embora a erosão das margens de estuários possa ser tratada como um processo natural, apresentando variações tanto em escala espacial como temporal, ela pode ser exarcebada pela ação humana (Semeniuk, 1980).

A proteção desempenhada pelo ecossistema manguezal contra a erosão das linhas de costa é considerada importante função exercida por este ecossistema. Isto se deve ao emaranhado sistema radicial das espécies típicas de mangue, que entrelaçado amortece a energia do fluxo d'água e das ondas causando turbulência ao adentrarem ao bosque. Quando o fluxo da maré perde força (estofo da preamar) ocorre à deposição do material sedimentar em suspensão. As ramificações radiciais, principalmente das mais finas, contribuem para a retenção das partículas de sedimento devido à força eletrostática relacionada com a interação das trocas de cátions entre a superfície das raízes de absorção e os colóides orgânicos e grãos finos do sedimento, estabilizando desta forma o substrato (Spenceley, 1977; Cintrón et al., 1980; Semeniuk, op cit.; Hamilton \& Snedaker, 1984; Othman, 1994; Furukawa \& Wolanski, 1996; Mazda et al., 1997 a e b). 
Analisando as Figuras 35, 36 e 37 nota-se um "desnível" entre o bosque remanescente e a área localizada a sua frente, preteritamente ocupada pela franja do bosque de mangue queimada durante o incêndio no evento ocorrido em 1998.

A queima desta vegetação acarretou e/ou intensificou o processo de erosão na área. Após a supressão da cobertura vegetal, a vulnerabilidade destes sedimentos serem carreados devido ao intenso embate de ondas (Figura 41) provocado principalmente pelo tráfego de grandes embarcações e pelos ventos do quadrante sul que atingem frontalmente o bosque intensificou-se, provocando desta forma nítida erosão do sedimento. sendo que na Figura 42 nota-se resquícios de raízes das árvores queimadas em 1998.

O processo de erosão está agindo como um tensor no bosque uma vez que está começando a expor também o sistema radicial das árvores do bosque remanescente (Figura 43), em contato com o embate constante de ondas. Ellison (1993), concluiu que a erosão pode debilitar o suporte das árvores de mangue frente a tempestades, ventos fortes, ressacas, acarretando a morte dos indivíduos ainda em pé, sendo que este processo pode ser observado no local (Figura 44).

Cintrón et al. (1980), estudando a ecologia de manguezais em Porto Rico, frente a diferentes regimes de exposição a ondas, concluíram que o embate constante de ondas nas áreas menos abrigadas limita desenvolvimento e crescimento dos bosques.

Estudo feito por Semeniuk (1980) nos manguezais ao longo da costa noroeste da Austrália em processo erosivo, concluiu que a sucessão das comunidades é induzida pela rápida erosão da região, fazendo com que esses específicos habitats estejam continuamente migrando. Essa dinâmica faz com que bosques maduros bem desenvolvidos não consigam se estabelecer devido às constantes reposições de comunidades que ocorrem em anos ou décadas.

Podemos afirmar que a supressão da vegetação devido à queima acarretou e/ou intensificou processo de erosão na franja do bosque, tornando esta área incapaz de se regenerar naturalmente devido às novas condições impostas. Cabe ressaltar que durante todo o período de monitoramento (três anos) não foi observado qualquer recrutamento de plântulas nesta área.

Este registro vai de acordo com o proposto por Duke (2001), quando ele afirma que os bosques de mangue mais expostos (franjas) são particularmente mais vulneráveis aos 
fatores que influenciam sua ciclagem e regeneração, pois a estrutura da vegetação nestes bosques deve ser mantida, pois com este ambiente desflorestado, torna-se insustentável para a regeneração e vulnerável a um colapso do ecossistema como um todo.

Lugo (1997) cita que quando a estrutura vegetal do bosque de mangue é retirada, o sedimento pode sofrer erosão, e o aumento da profundidade do nível d'água no local impede o restabelecimento do bosque. A energia das ondas (naturais ou induzidas) pode ocasionar erosão do sedimento e um estresse no bosque de mangue, podendo este ser eliminado do local.

Os dados levantados no presente estudo mostram que embora os manguezais da Baixada Santista estejam altamente degradados, eles continuam desempenhando a importante função de retenção de sedimentos. A supressão desta vegetação nas margens do Porto de Santos acaba acarretando a necessidade de dragagens constantes do sedimento no canal de navegação, sendo que este assunto é de extrema importância econômica pelos altos custos com a dragagem e ecológicos, devido aos altos níveis de contaminação destes sedimentos.

\section{6 - Síntese do Funcionamento do Manguezal da Ilha Barnabé}

De acordo com modelo proposto por Lugo (1978) e adaptado por Lugo et al. (1981) para o ecossistema manguezal (Figura 1), podemos afirmar que o incêndio que atingiu o bosque de mangue da Ilha Barnabé, teve um impacto tipo 4 sobre o sistema, removendo parte da estrutura já armazenada, sendo possível a sua recomposição, pois foram mantidos os aportes de energias subsidiárias para o sistema, possibilitando que ele volte a armazenar biomassa na forma de estrutura vegetal. Isto pode ser visto nas áreas onde está ocorrendo a regeneração natural do bosque.

Podemos concluir também que a contaminação do sedimento está agindo como um tensor do tipo 5, uma vez que as deformações foliares estão aumentando os gastos energéticos do sistema, interferindo nos processos respiratórios e fotossintéticos. Não podemos descartar o efeito sinérgico destes dois tensores, que podem prejudicar a regeneração deste bosque a longo prazo, ou fazê-lo retornar apenas a níveis inferiores de complexidade, diferindo desta forma das condições pretéritas ao evento. 
Podemos utilizar o modelo proposto por Duke (2001) adaptando-o a realidade ambiental estudada no bosque de mangue da Ilha Barnabé (Figura 45). Nesse caso, teríamos uma perda de habitat na franja do bosque (A), decorrente da perda da vegetação e conseqüentemente erosão da área, impossibilitando a fixação de novas plântulas. Nas partes internas do bosque ocorreu simultaneamente (B) a regeneração vegetativa, pelo rebrotamento de algumas árvores de L. racemosa e A. schaueriana e estratégia reprodutiva envolvendo produção de propágulos, colonização e desenvolvimento das plântulas nas áreas onde a formação de clareiras possibilitou a entrada de luz, favorecendo o desenvolvimento das mesmas. Porém o processo erosivo presente na franja do bosque pode interferir também na regeneração da parte interna do bosque, expondo-o ao maior hidrodinamismo. Nessa análise poderíamos ainda ter "vias de acesso" (C) aos estágios iniciais de desenvolvimento, desde as fases de colonização até a senescência do bosque.

$\mathrm{Na}$ Figura 46, propõem-se um perfil esquemático da ação dos tensores e dos processos regenerativos ocorridos no bosque de mangue da Ilha Barnabé. 


\section{8 - CONCLUSÕES}

- A caracterização estrutural, especialmente os valores de área basal morta, demonstraram a grande magnitude dos diversos impactos causados na cobertura vegetal pelos tensores atuantes na área, principalmente aquele envolvendo derramamento e combustão de produto químico (DCPD) em 1998, mostrando-se ferramenta adequada para análise de áreas alteradas;

- A mortandade de alguns indivíduos na parte interna do bosque remanescente acarretou a formação de clareiras no dossel, possibilitando recrutamento de novos indivíduos e rebrotamento de indivíduos parcialmente atingidos, estabelecendo processo de regeneração desta cobertura vegetal;

- A produção de serapilheira do bosque, apesar do reduzido tempo de monitoramento, mostrou padrão que pode estar evidenciando uma desordem funcional no sistema, devido a pequena contribuição de folhas e a grande de partes reprodutivas (flores e propágulos);

- Embora o presente estudo não tenha efetuado análises químicas do sedimento, podese supor a presença de substâncias químicas no sedimento do bosque, responsáveis pelas deformações foliares e abortos de propágulos encontrados na área;

- A mortandade massiva que ocorreu na franja do bosque no evento de 1998 acarretou e/ou intensificou processo erosivo na margem junto ao Canal de Santos;

- Com base nos resultados obtidos no presente estudo, nota-se que para um completo entendimento das respostas do ecossistema manguezal frente a ação de tensores, urge a necessidade de elaboração de projetos de pesquisa que vislumbrem monitoramentos à longo prazo. 


\section{9 - REFERÊNCIAS BIBLIOGRÁFICAS}

ABESSA, D. M. S. 2002. Avaliação da qualidade de sedimentos do sistema estuarino de Santos, SP, Brasil. Tese de doutorado, Universidade de São Paulo, Instituto Oceanográfico, 290p.

ADAIME, R. R. 1985. Produção de bosques de mangue da Gamboa Nóbrega (Cananéia, 25 Lat. S - Brasil). Tese de doutorado, Universidade de São Paulo, Instituto Oceanográfico, $305 \mathrm{p}$.

AZEVEDO, A. (Ed.) 1965. A Baixada Santista: aspectos geográficos. Editora da Universidade de São Paulo, São Paulo, 4vols.

BALL, M. C. 1988. Ecophysiology of mangroves. Trees, (2): 129-142.

BÖER, B. 1993. Anomalous pneumatophores and adventitious roots of Avicennia marina (Forssk.) Vierh. Mangroves two years after the 1991 Gulf War oil spill in Saudi Arabia. Marine Pollution Bulletin. 27: 207-211.

BROWN, S. \& A. E. LUGO, 1982. A comparison of structural and functional characteristics of saltwater and freshwater forested wetlands, pp. 109-130. In: B. Gopal, R. E. Turner, R.W. Wetzel \& D. F. Whingham (eds.), Proceedings of the First International Wetlands Conference, Wetlands: Ecology and Management, New Delhi, India.

CETESB. 1978. Poluição das águas no Estuário e Baía de Santos. Relatório Técnico, CETESB. Vols 1 e 2.

CETESB. 1983. Estudo dos manguezais da Baixada Santista. Relatório anual. CETESB. São Paulo.

CETESB. 1985. Baixada Santista - Memorial descritivo. Carta do Meio Ambiente e de sua dinâmica. Relatório Técnico CETESB. São Paulo, SP. 33p.

CETESB. 1988. Estudo dos manguezais da Baixada Santista - Relatório Final. São Paulo: CETESB. 70p.

CETESB. 1990. Ação da CETESB em Cubatão: situação em janeiro de 1990. CETESB, Relatório Técnico, São Paulo, São Paulo. 33 p.

CETESB. 1991. Avaliação do estado da degradação dos ecossistemas da Baixada Santista SP. CETESB. Relatório Técnico. São Paulo, São Paulo. 45 p.

CETESB. 1994. Estudo da viabilidade da recuperação dos manguezais em Cubatão. Relatório Técnico. CETESB. São Paulo. 
CETESB. 1998. Registro de Acidente Ambiental. Operação 259/98. CETESB. São Paulo.

CETESB. 1999. Registro de Acidente Ambiental. Operação Brasterminais. Maio de 1999. CETESB. São Paulo.

CETESB. 2001. Sistema estuarino de Santos e São Vicente. Relatório Técnico. Procop: Programa de Controle de Poluição. (CD-ROM).

CINTRON, G. \& Y, SCHAEFFER-NOVELLI. 1983. Mangrove forests: Ecology and response to natural and man induced stressors. In: Ogden, J.C. \& Gladfelter, E.H. (Eds.) Coral reefs, seagrass beds and mangroves: Their interaction in the coastal zones of the Caribbean. Unesco Reports in Marine Science, n.23, appendix 1, p.87110 .

CINTRÓN, G. \& Y, SCHAEFFER-NOVELLI. 1984. Methods for studying mangrove structure, pp. 91-113. In: S. C. Snedaker \& J. G. Snedaker (eds.) The mangrove ecosystem: Research methods, UNESCO, Bungay, United Kingdom, 251 p.

CINTRÓN, G. \& Y, SCHAEFFER-NOVELLI. 1985. Caracteristicas y desarrolo estructural de los manglares de norte y sur America. Ciencia Interamericana, vol. 25(1-4): 4-15.

CINTRÓN, G.; C. GOENAGA \& J, GONZALES-LIBOY. 1980. Ecologia del manglar en una zona arida: exposición al oleaje y estrutura del manglar. Boletim do Instituto Oceanográfico da Universidade de São Paulo. 29(2): 113-127.

CLARKE, P. L. 1994. Baseline studies of temperate mangrove growth and reproduction; demographic and litterfall measures of leafing and flowering. Australian Journal of Botany. 42: 37- 48.

CLARKE, P. L.; P. J. MYERSCOUGH. 1993. The interdital distribuition of the grey mangrove (Avicennia marina) in southeastern Australia: The effects of physical conditions, interspecific competition, and predation on propagule establishment and survival. Australian Journal of Ecology. 18: 307-315.

CLOUGH, B. F. 1992. Primary Production and Growth of Mangrove Forests. In: Tropical Mangrove Ecosystems. A. I. Robertson \& D. M. Alongi (eds.). Coastal and Estuarine Studies. American Geophysical Union, Washington, D. C., 329p.

CODESP - Porto de Santos. 2003. Companhia Docas do Estado de São Paulo. Disponível: www.portodesantos.com [capturado em 18 de julho de 2003].

COELHO-JR, C. 2003. Ecologia de Manguezais: Zonação e dinâmica da cobertura vegetal em gradientes ambientais, Cananéia, São Paulo, Brasil. Tese de Doutorado. Instituto Oceanográfico da Universidade de São Paulo. 166p. 
COMELLI, F. A M.; A. C. E. PONTE \& S. M. C. A. CLARO. 1996. Aspectos estruturais de um manguezal de Cubatão. In: Anais do III Simpósio de ecossistemas da costa brasileira, Serra Negra, São Paulo. ACIESP, Serra Negra. vol.I: pp. 97- 103.

COSTANZA, R., , A. RALPH; R. GROOT; S. FARBER; M. GRASSO; B. HANNON; K. LIMBURG; S. NAEEM; R. V. O'NEILL; J. PARUELO; R. G. RASKIN; P. SUTTON \& M. VAN DEN BELT. 1997. The value of the world's ecosystem services and natural capital. Nature. 387: 253-260.

CUNHA-LIGNON, M. 2001. Dinâmica do manguezal no sistema de Cananéia-Iguape, Estado de São Paulo - Brasil. Dissertação de mestrado. Instituto Oceanográfico, Universidade de São Paulo, 105 p.

DAY, J.W.; C. CORONADO-MOLINA; F. R. VERA-HERRERA; R. R. TWILLEY; V. H. RIVERA-MONROY; H. ALVAREZ-GUILLEN; R. DAY \& W. CONNER 1996. Aquatic Botany, 55:39-60.

DELGADO, P.; P. F. HENSEL; A. JIMÉNEZ \& J. W. DAY. 2001. The importance of propagule establishment and physical factors in mangrove distributional patterns in a Costa Rican estuary. Aquat. Bot. (71): 157-178.

DIRETORIA DE HIDROGRAFIA E NAVEGAÇÃO. 1984. Tábuas de marés. Ministério da Marinha.

DUKE, C. N. 1990. Phenological trends with latitude in the mangrove tree Avicennia marina. Journal of Ecology. 78: 113-133.

DUKE, C. N. 2001. Gap creation and regeneration processes driving diversity and structure of mangrove ecosystems. Wetlands and Ecology Management. (9): 257-269.

DUKE, N. K. \& A. J. WATKINSON. 2002. Chlorophyll-deficient propagules of Avicennia marina and apprent longer term deterioration of mangrove fitness in oil-polluted sediments. Marine Pollution Bolletin. 44: 1269-1276.

DUKE, N. C.; Z. S. PINZÓN \& M. C. PRADA. 1999. Recovery of tropical mangrove forests, following a major oil spill: a study of recruitment and growth, and the benefits of planting. In: YÁÑEZ-ARANCIBIA, A. AND LARA-DOINGUEZ, A. L. (Eds.), Ecosistemas de Manglar en América Tropical. México, Instituto de Ecología, UICN/ROMA, p. 231-254.

ELLISON, J.C. 1993. Mangrove retreat with rising sea-level, Bermuda. Est., Coast. Shelf Sci. 37: 75-87.

ELLISON, A. M. \& E. J. FARNSWORTH. 1993. Seedling survivirship, growth, and response to disturbance in Belizean Mangal. American Journal of Botany, vol. 80(10): 1137-1145. 
ELLISON, A. M. \& E. J. FARNSWORTH. 1996. Antropogenic Disturbance of Caribbean Mangrove Ecosystem: Past Impacts, Present Trends and Future Predictions. Biotropica, vol. 28(4 $\left.4^{\mathrm{a}}\right)$ : 549-565.

EQUISTAR. 2003. Equistar Chemical Company. Disponível: www.equistarchem.com [capturado em 16 de março de 2003].

FURUKAWA, K. \& E. WOLANSKI. 1996. Sedimentation in mangrove forests. Mangroves and Salt Marshes. 1: 3-10.

GILL, A.M. \& P. B. TOMLINSON. 1971. Studies on the growth of red mangrove (Rhizophora mangle L.). 3. Phenology of the shoot. Biotropica 3:109-124.

GOLDENTEIN, L. 1972. A industrialização da Baixada Santista. Coleção de teses e monografias, $n^{\circ} 7$. Universidade de São Paulo, Instituto de Geografia. São Paulo, SP. $342 p$.

HÁ, H. T.; C. M. DUARTE; H. TRI; G. TERRADOS \& B. BORUM. 2003. Growth and population dynamics during esrly stages of the mangrove Kandelia candel in Halong Bay, North Viet Nam. Estuarine and Shelf Science. 58: 435-444.

HAMILTON, L.S. \& S. C. SNEDAKER. 1984. Handbook for mangrove area management. UNEP, Gland.

HERZ, R. 1987. A regional program on coastal monitoring and management of mangrove in Brazil. In: SYMPOSIUM ON COASTAL AND OCEAN MANAGEMENT, 5., 1987, New York. Proceedings. Seattle, ASMCE., (2): 2262-2268.

HIDROCONSULT - 1974. Consultoria, Estudos e Projetos S.A. (s/data). Principais projetos. São Paulo. 30p.

JIMENEZ, J. A. \& K. SAUTER. 1991. Structure and dynamics of mangrove forests along a flooding gradient. Estuaries, 14 (1): 49-56.

JIMÉNEZ, J. A.; A. E. LUGO \& G. CINTRÓN. 1985. Tree motalility in mangrove forests. Biotrop., 17(3): 177-185.

JORNAL A TRIBUNA. 1998. Fogo na Ilha Barnabé põe a Cidade em perigo. Jornal A Tribuna. Caderno: Região. pp: A9-A14.

KITAYA, Y.; V. JINTANA; S. PIRIYAYOYHA; D. JAIJING; K. YABUKI; S. IZUTANI; A. NISHIMIYA \& M. IWASAKI. 2002. Early growth of seven mangrove species planted at different elevations in a Thai estuary. Trees. 16: 150-154.

KLEKOWSKI, E.J., J. J. CORREDOR; J. M. MORRELL \& C. A. D. CASTILLO. 1994. Petroleum pollution and mutation in mangroves. Mar. Poll. Bull. 28: 166-169. 
KRAUSS, K. W. \& J A ALLEN. 2003a. Influence of salinity and shade on seedling photosynthesis and growth of two mangrove species, Rhizophora mangle and Bruguiera sexangula, introduced to Hawaii. Aquatic Botany. 77: 311-324.

KRAUSS, K. W. \& J. A. ALLEN 2003b. Factors influencing the regeneration of the mangrove Bruguiera gymnorrhiza (L.) Lamk. On a tropical Pacific island. Forest Ecology and Management, vol. 176: 49-60.

KUTNER, A. S. 1976. Levantamentos sedimentológicos de apoio na pesquisa e reconhecimento da áreas portuárias. Anais do $1^{\circ}$ Congresso Bras. de Geol. de Engenharia. Vol. 2: Rio de Janeiro.

LAMPARELLI, C. C. 1995. Dinâmica da serapilheira em manguezais de Bertioga, região sudeste do Brasil. Tese de Doutorado. Faculdade de Saúde Pública da Universidade de São Paulo.

LUGO, A. E. 1978. Stress and Ecosystems. pp. 62-98. In: J. H. Thorp \& J. W. Gibbons (eds.), Energy and Environmental Stress in Aquatic Systems. DOE. Symposium Series. National Technical Information Service, Springfield, USA.

LUGO, A. E. 1980. Mangrove ecosystem: Sucessional or steady-state? Biotrópica. 12:6572.

LUGO, A.E. 1997. Old-Growth mangrove forests in the United States. Conservation Biology, 11(1): 11-20.

LUGO, A.E. 1999. Mangrove ecosystem research with emphasis on nutrient cycling. In: YANEZ-ARANCIBIA, A. \& A.L. LARA-DOMINGUEZ (Eds.). Ecosistemas de manglar en America Tropical. México: UICN/ORMA, p.17-38.

LUGO, A. E. \& S. C. SNEDAKER. 1974. The ecology of mangroves. A Rev. Ecol. Syst., (5): 39-64.

LUGO, A. E.; M. M. BRINSON \& S. BROWN. 1990. Concepts in wetland ecology, pp. 53-85. In: A. E. Lugo; M. Brinson \& S. Brown (eds.), Forested wetlands. Ecosystems of the world, Elsevier, Amsterdam, 527p.

LUGO, A. E.; G. CINTRÓN \& C. GOENAGA. 1981. Mangrove ecosystem under stress. Pp. 129-153. In: G. W. Barret \& R. Rosemberg (eds.). Stress Effects on Natural Ecosystems. Jonh Wiley \& Sons Ltd.

MANDURA, A. S. 1997. A mangrove stand under sewage pollution stress: Red Sea. Mangroves and Salt Marshes. 1: 255-262.

MAZDA, A. Y.; M. MAGI; M. KOGO \& P. N. HONG. 1997a. Mangroves as a coastal protection from waves in the Tong King delta, Vietnam. Mangroves and Salt Marshes. 1: 127-135. 
MAZDA, A. Y.; E. WOLANSKI; B. KING; A. SASE; D. OHTSUKA \& M. MAGI. 1997b. Drag force due to vegetation in mangrove swamps. Mangroves and Salt Marshes. 1: 193-199.

MCKEE, L.K., 1993. Soil physicochemical patterns and mangroves species distribuition: reciprocal effects? Journal of Ecology. 81: 477-487.

MCKEE, L.K., 1995. Interspecific variation in growth, biomass partitioning, and defensive characteristics of neotropical mangrove seedlings: response to light and nutrient availability. Am. J. Bot. 82, 299-307.

MCKEE, L.K \& I. A. MENDELSSOHN. 1987. Root metabolism in the black mangrove, Avicennia germinans (L.) L.: response to hypoxia. Environmental and Experimental Botany. 27: 147-156.

MENEZES, G. V. 1994. Produção e decomposição de bosque de mangue da Ilha do Cardoso, Cananéia, SP. Dissertação de mestrado. Universidade de São Paulo, Instituto Oceanográfico, $116 \mathrm{p}$.

MENEZES, G. V. 2000. Recuperação de manguezais: um estudo de caso na Baixada Santista, Estado de São Paulo, Brasil. Tese de Doutorado, Instituto Oceanográfico, Universidade de São Paulo, 164 p. + Anexos com figuras e tabelas.

ODUM, H. T. 1967. Work circuitsand system stress. In: E. E. Young (eds.). Symposium on Primary Productivity and Mineral Cycling in Natural Ecosystems. Univ. of Marine Press. Orono. Maine. Pp. 81-138.

ODUM, E. P. 1981. The effects of stress on the trajectory of ecological succession. pp. 4347. In: G. W. Barret \& R. Rosemberg (eds.). Stress Effects on Natural Ecosystems. Jonh Wiley \& Sons Ltd.

ODUM, W. E. \& R. E. JOHANNES. 1975. The response of mangrove to man induced environmental stress. In: WOOD, E. J. F. \& JOHANNES, R. E. (eds). Tropical marine pollution. Oceanography Series. Amsterdam, Elsevier, p. 52-62.

OTHMAN, A. M. 1994. Value of mangroves in coastal protection. Hydrobiologia. 285: 277-282.

PATTERSON, C. S.; I. A. MENDELSSOHN \& E. M. SWENSON. 1993. Growth and survival of Avicennia germinans seedlings in a mangal/saltmarsh community in Lousiana, U. S. A. Journal of Coastal Research. 9(3): 801-810.

PELLEGRINI, J. A. C. 2000. Caracterização da planície hipersalina (apicum) associado a um bosque de mangue em Guaratiba - Baía de Sepetiba - RJ. Dissertação de mestrado. Instituto Oceanográfico, Universidade de São Paulo, 101 p. 
PENTEADO. A. R. 1965. As bases geológicas. In: Azevedo, A. (Ed.) A Baixada Santista: aspectos geográficos. Editora da Universidade de São Paulo, SP. v 1.

PERIA, L. C. S.; P. P. C. P. FERNANDES; G. V. MENEZES; M. GRASSO \& M. M. P. TOGNELLA. 1990. Estudos estruturais comparativos entre bosques de mangue impactados (Canal de Bertioga) e não-impactados (Ilha do Cardoso), Estado de São Paulo, pp. 183-193. In: Anais do II Simpósio de Ecossistemas da Costa Sul e Sudeste Brasileira: estrutura, função e manejo, Águas de Lindóia, São Paulo, Academia de Ciências e do Estado de São Paulo, v 2.

PONTE, A. C. E.; I. A. Z. FONSECA; M. MARQUES; M. L. FREITAS \& S. M. C. A. CLARO. 1984. Produção de serapilheira e decomposição do material foliar em ecossistema de mangue. In: Anais do IV Congr. SBSP. 103-107.

PONTE, A. C. E.; I. A. Z. FONSECA \& S. M. C. A. CLARO. 1987. Impacto causado por petróleo no manguezal do Canal de Bertioga - Estrutura de vegetação. In: Simpósio Sobre Ecossistemas da Costa Sul e Sudeste Brasileira. Síntese dos Conhecimentos, Cananéia, São Paulo: ACIESP, v.2, p.138-47.

PONTE, A. C. E.; I. A. Z. FONSECA \& S. M. C. A. CLARO. 1990. Produção de serapilheira em bosque impacto por petróleo. In: Simpósio de Ecossistemas da Costa Sul e Sudeste Brasileira. Estrutura, função e manejo, Águas de Lindóia, São Paulo: ACIESP, v.2, p.241-253.

POOL, D. J.; A. E. LUGO \& S. C. SNEDAKER. 1975. Litter production in mangrove forests of Southern Florida and Puerto Rico. In: WALSH, G., SNEDAKER, S. C., TEAS, H. (Eds). Proceedings of international symposium on biology and Management of Mangroves, Gainesville, IFAS, University of Florida, v.1, p. 213237.

POZZI-NETO, D. 2001. Baixada Santista, manguezal e vazamento de óleo: uma valoração econômica-ecológica. Dissertação de Mestrado. Programa de Pós-Graduação em Ciência Ambiental. Universidade de São Paulo. 114 p.

RABINOWITZ, D. 1975. Planting experiments in mangroves swamps of Panama. In: Walsh, G. E.; Snedaker, S. C. \& Teas, H. J. (eds.) Proceeding of International Symposium on Biology and Management of Mangroves. Institute of Food and Agriculture Science, Univ. of Florida, Gainesville, p. 385-393.

RABINOWITZ, D. 1978a. Early growth of mangrove seedlings in Panama, and Hypothesis concerning the relationship of dispersal and zonation. J. Biogeogr. 5: 113-133.

ROBERTSON, W. B. 1962. Fire and vegetation in the Everglades. Pages 67-80. In: Proceedings of the first annual Tall Timbers fire ecology conference. Tall Timbers Research Station, Tallahassee, Florida. 
RODRIGUES, J. C. 1965. As bases geológicas. In: Azevedo, A. (Ed.). A Baixada Santista: aspectos geográficos. Editora da Universidade de São Paulo, SP. v 1.

RODRIGUES, F. O. ; D. O. MOURA \& C. C. LAMPARELLI. 1989. Efeitos do óleo nas folhas de mangue. Revista Ambiente. 3(1): 36-45.

RODRIGUES, F. O. ; D. O. MOURA \& C. C. LAMPARELLI. 1990. Evolução das alterações estruturais e funcionais provocadas por óleo no manguezal do Rio Iriri. In: Simpósio de Ecossistemas da Costa Sul e Sudeste Brasileira. Estrutura, função e manejo. Águas de Lindóia, 1990. São Paulo: ACIESP, v.2, p.194-208.

SAENGER, P.E., E. HEGERL \& J. DAVIE. 1983. Global status of mangrove ecosystems. The Environmentalist 3 (Suppl. 3): 1-88.

SANTOS, E. 1965. Características climáticas. Baixada Santista: aspectos geográficos. In: Departamento de Geografia da Faculdade de Filosofia e Letras da Universidade de São Paulo. V. 1.

SCHAEFFER-NOVELLI, Y. 1986. Rompimento de oleoduto. Avaliação de impacto ambiental no Canal da Bertioga - SP. Perícia de Juízo. Ministério Público do Estado de São Paulo.

SCHAEFFER-NOVELLI, Y. 1987. Manguezais brasileiros: região sul-sudeste. In:Anais do Simpósio sobre ecossistemas da costa sul e sudeste: síntese dos conhecimentos, Cananéia, São Paulo. ACIESP, Cananéia, São Paulo. Vol. 1 p. 78.

SCHAEFFER-NOVELLI, Y. 1989. Perfil dos ecossistemas litorâneos brasileiros, com especial ênfase sobre o ecossistema manguezal. Publção. Esp. Inst. Oceanogr. S. Paulo. (7): 16p.

SCHAEFFER-NOVELLI, Y. 1991. Manguezais brasileiros. Tese de Livre Docência. Universidade de São Paulo, Instituto Oceanográfico. 2 vols.

SCHAEFFER-NOVELLI, Y. 2002. Manguezal: ecossistema que ultrapassa suas próprias fronteiras. In: Congresso Nacional de Botânica, 53., 2002, Recife, p. 34-37.

SCHAEFFER-NOVELLI, Y. \& G. CINTRÓN. 1986. Guia para o estudo de áreas de manguezal, estrutura, função e flora. Caribbean Ecological Research, 1986. São Paulo, 150 p. +3 apêndices.

SCHAEFFER-NOVELLI, Y.; G. CINTRÓN-MOLERO; R. R. ADAIME. \& T. M. CAMARGO. 1990. Variability of mangrove ecosystems along the Brazilian coast. Estuaries. (13) 2: 204-218. 
SCHAEFFER-NOVELLI, Y.; R. P. MENGHINI; R. K. TAMASATO; R. ALMEIDA; N. C. PAIXÃO; M. CUNHA-LIGNON; K. SUGUIU \& G. N. S. PATU. 2003. Baixada Santista, Estado de São Paulo, Brasil: Instrumento Técnico Científico. BIOMA Centro de Ensino e Informação sobre Zonas Úmidas Costeiras Tropicais com ênfase no ecossistema manguezal. Instituto Oceanográfico - USP, São Paulo, SP. SP. Ref. Rep. nº 08123,030,384/98-05, ofício do Ministério Público Federal no município de Santos. 40p.

SEMENIUK, V. 1980. Mangrove zonation along an eroding coastline in King Sound North-Western Australia. Blackwell Scientific Publications, p.789-812.

SIEDLECKA, A. 1995. Some aspects of interactions between heavy metals and plant mineral nutrients. Acta Societatis Botanicorum Poloniae. Vol. 64 (3): 265-272.

SMITH, T. J. III 1987. Effects of light and intertidal position on seedling survival and growth in tropical, tidal forests. J. Expl. Mar. Biol. Ecol. (11): 133-146.

SMITH III, T. J. 1992. Forest Structure, pp 101-136. In: A. I. Robertson \& D. M. Alongi (eds.), Coastal and Estuarine Studies, v. 41, Tropical mangrove ecosystems. American Geophysical Union, Washington, D. C., 329p.

SNEDAKER, S. C.; JIMENEZ, J. A. \& BROWN, M. S. 1981. Anomalous roots in Avicennia germinans (L.) in Florida and Costa Rica. Bull. Mar. Sci. 31(2): 467-470.

SOARES, M. L. G. 1997. Estudo da biomassa aérea de manguezais do sudeste do Brasil análise de modelos. Tese de doutorado, Universidade de São Paulo, Instituto Oceanográfico, 2 vols.

SOARES, M. L. G. 1999. Estrutura vegetal e grau de perturbação dos manguezais da Lagoa da Tijuca, Rio de Janeiro, RJ, Brasil. Rev. Brasil. Biol., 59(3): 503-515.

SPENCELEY, A. P. 1977. The role of pneumatophores in sedimentary processes. Marine Geology. 24: M31-M37.

TAM, N. F. Y.; Y. S. WONG; C. Y. LAN \& L. N. WANG. 1998. Litter production and decomposition in a subtropical mangrove swamp receiving wastewater. Journal of Experimental Marine Biology and Ecology. 226: 1-18.

TEXMARK, 2003. Texmark CXI. dicyclopentadiene (DCPD), resin intermediates, nbutanol and contract processing. Disponível: www.texmark.com. [capturado em $16 \mathrm{de}$ março de 2003].

TOMLINSON, P.B. 1986. The Botany of Mangroves (Cambridge Tropical Biology Series). Cambridge: Cambridge University Press, 419p. 
TOMMASI. L. R. 1979. Considerações ecológicas sobre o Sistema Estuarino de Santos, São Paulo. Tese de Livre Docência. Universidade de São Paulo, Instituto Oceanográfico. São Paulo. 2 vols.

TWILLEY, R. R.; A. E. LUGO \& C. PATTERSON-ZUCCA. 1986. Litter production and turnover in basin mangrove forests in southwest Florida. Ecology. 67(3): 670-683.

TWILLEY, R. R., S. C. SNEDAKER, A. YÁÑES-ARANCIBIA \& E. MEDINA. 1996. Biodiversity and ecosystem processes on tropical estuaries: perspectives of mangrove ecosystems. In: MOONEY, H. A ; J. H. CUSHMAN \& E. MEDINA (eds): Functional Roles Biodiversity: A Global Perspective, p.327-370.

WALSH, G. E. 1974. Mangroves forests: a review. In: R. J. Reinold \& W. H. Ed. Queen. Ecology of Halophytes. Academia Press, Inc. 605 p.

WILCKEN, C. F.; R. C. B. MORAES; M. L. HADDAD \& J. R. P. PARRA. 1998. Técnica de medição de área foliar consumida por insetos através de digitalizador de imagens. Scientia Agricola. Vol. $55 \mathrm{n}^{\circ} 2$. 


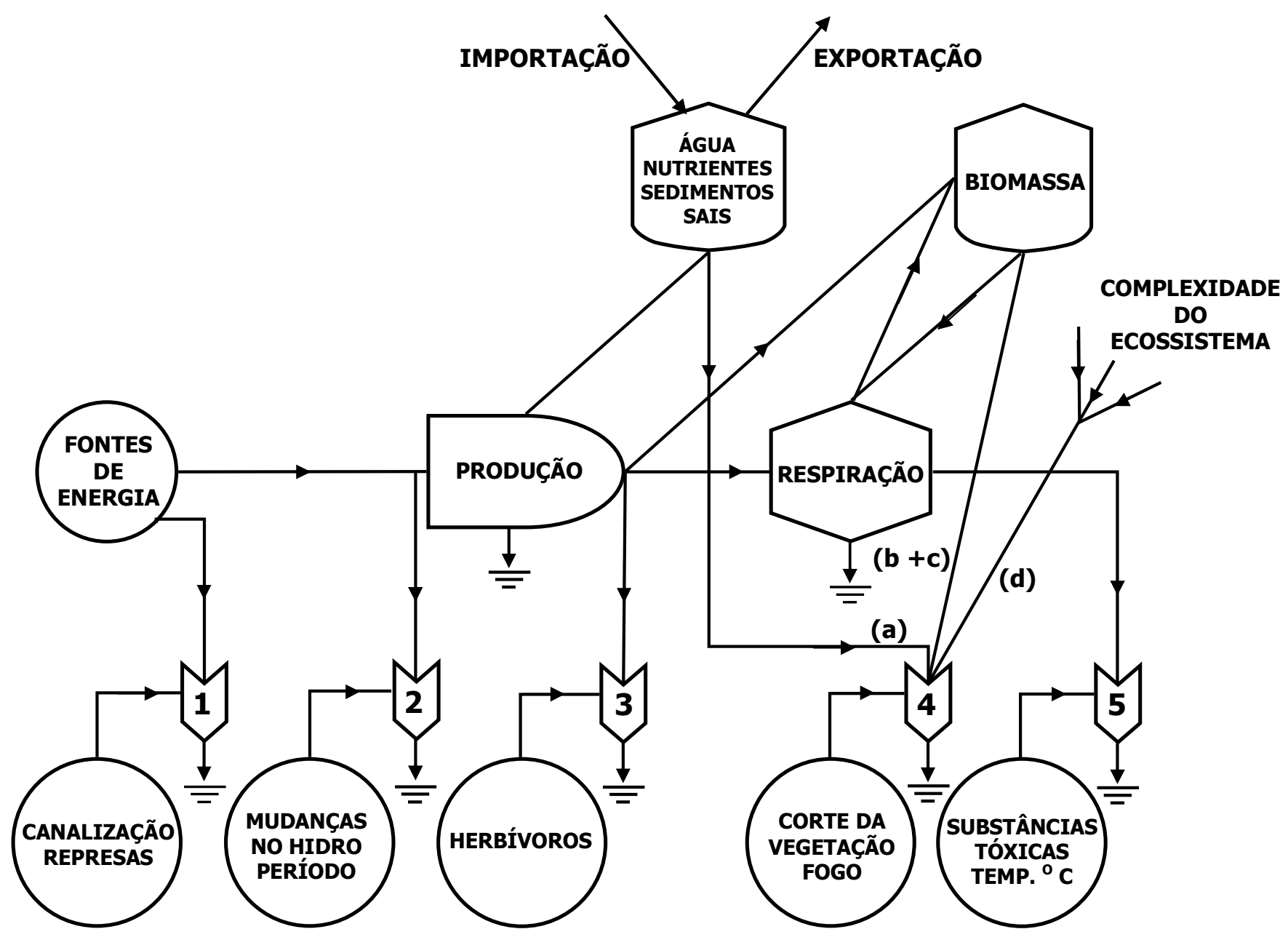

Figura 1 - Diagrama proposto por Lugo (1978) e modificado por Lugo et al. (1981), ilustrando os diferentes pontos de atuação dos tensores no ecossistema manguezal. 


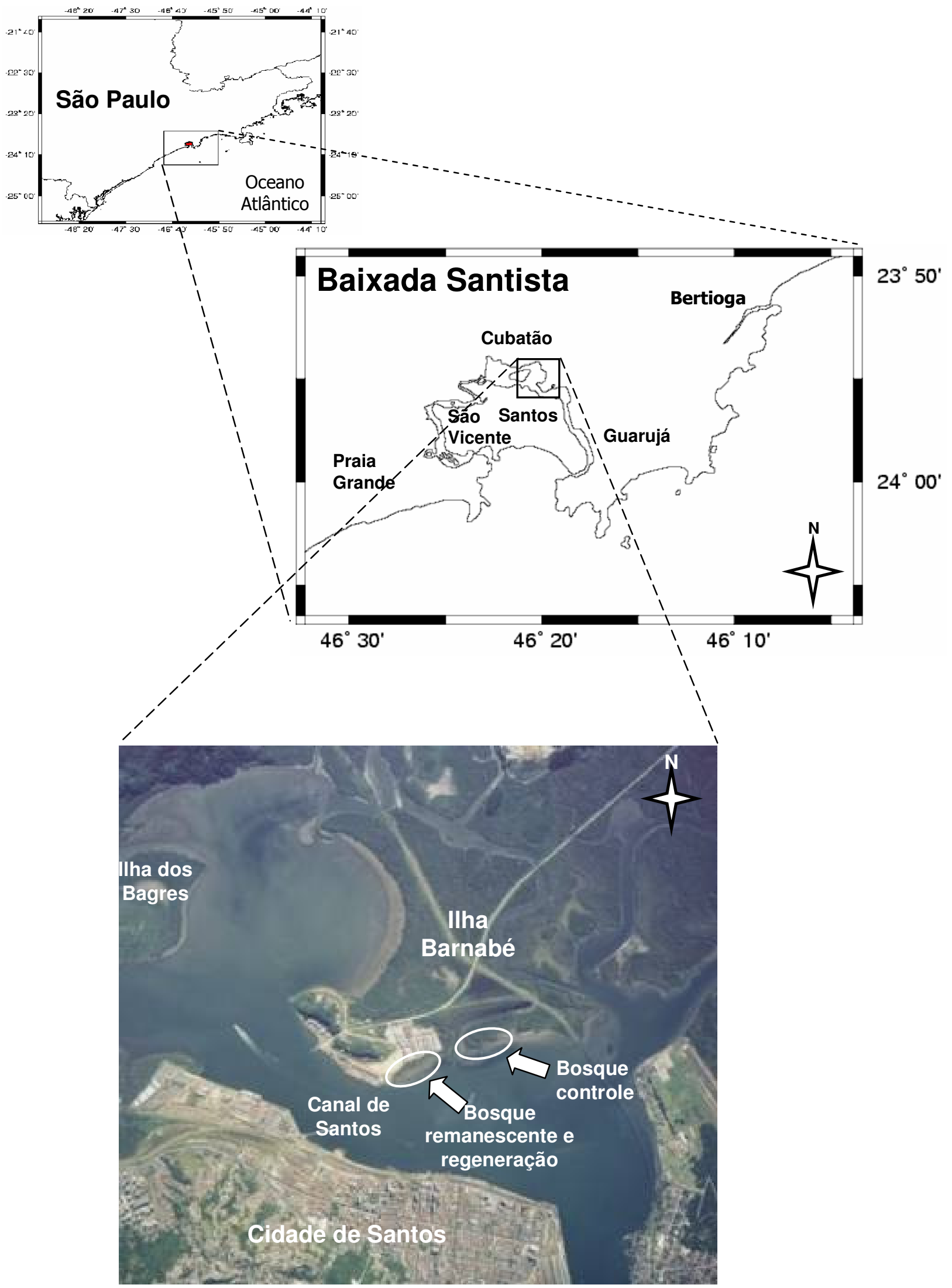

Figura 2 - Localização das áreas de estudo, com bosques de mangue situando-se na porção leste da Ilha Barnabé (Foto aérea obtida no site www.agem.sp.gov.br). 


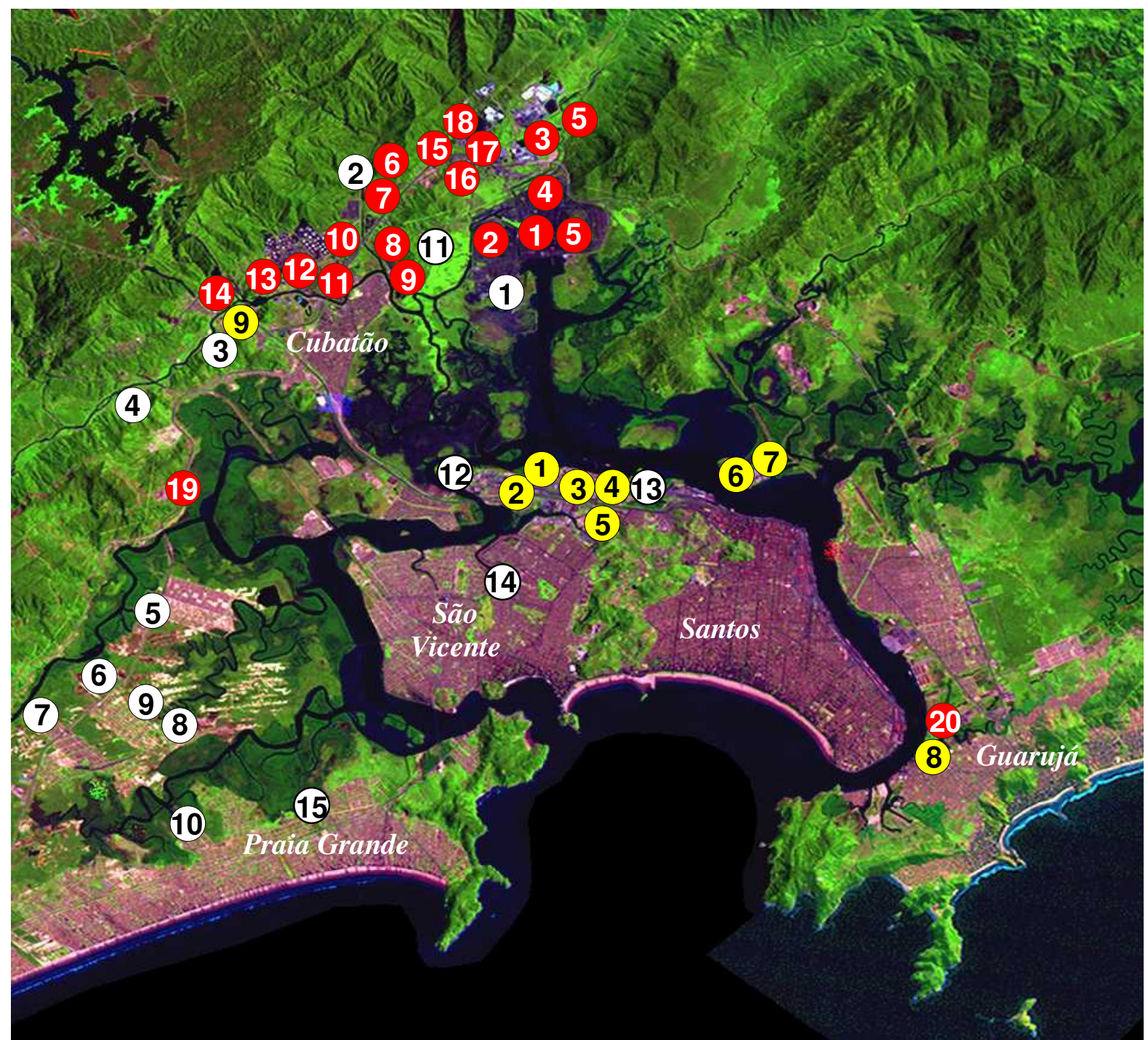

Figura 3 - Localização das principais fontes de contaminantes químicos para a região da Baixada Santista, segundo Cetesb (2001) (Imagem Landsat obtida no site www.cdbrasil.cnpm.embrapa.br).

\section{Industrias (círculos vermelhos):}

1 - Cosipa; 2 - IFC; 3 - Manah; 4 - Serrana; 5 - Ultrafértil PG; 6 - Union Carbide; 7 - Alba; 8 - Rhodia; 9 - Carbocloro; 10 Petrocoque; 11 - CBE; 12 - Petrobrás RPBC; 13 - Ultrafértil CB; 14 - Cia. Santista de Papel; 15 - Copebrás; 16 - Columbia; 17 Solorrico; 18 - Liquid Química; 19 - Ciel; 20- Dow Química.

Terminais de Granéis Liquidos (círculos amarelos):

1 - Petrobrás DTCS (Alemoa); 2 - Dibal; 3 - União; 4 - Stolthaven; 5 - Mobil; 6 - Granel; 7 - Brasterminais; 8 - Dow Química; 9 Petrobrás DTCS (Cubatão).

Áreas contaminadas (círculos brancos):

1 - Cosipa (Dique do Furadinho); 2 - Rhodia Perequê; 3 - Petrobrás - DTCS; 4 - Lixão de Pilões; 5 - Rhodia PI06; 6 - Rhodia Km 67; 7 - Rhodia Km 69; 8 - Rhodia Quarentenário; 9 - Rhodia PI05; 10 - Profundir; 11 - Aterro Sanitário de Cubatão; 12 - Lixão da Alemoa; 13 - Desvio de Lixo (Codesp); 14 - Lixão do Dique de Sambaiatuba (São Vicente); 15 - Lixão de Praia Grande. 


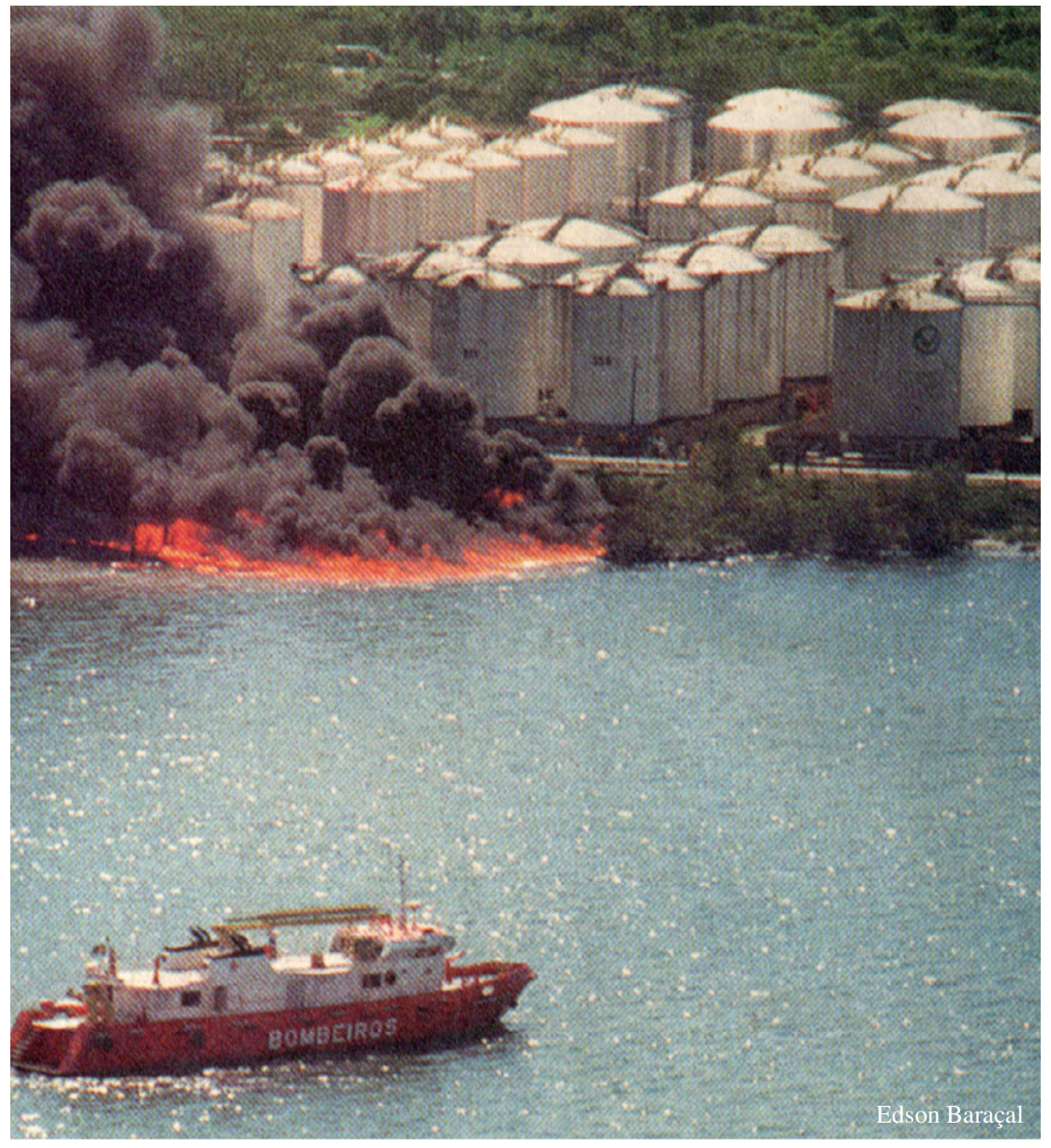

Figura 4 - Visão do evento ocorrido na área de estudo, 3 de setembro de 1998, com derramamento e combustão de produto químico (DCPD diciclopentadieno). 


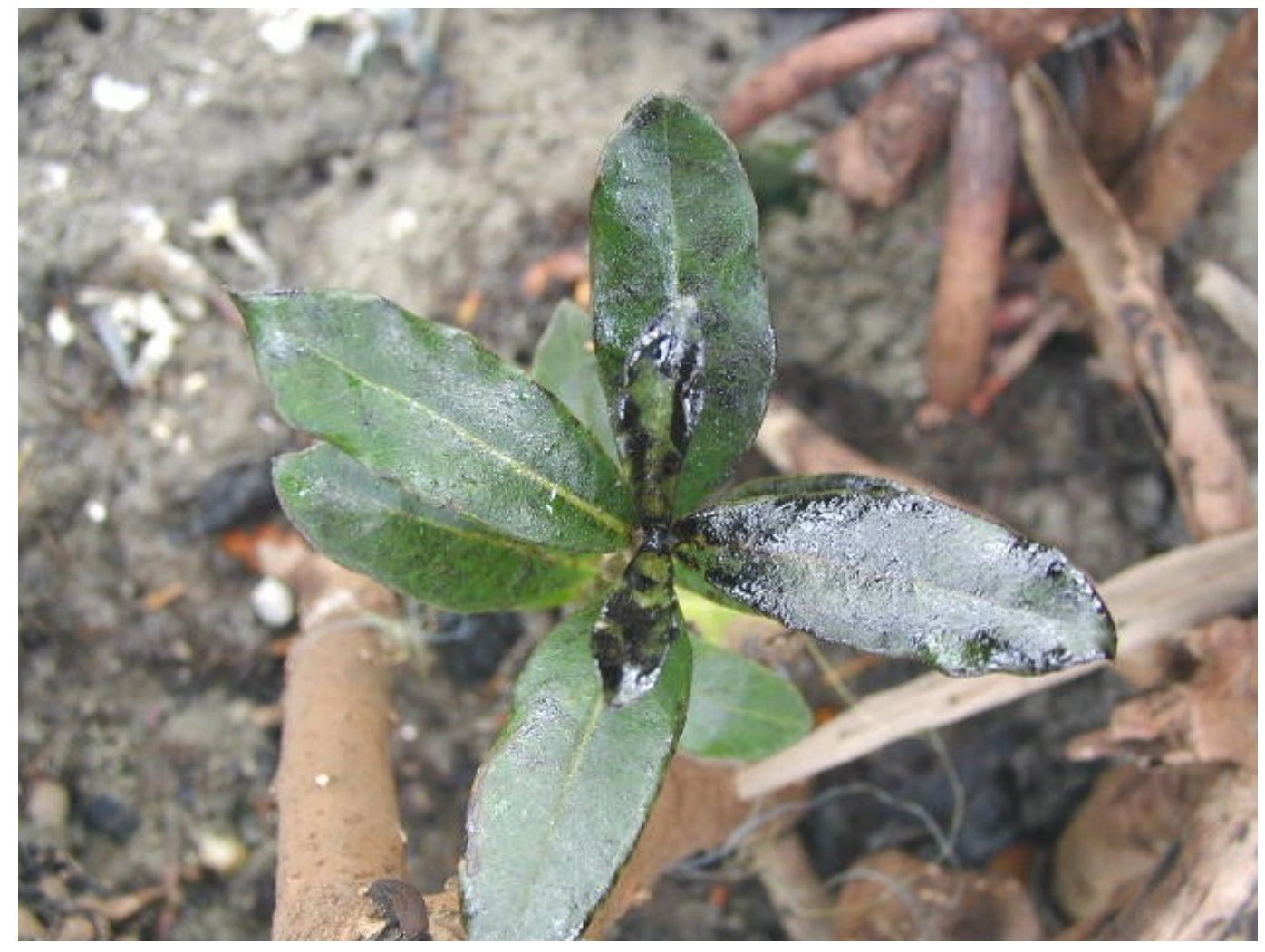

Figura 5 - Detalhe de plântula de Avicennia schaueriana com manchas de óleo sobre as folhas, durante evento ocorrido no dia 27 de abril de 2004. 


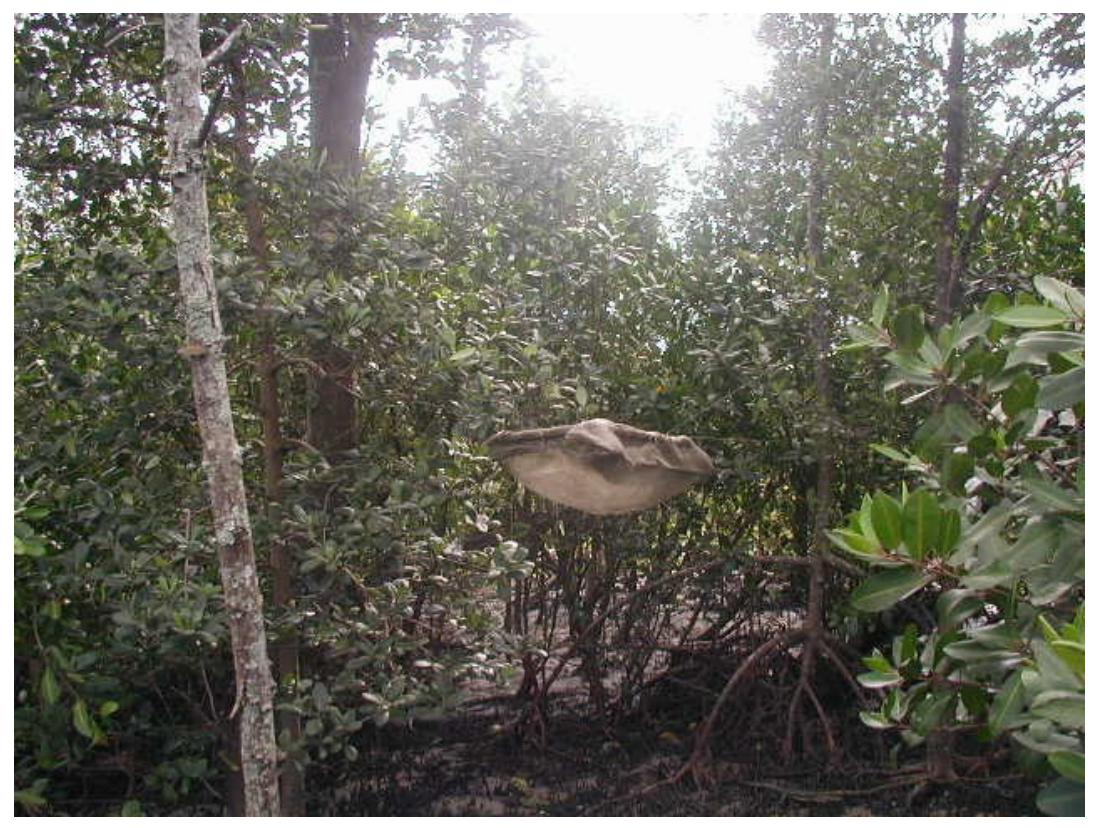

Figura 6 - Cesta coletora de serapilheira instalada no bosque de mangue da Ilha Barnabé

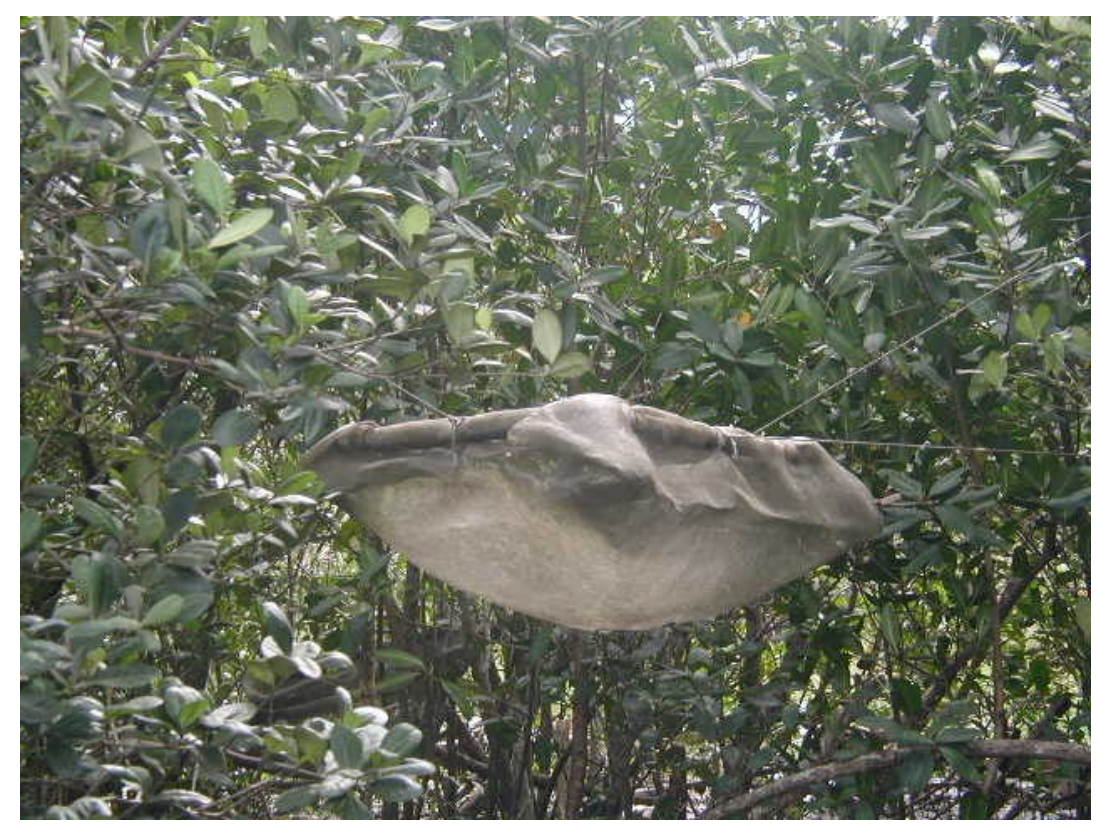

Figura 7 - Detalhe da cesta coletora de serapilheira. 


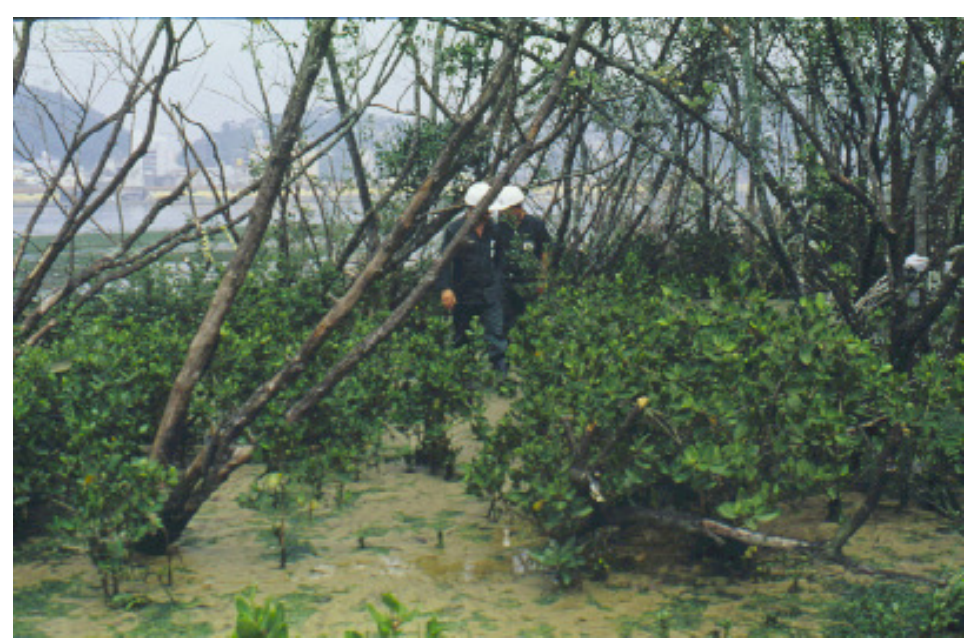

Figura 8 - Detalhe do início do processo de regeneração da cobertura vegetal no bosque de mangue da Ilha Barnabé, no ano de 2000.

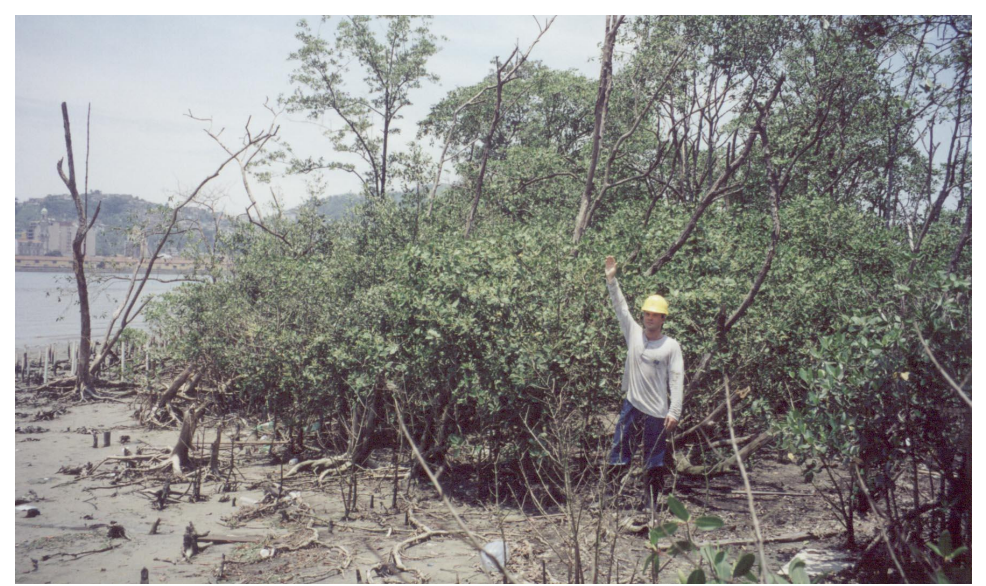

Figura 9 - Detalhe do processo de regeneração da cobertura vegetal no bosque de mangue da Ilha Barnabé, no ano de 2002.

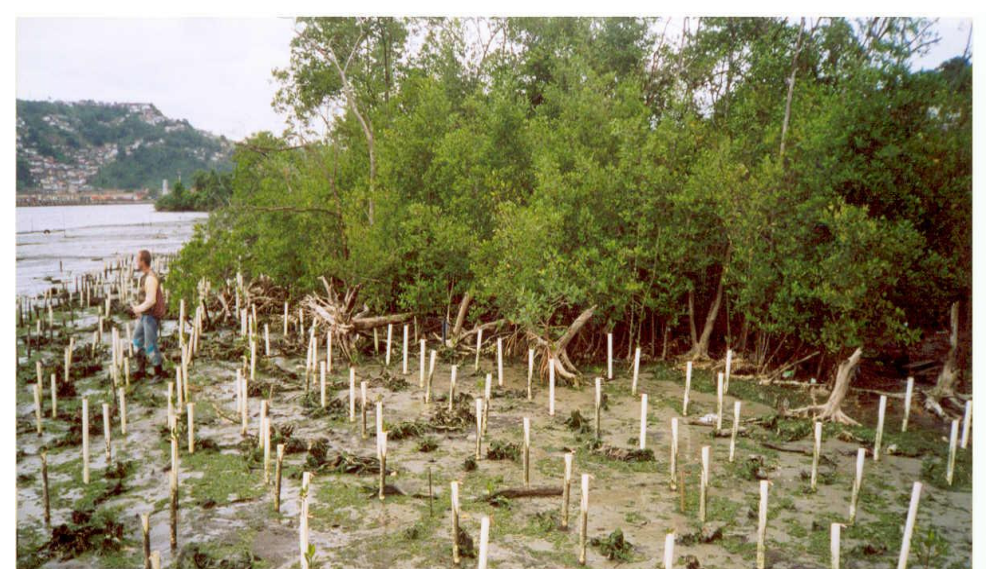

Figura 10 - Detalhe do processo de regeneração da cobertura vegetal no bosque de mangue da Ilha Barnabé, no ano de 2004. 


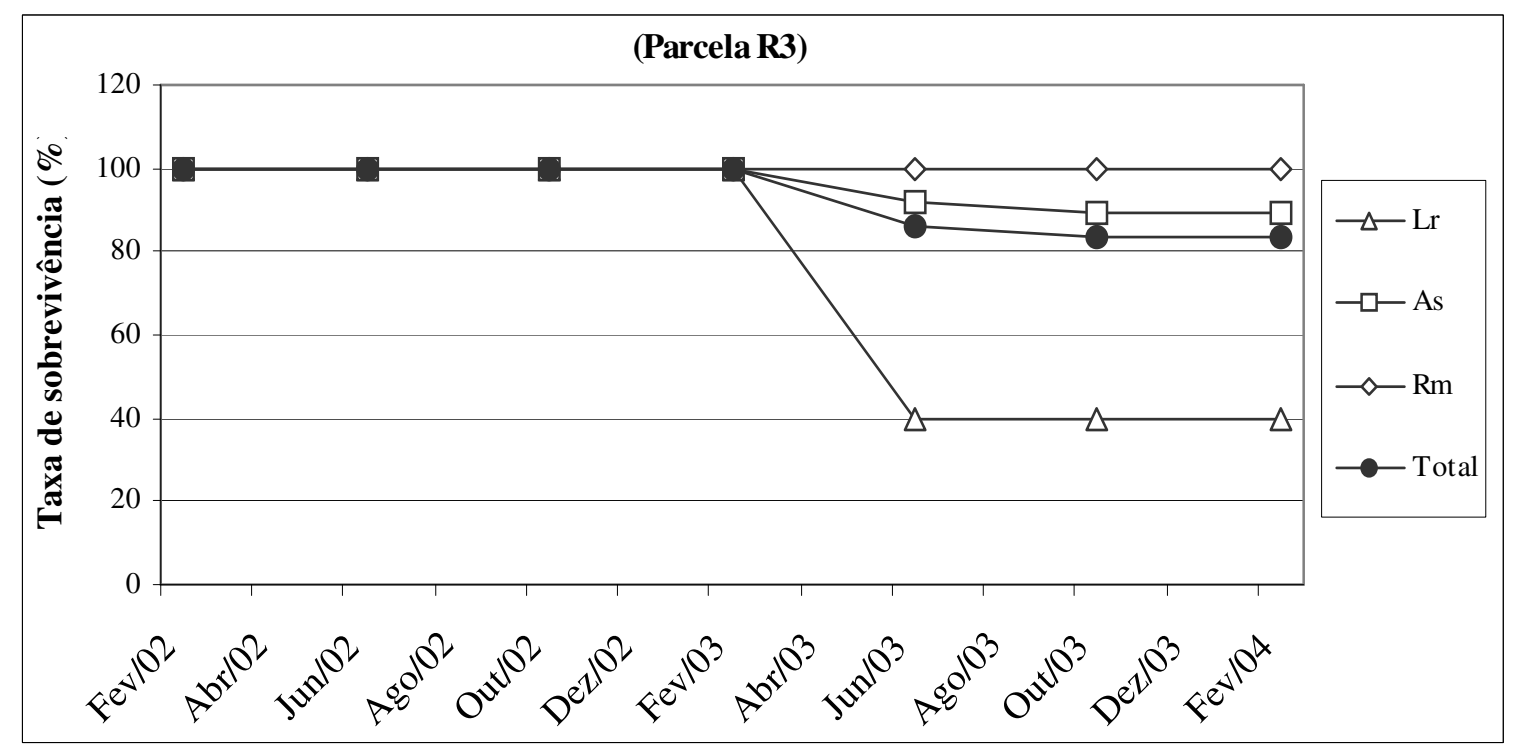

Figura 11 - Taxa de sobrevivência por espécie, na parcela em regeneração (R2), ao longo dos dois anos de monitoramento no bosque de mangue da Ilha Barnabé. $(\mathrm{Lr}=$ Laguncularia racemosa; As = Avicennia schaueriana $)$.

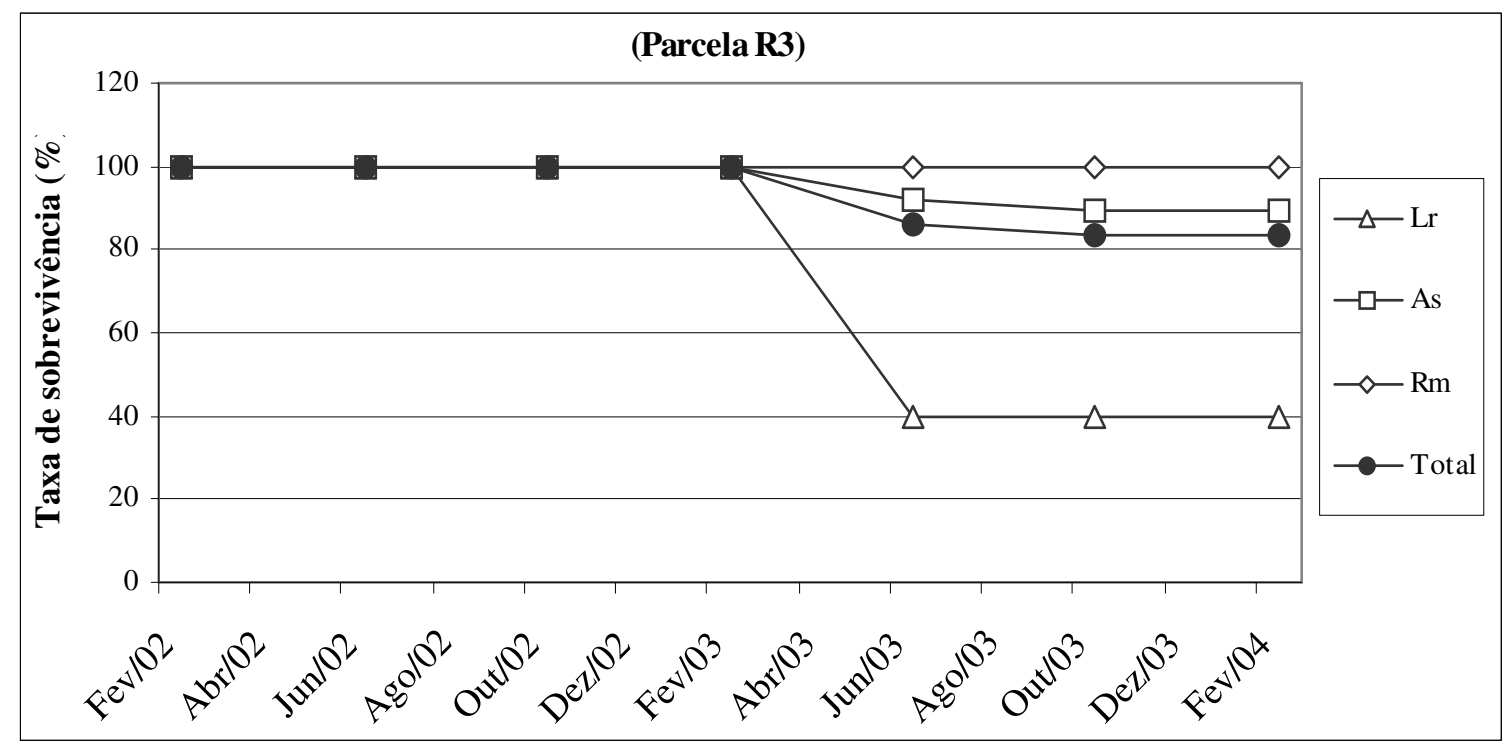

Figura 12 - Taxa de sobrevivência por espécie, na parcela em regeneração (R3), ao longo dos dois anos de monitoramento no bosque de mangue da Ilha Barnabé. $\quad(\mathrm{Lr}=$ Laguncularia racemosa $;$ As = Avicennia schaueriana $; \mathrm{Rm}=$ Rhizophora mangle). 


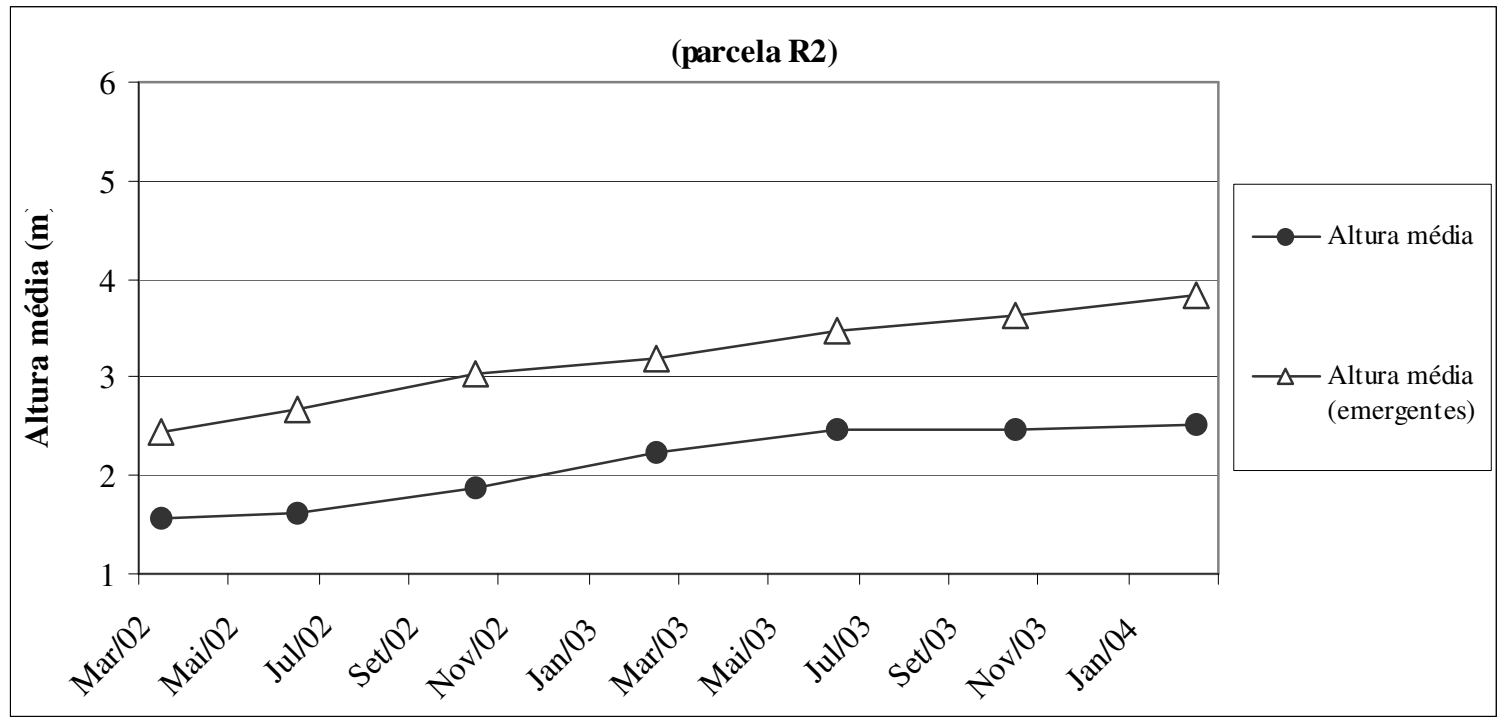

Figura 13 - Incremento na altura média dos indivíduos e dos indivíduos emergentes da parcela em regeneração (R2), ao longo dos dois anos de monitoramento no bosque de mangue da Ilha Barnabé.

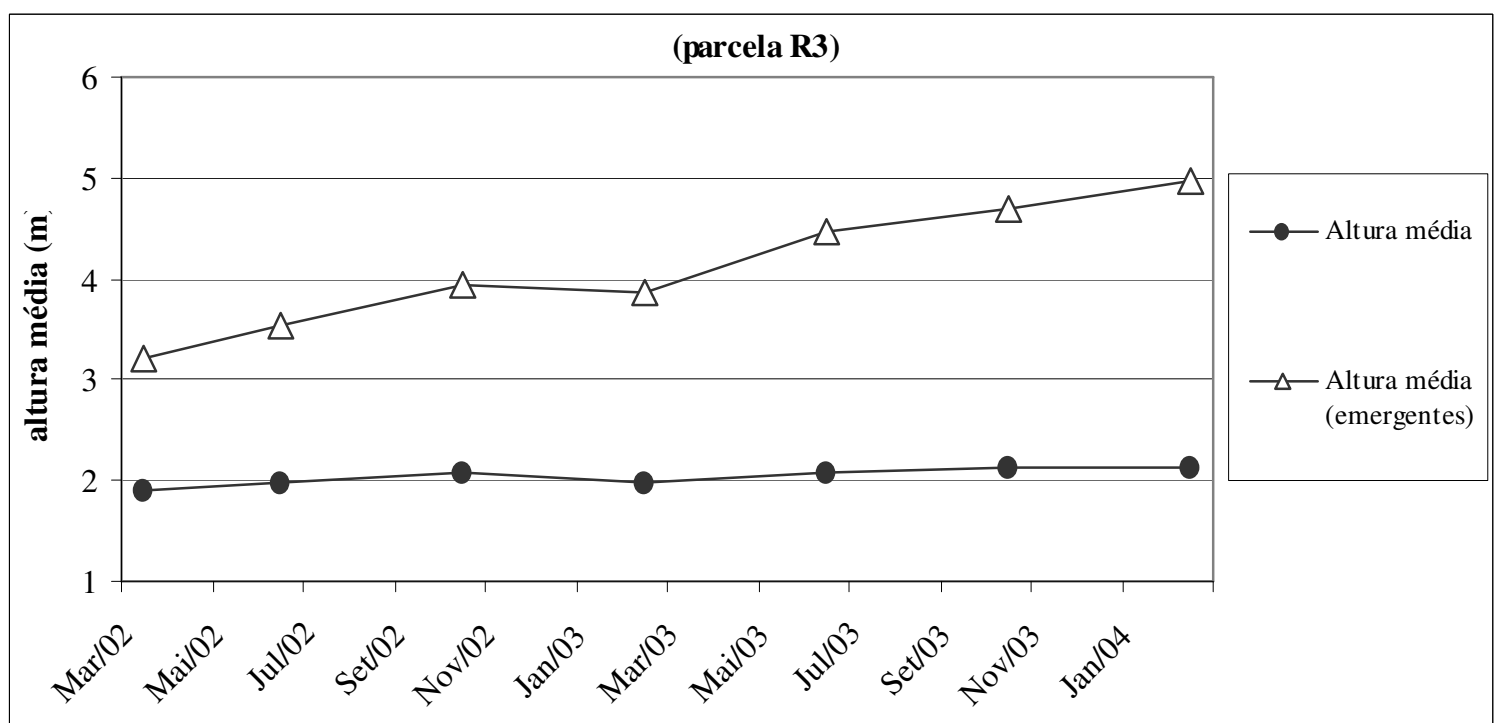

Figura 14 - Incremento na altura média dos indivíduos e dos indivíduos emergentes da parcela em regeneração (R3), ao longo dos dois anos de monitoramento no bosque de mangue da Ilha Barnabé. 

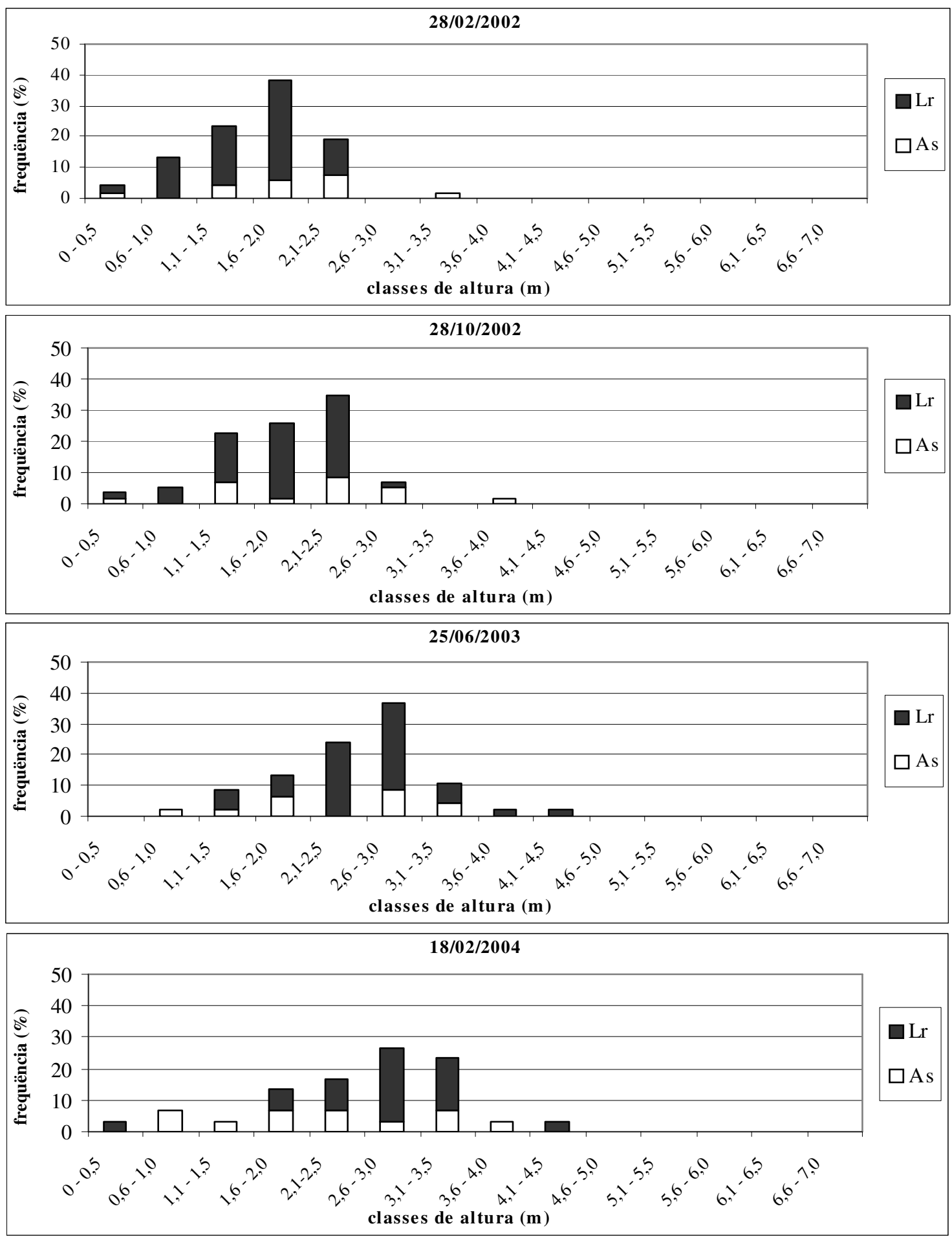

Figura 15 - Distribuição da frequiência de indivíduos, por classe de altura, na parcela em regeneração (R2), ao longo dos dois anos de monitoramento no bosque de mangue da Ilha Barnabé. 

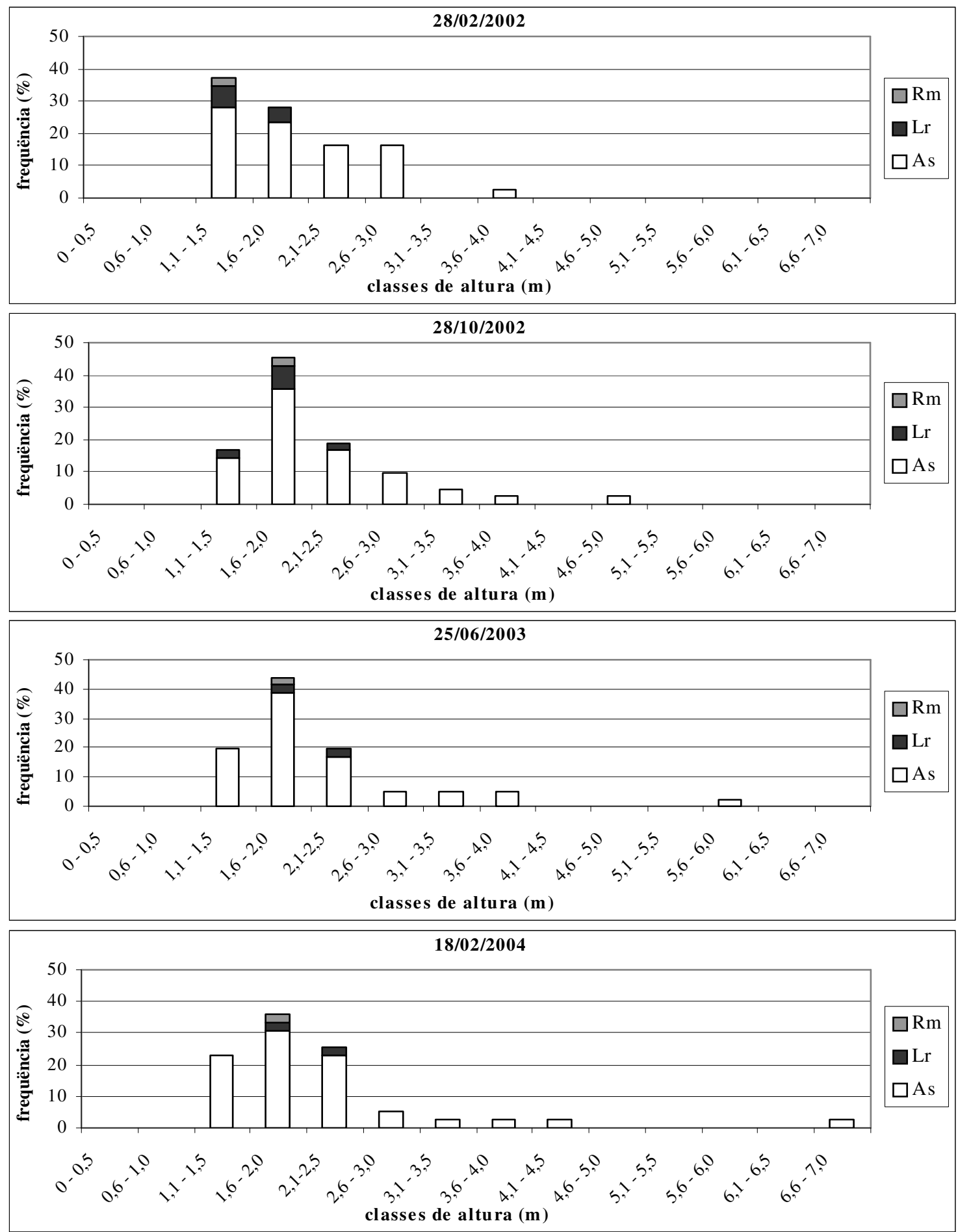

Figura 16 - Distribuição da frequiência de indivíduos, por classe de altura, na parcela em regeneração (R3), ao longo dos dois anos de monitoramento no bosque de mangue da Ilha Barnabé. 


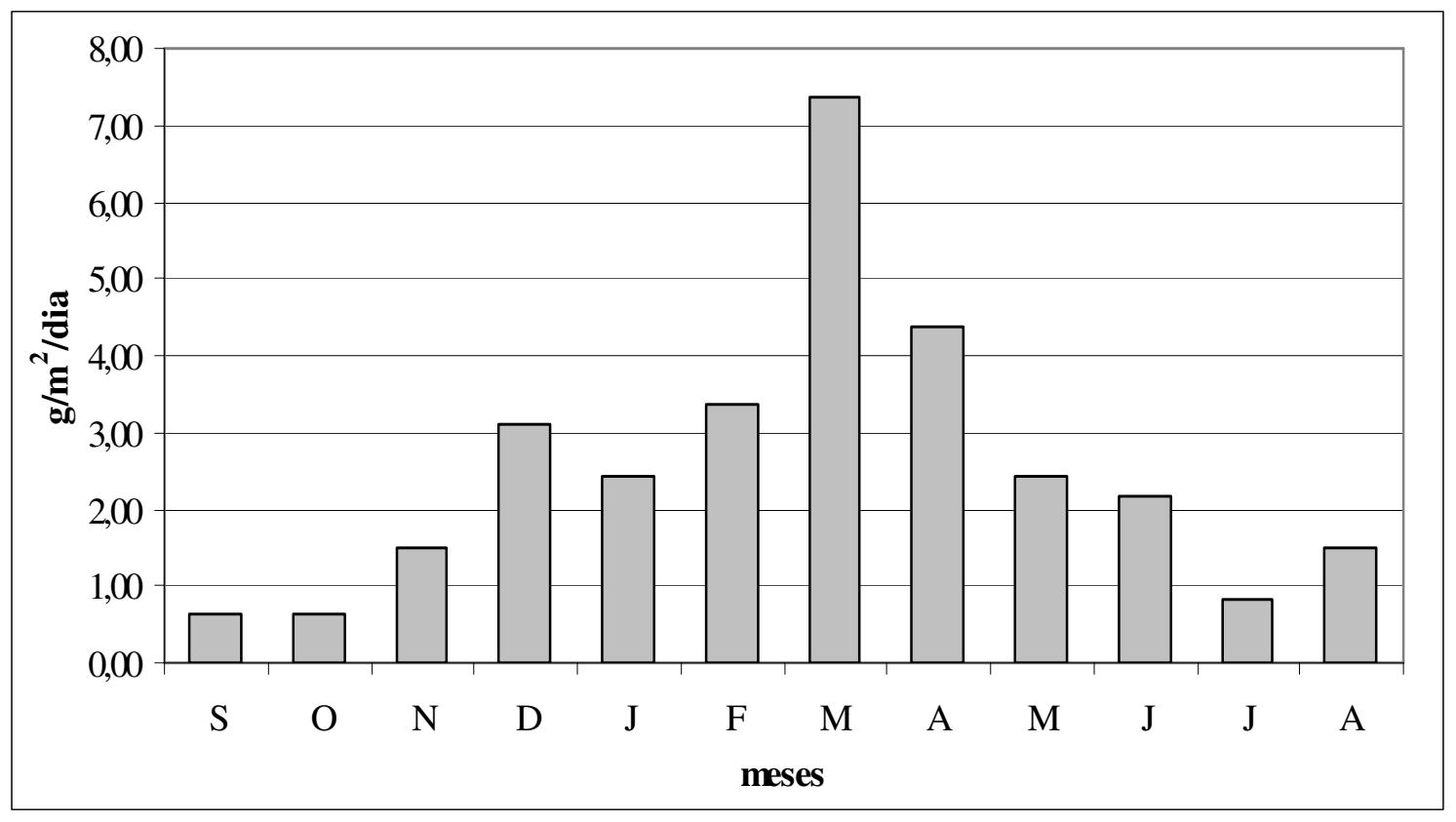

Figura 17- Médias mensais da queda de serapilheira, no bosque de mangue da Ilha Barnabé. 


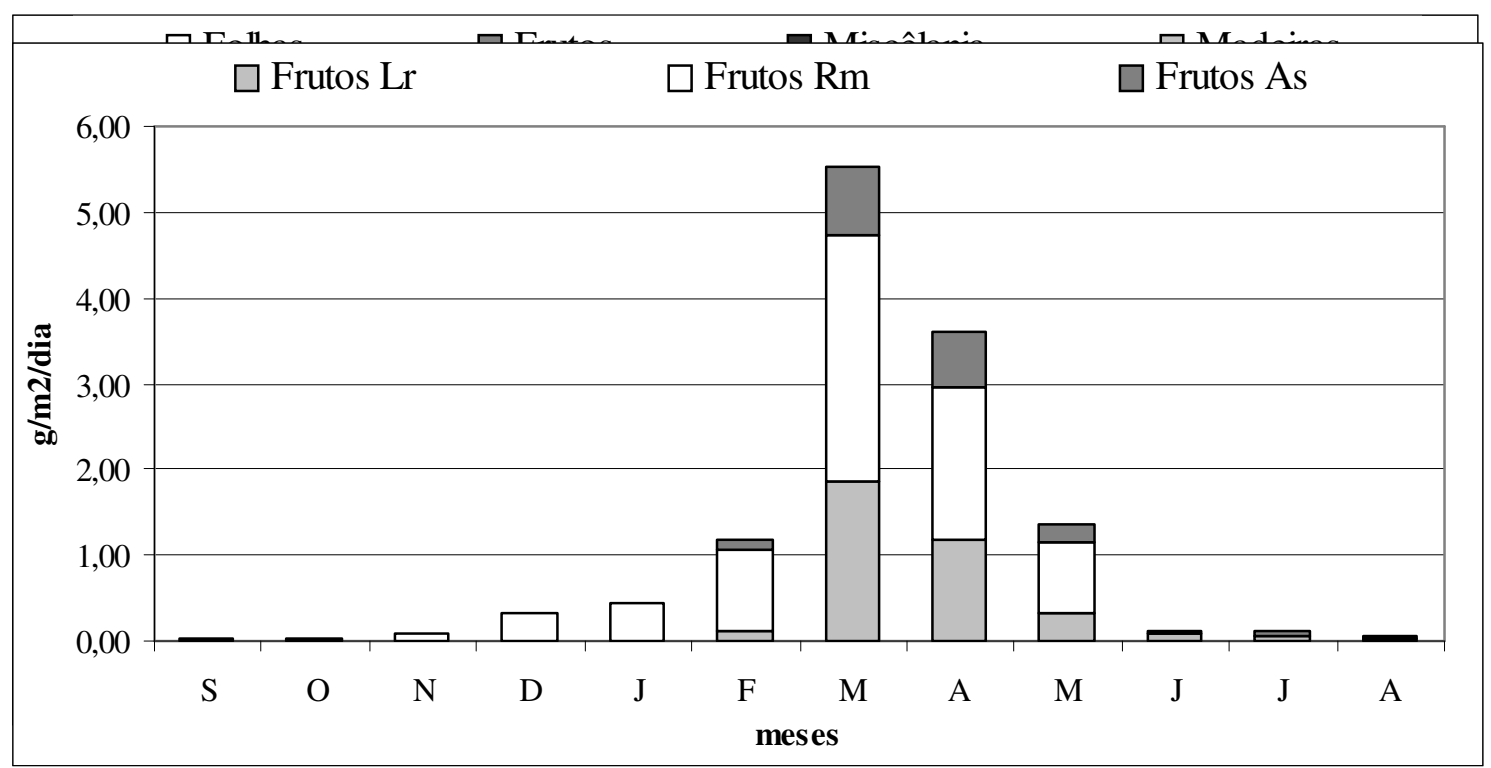

Figura 18 - Médias mensais de cada compartimento na queda de serapilheira, no bosque de mangue da Ilha Barnabé.

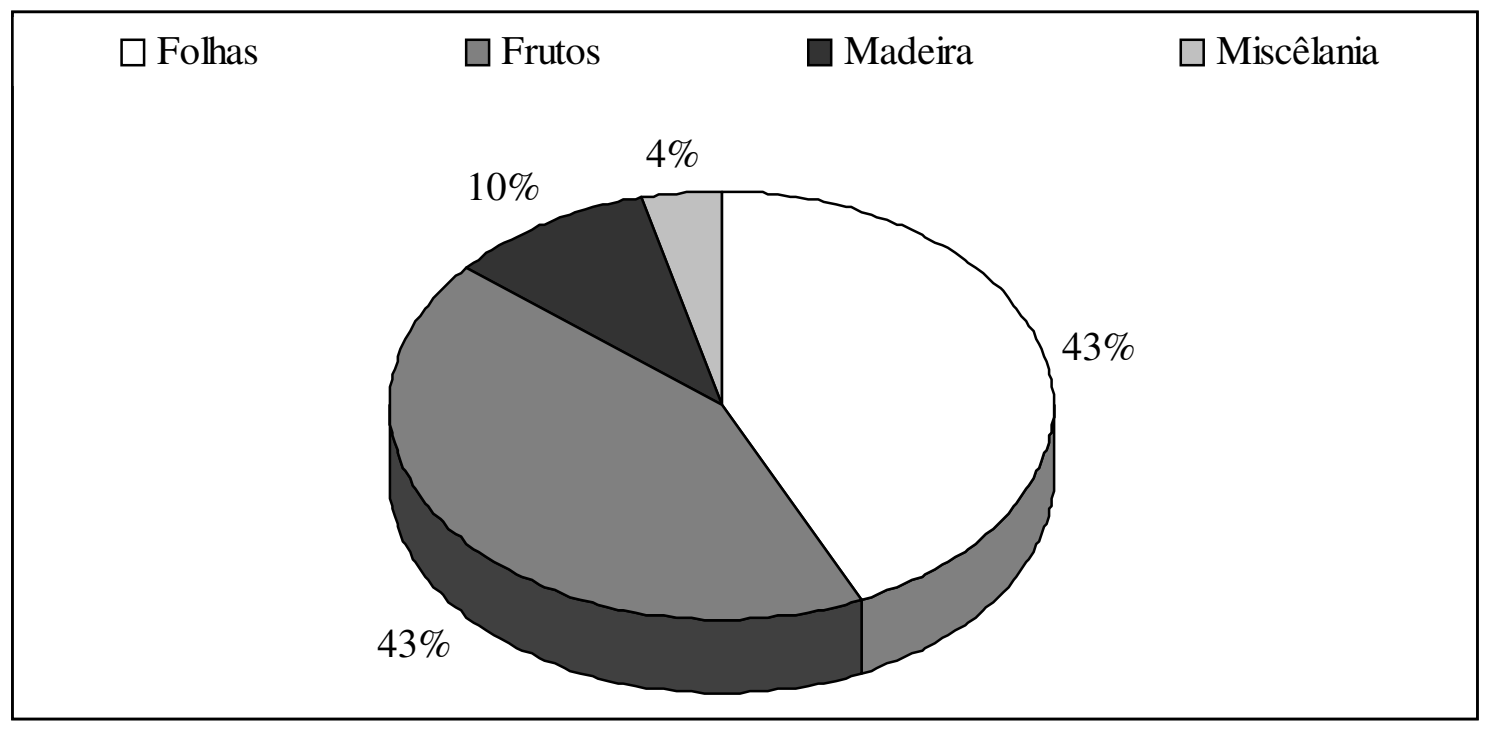

Figura 19 - Contribuição em porcentagem de cada compartimento na queda anual de serapilheira do bosque de mangue da Ilha Barnabé. 


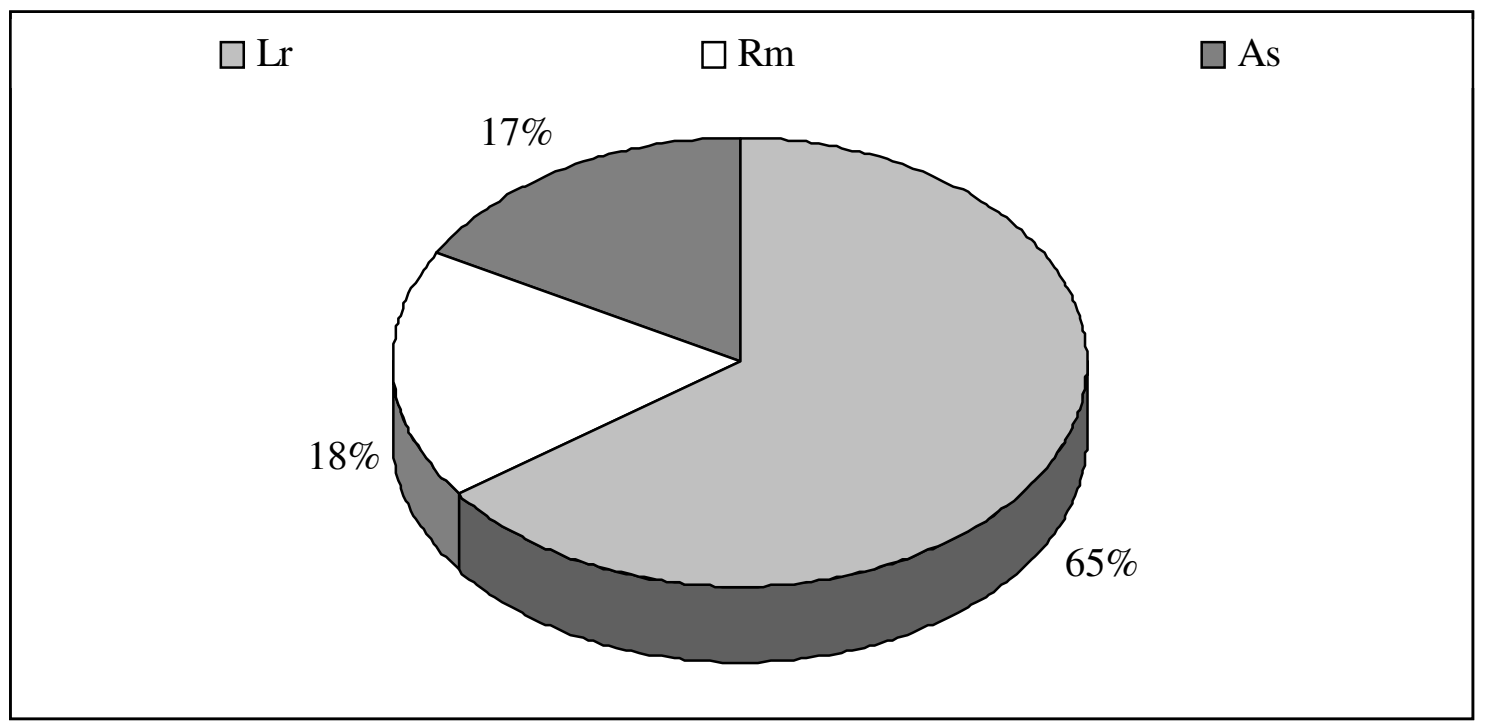

Figura 20 - Contribuição em porcentagem de cada espécie na queda anual de folhas na serapilheira do bosque de mangue da Ilha Barnabé. $(\mathbf{R m}=$ Rhizophora mangle; $\mathrm{Lr}=$ Laguncularia racemosa; As = Avicennia schaueriana $)$.

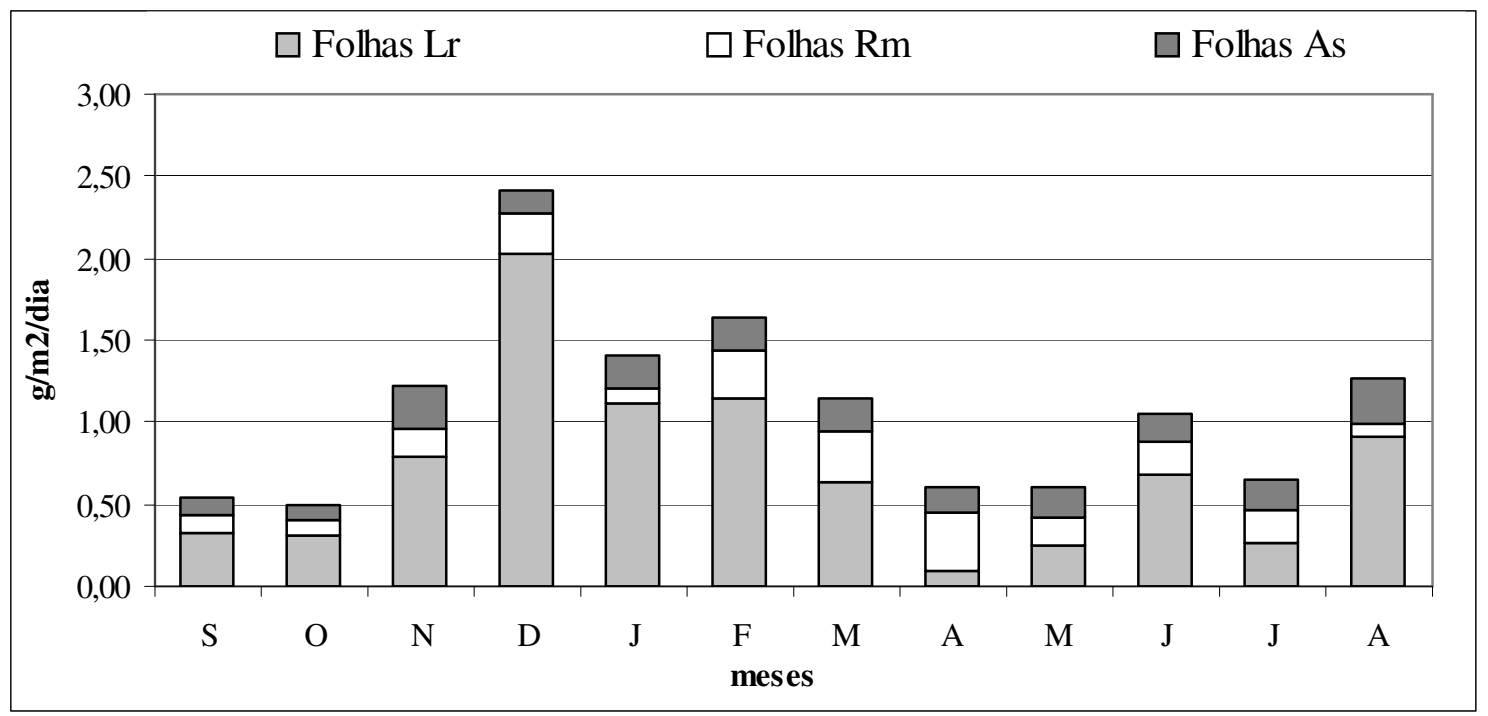

Figura 21 - Médias mensais da queda de folhas da serapilheira, no bosque de mangue da Ilha Barnabé. $(\mathbf{R m}=$ Rhizophora mangle $; \mathbf{L r}=$ Laguncularia racemosa $;$ As = Avicennia schaueriana). 


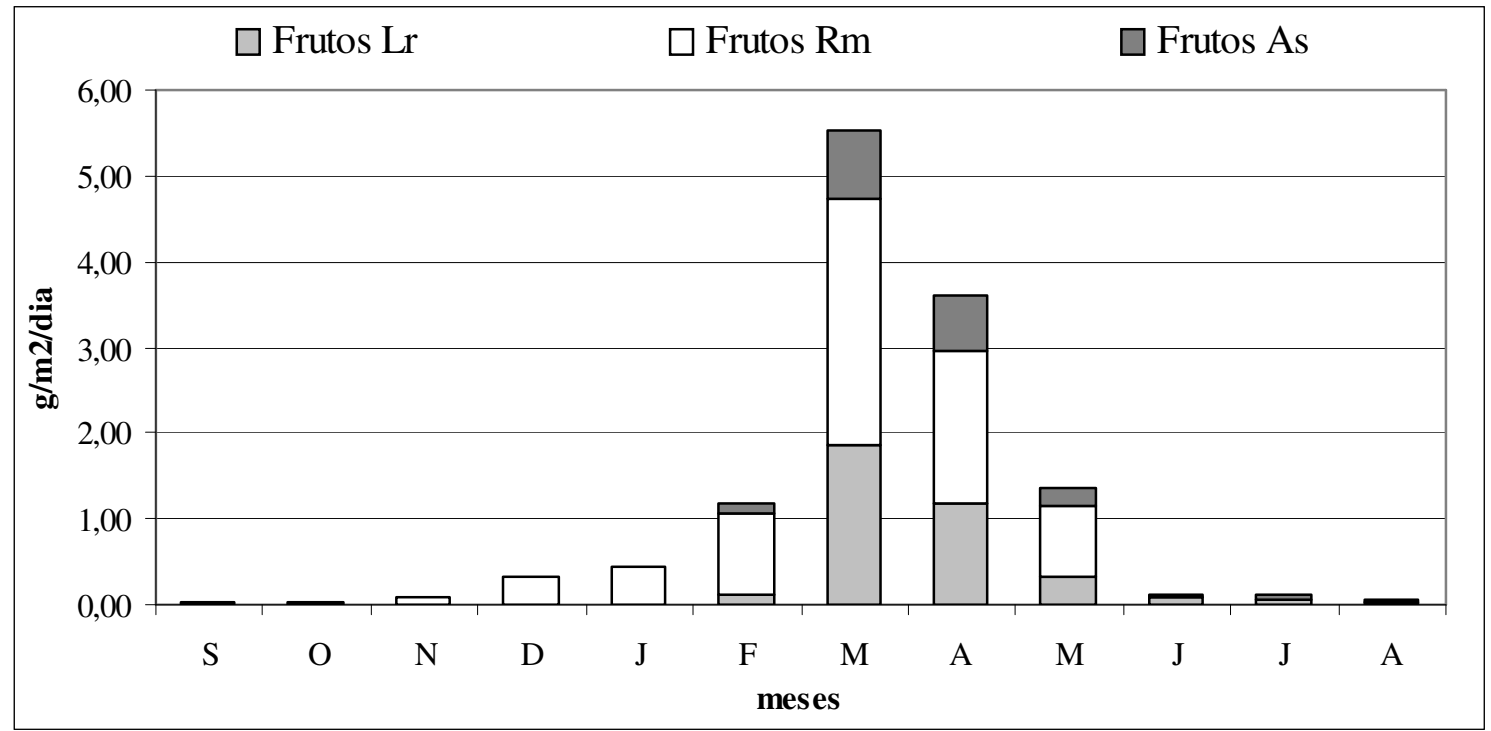

Figura 22 - Médias mensais da queda de frutos da serapilheira, no bosque de mangue da Ilha Barnabé. $(\mathbf{R m}=$ Rhizophora mangle $; \mathbf{L r}=$ Laguncularia racemosa; As = Avicennia schaueriana) .

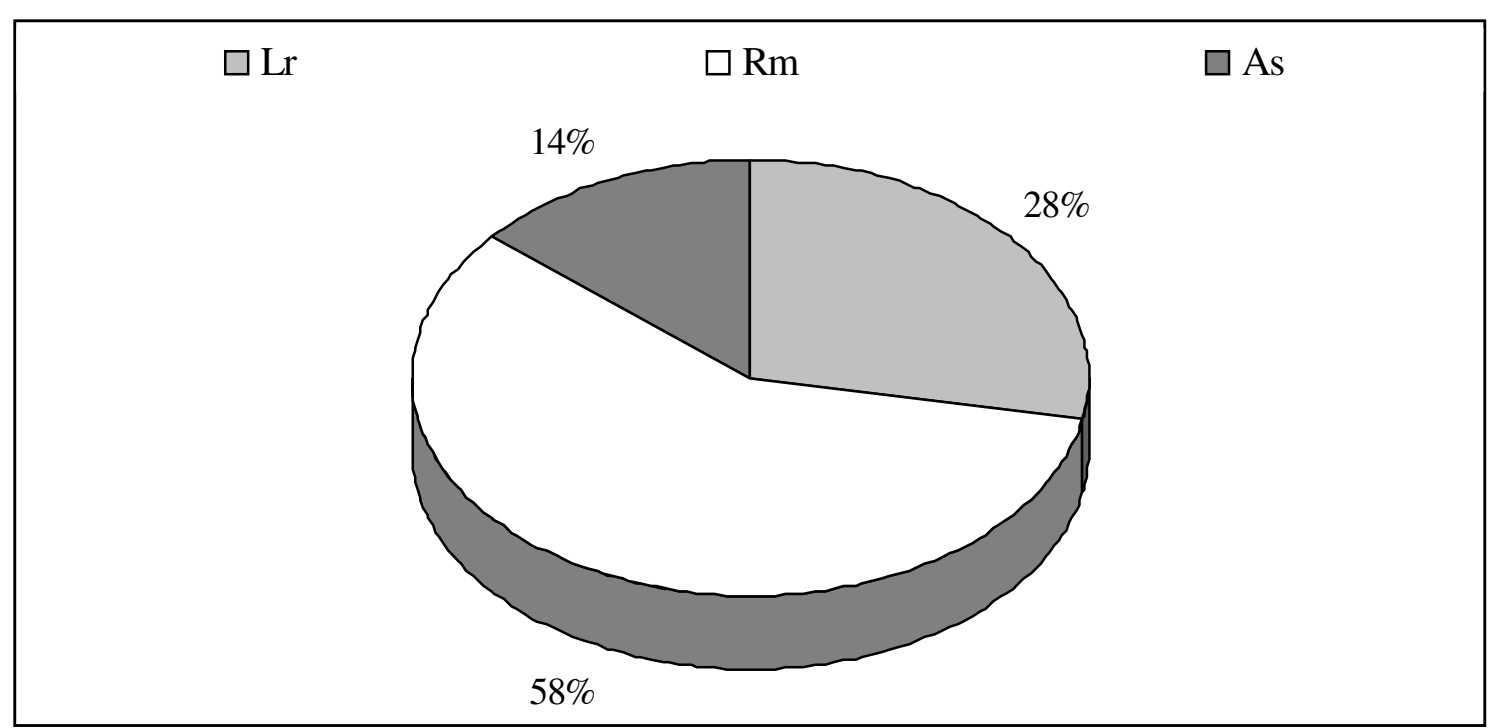

Figura 23 - Contribuição em porcentagem de cada espécie na queda anual de frutos na serapilheira do bosque de mangue da Ilha Barnabé. $(\mathbf{R m}=$ Rhizophora mangle; $\mathrm{Lr}=$ Laguncularia racemosa; As = Avicennia schaueriana $)$. 


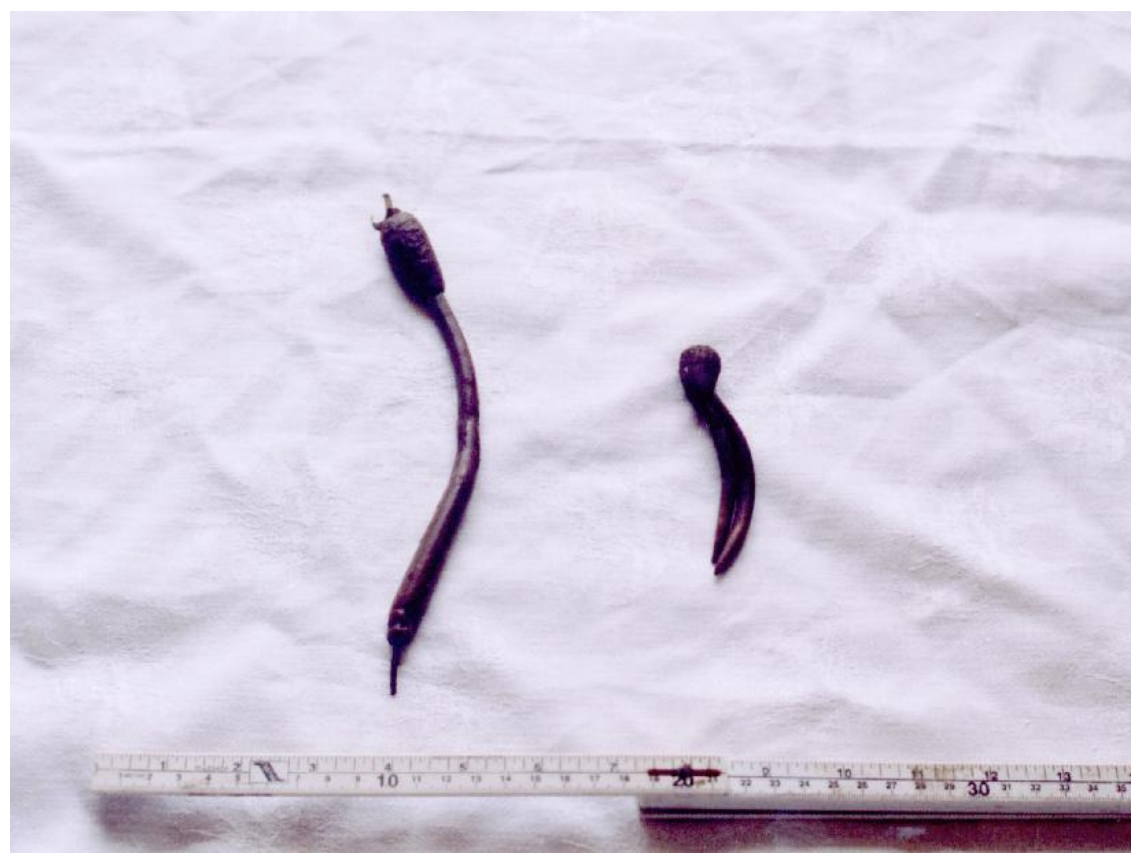

Figura 24 - Propágulos deformados e abortados de Rhizophora mangle coletados pelas cestas de serapilheira no bosque de mangue da Ilha Barnabé. 


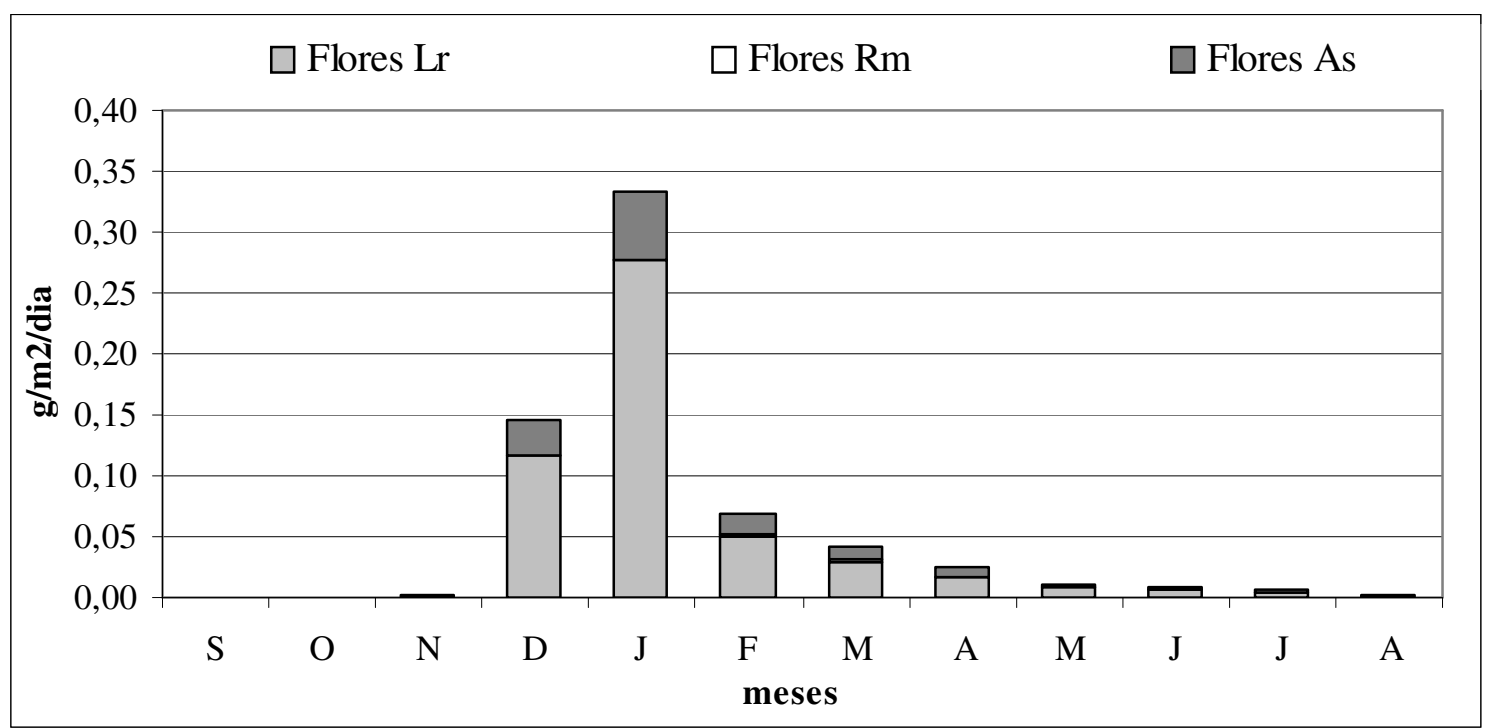

Figura 25 - Médias mensais da queda de flores da serapilheira, no bosque de mangue da Ilha Barnabé. $(\mathbf{R m}=$ Rhizophora mangle $; \mathbf{L r}=$ Laguncularia racemosa; As = Avicennia schaueriana).

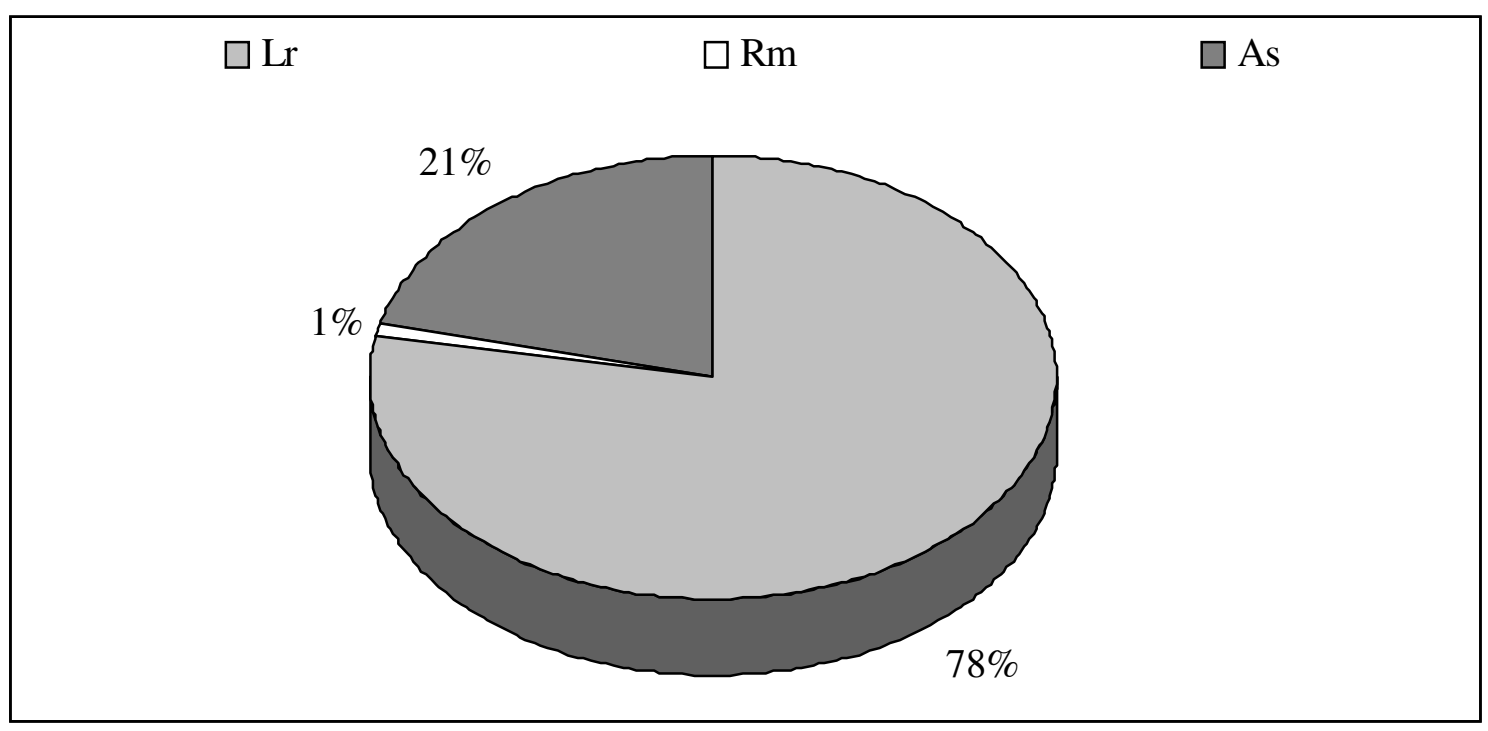

Figura 26 - Contribuição em porcentagem de cada espécie na queda anual de flores na serapilheira do bosque de mangue da Ilha Barnabé. $(\mathbf{R m}=$ Rhizophora mangle; $\mathbf{L r}=$ Laguncularia racemosa $;$ As = Avicennia schaueriana $)$. 


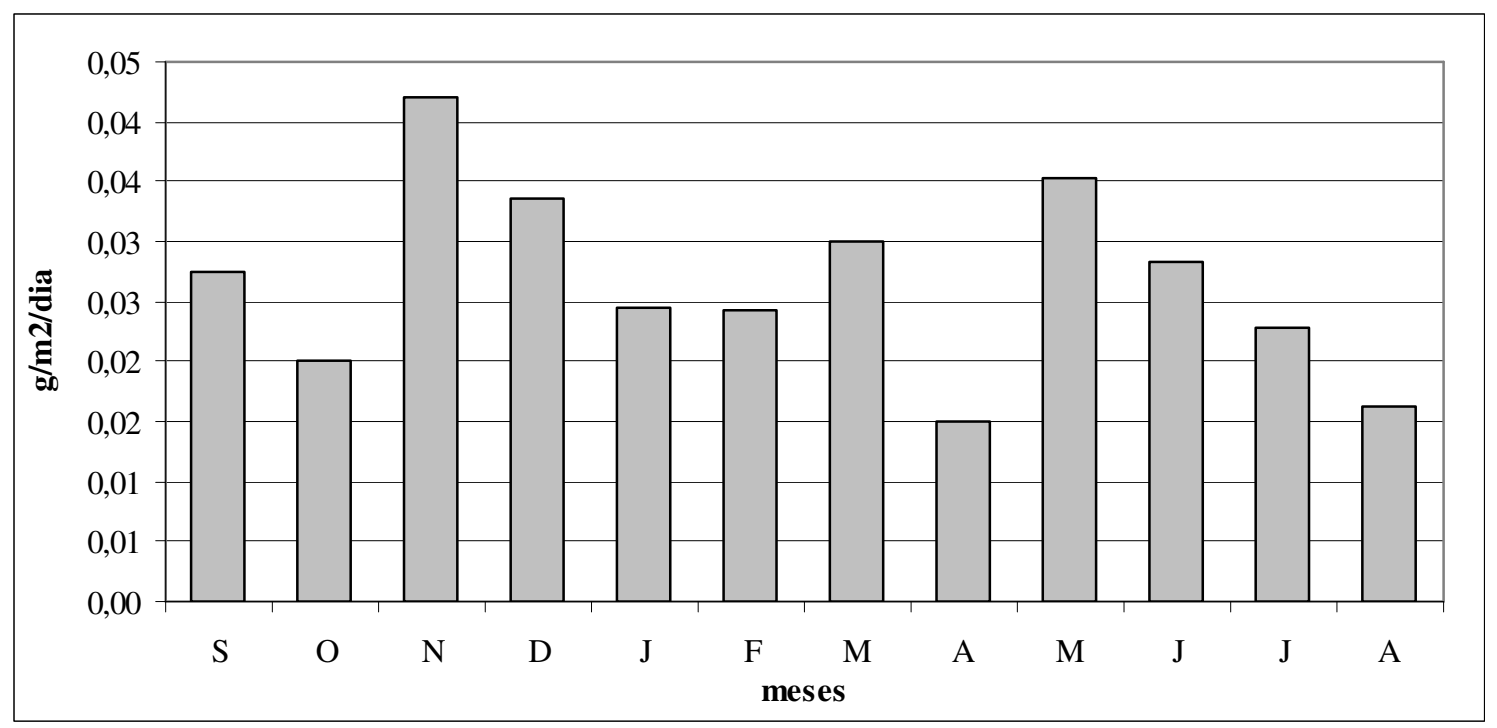

Figura 27 - Médias mensais da queda de estípulas da serapilheira, no bosque de mangue da Ilha Barnabé.

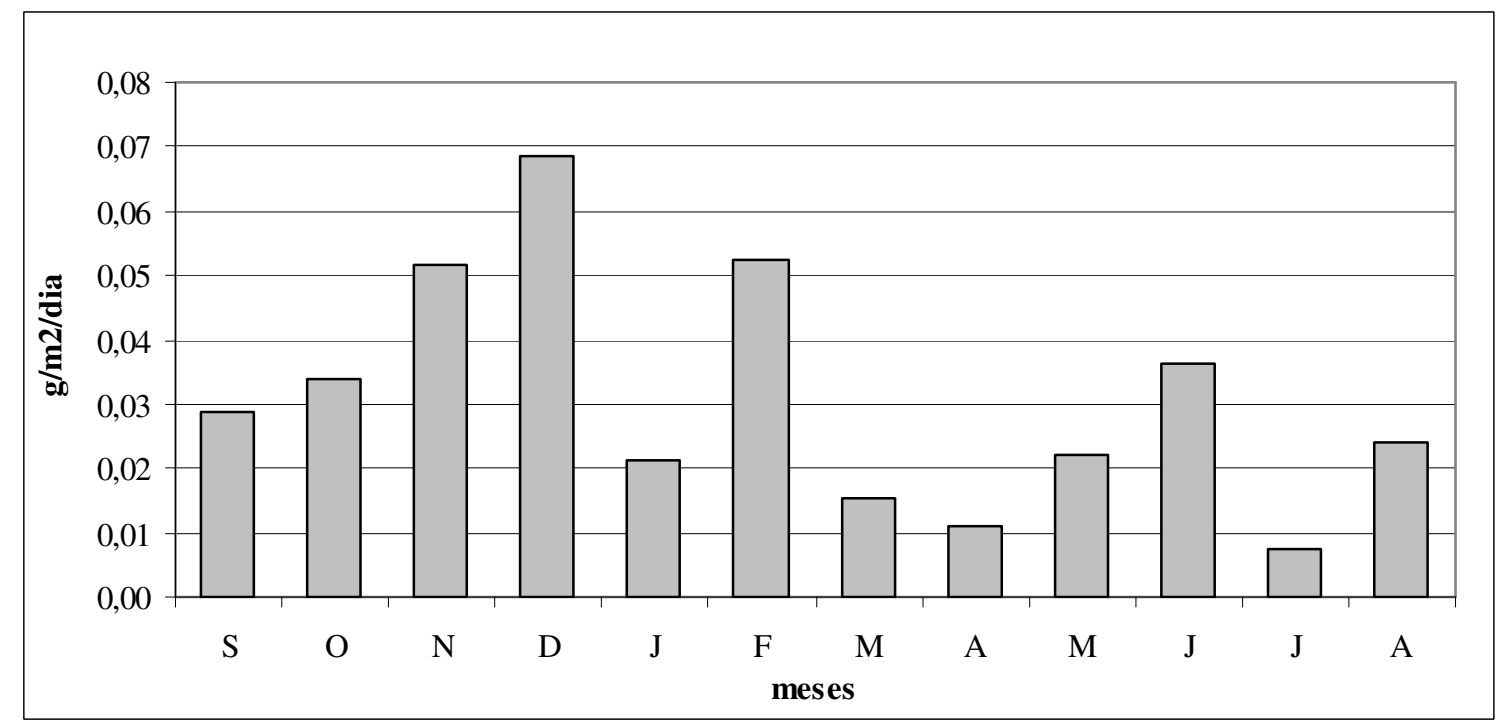

Figura 28 - Médias mensais da queda de detritos da serapilheira, no bosque de mangue da Ilha Barnabé. 


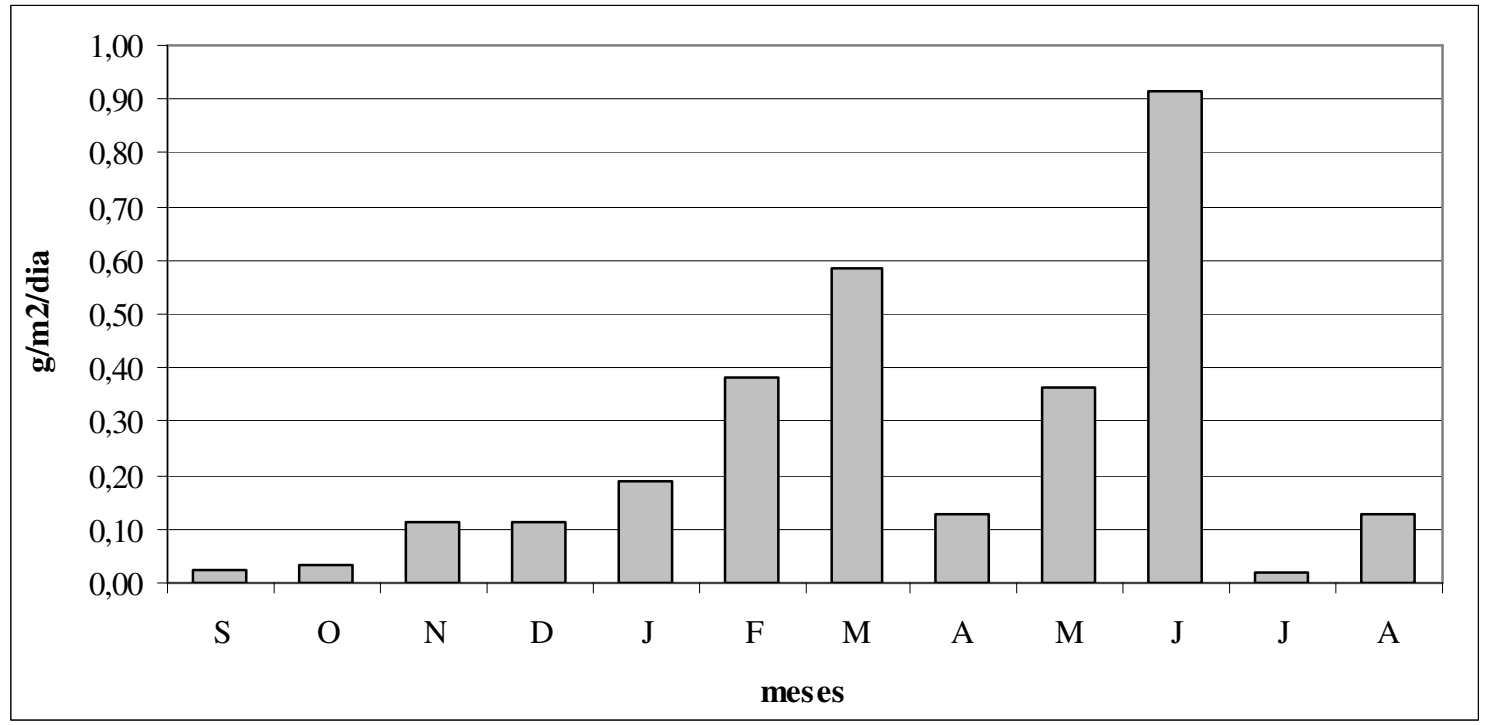

Figura 29 - Médias mensais da queda de madeira da serapilheira, no bosque de mangue da Ilha Barnabé. 

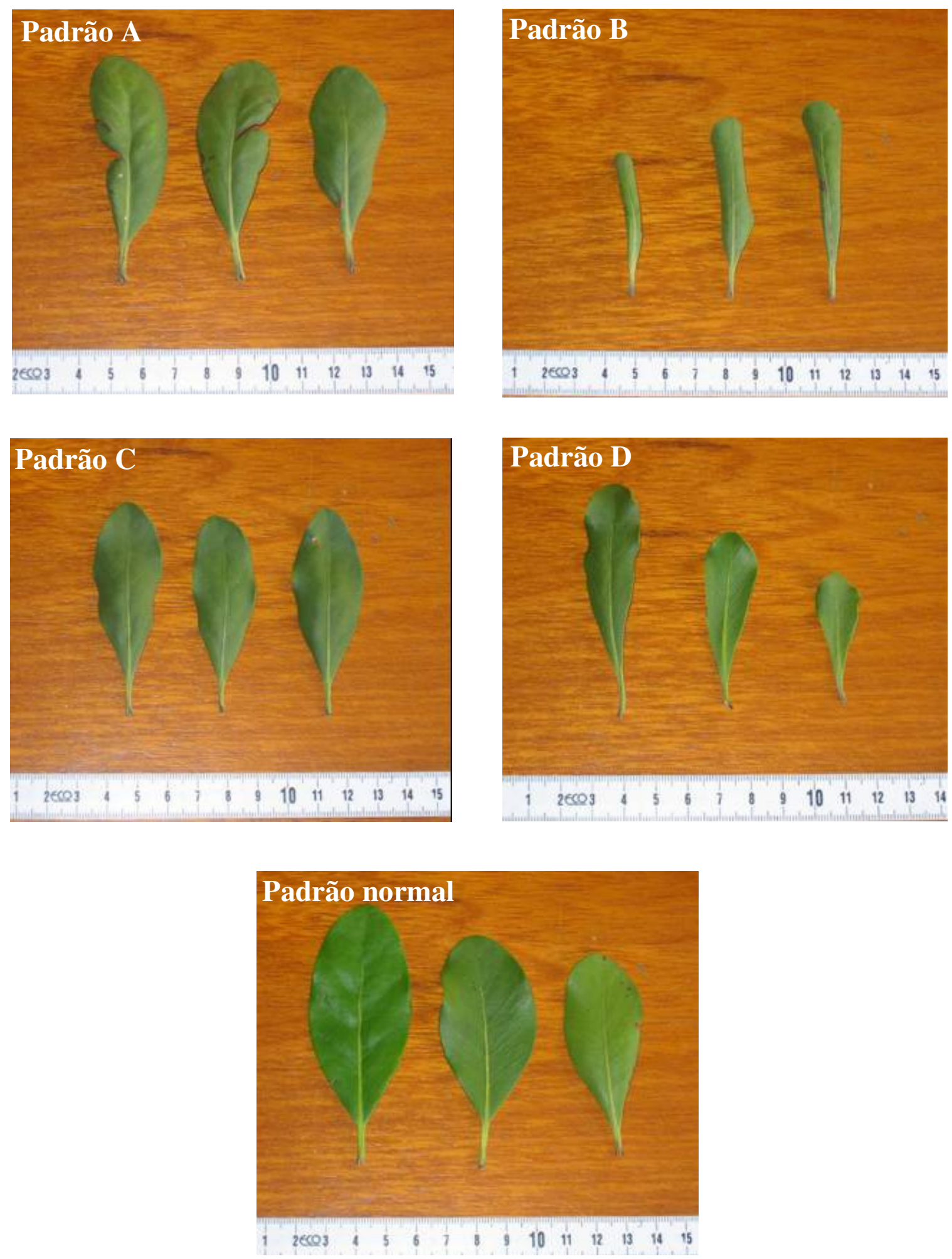

Figura 30 - Prancha com os padrões de folhas de Avicennia schaueriana coletadas nos bosques de mangue da Ilha Barnabé. 

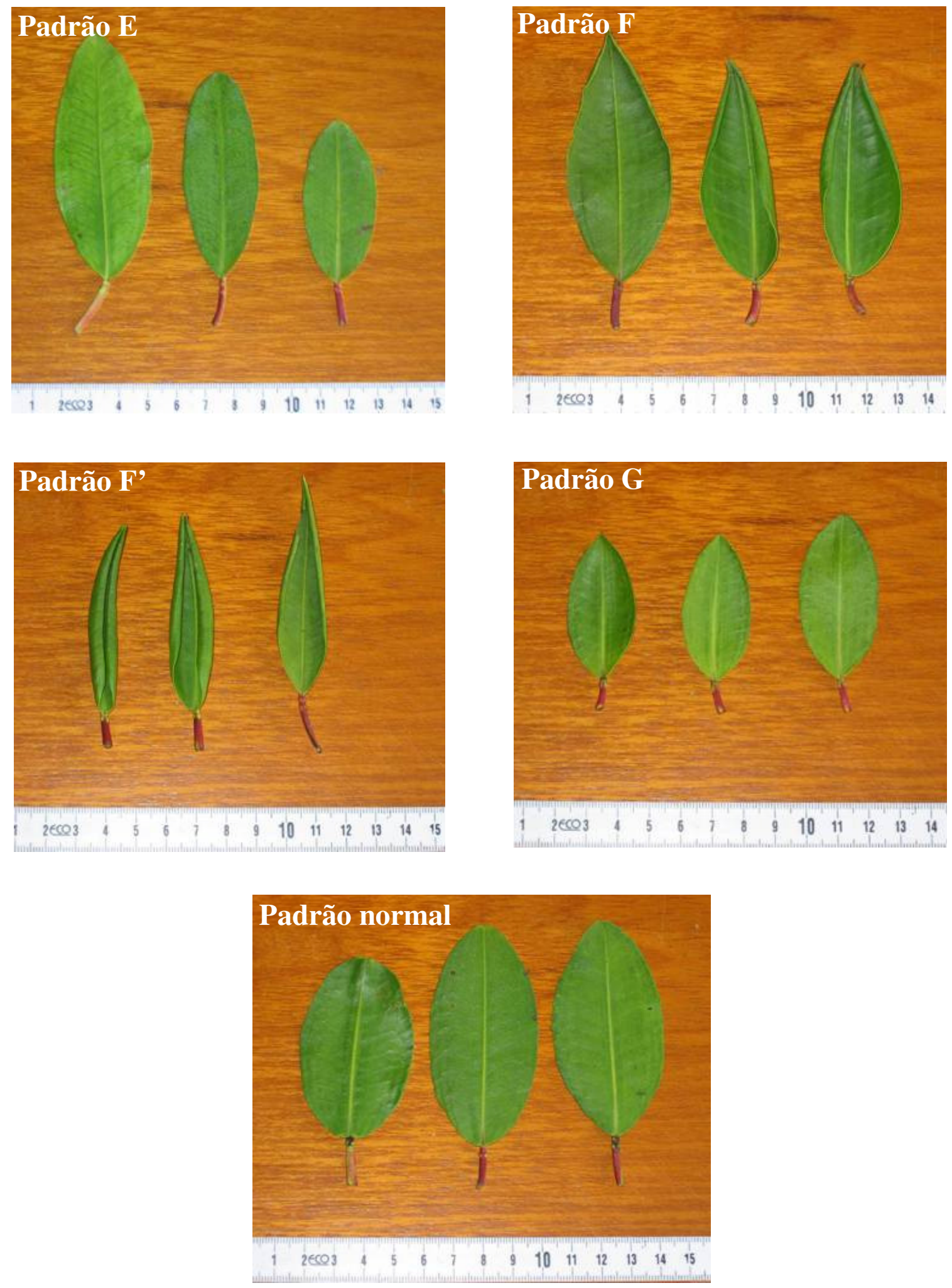

Figura 31 - Prancha com os padrões de folhas de Laguncularia racemosa coletadas nos bosques de mangue da Ilha Barnabé. 

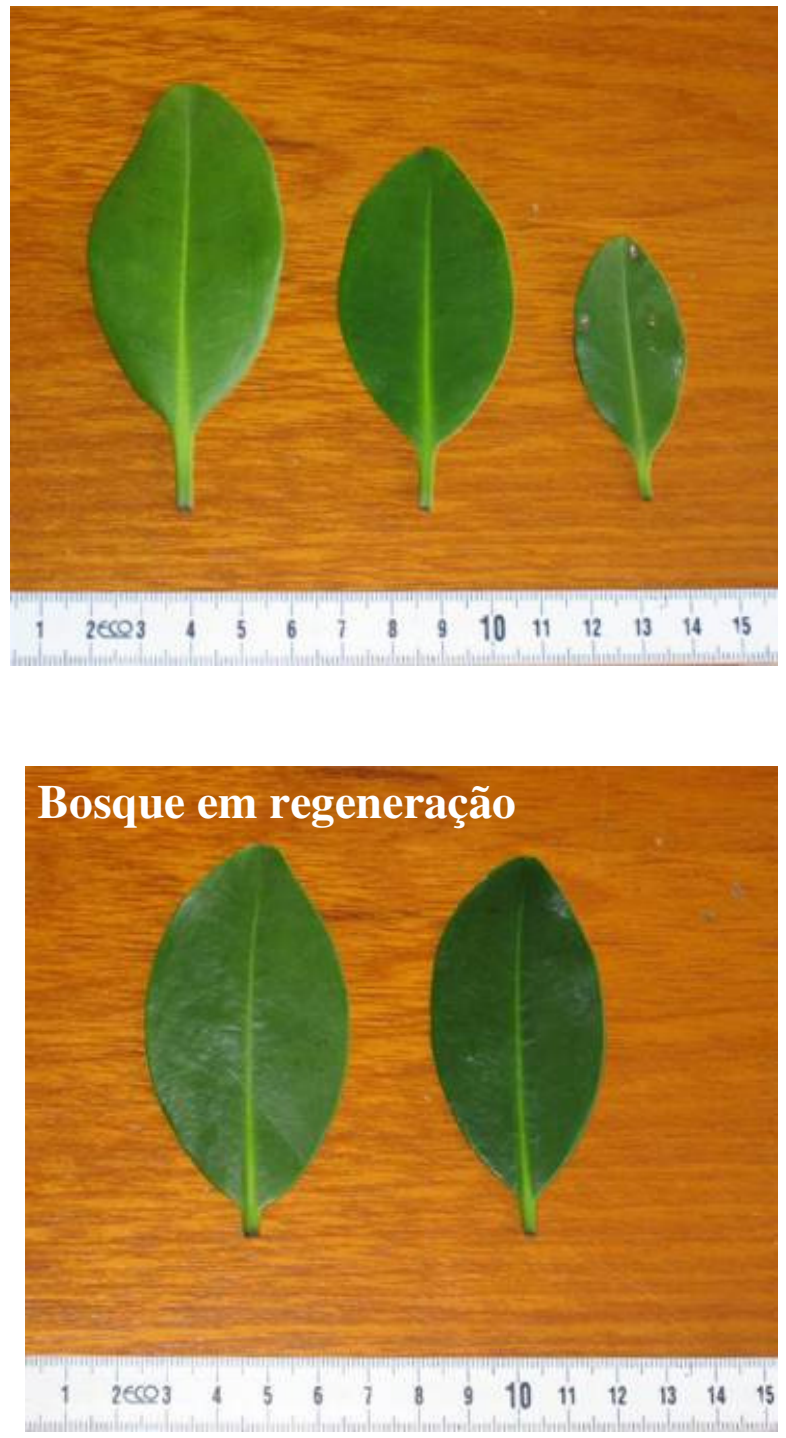

Figura 32 - Prancha com os padrões de folhas de Rhizophora mangle coletadas nos bosques de mangue da Ilha Barnabé. 


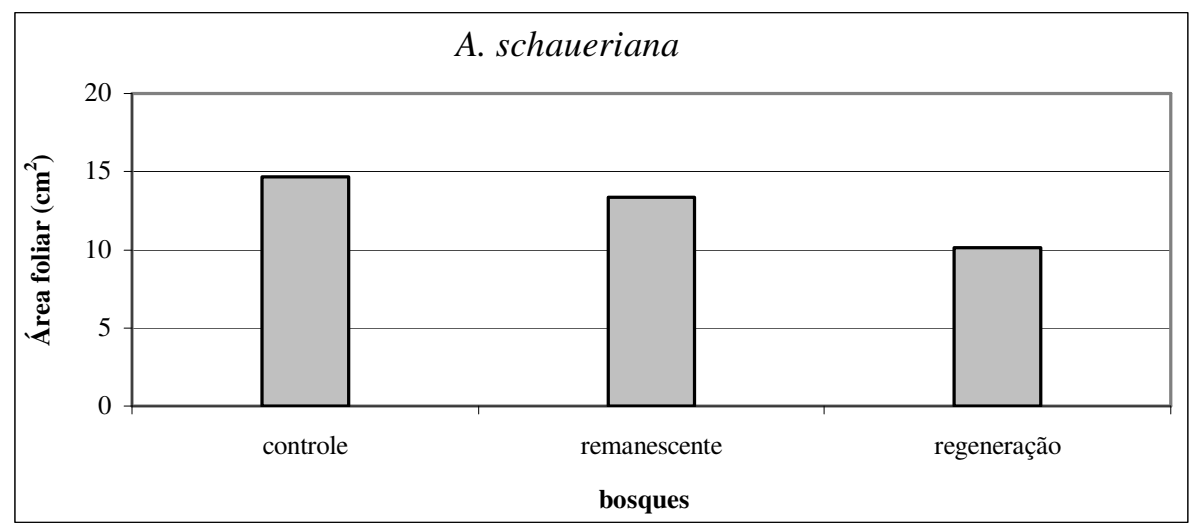

Figura 33 - Áreas foliares de Avicennia schaueriana dos bosques de mangue da Ilha Barnabé.

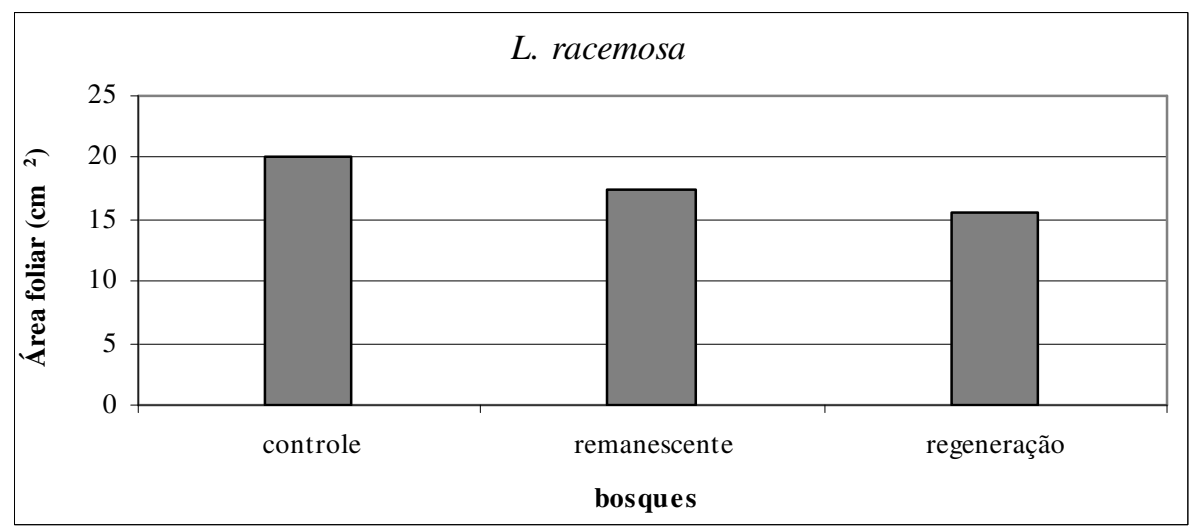

Figura 34 - Áreas foliares de Laguncularia racemosa dos bosques de mangue da Ilha Barnabé. 


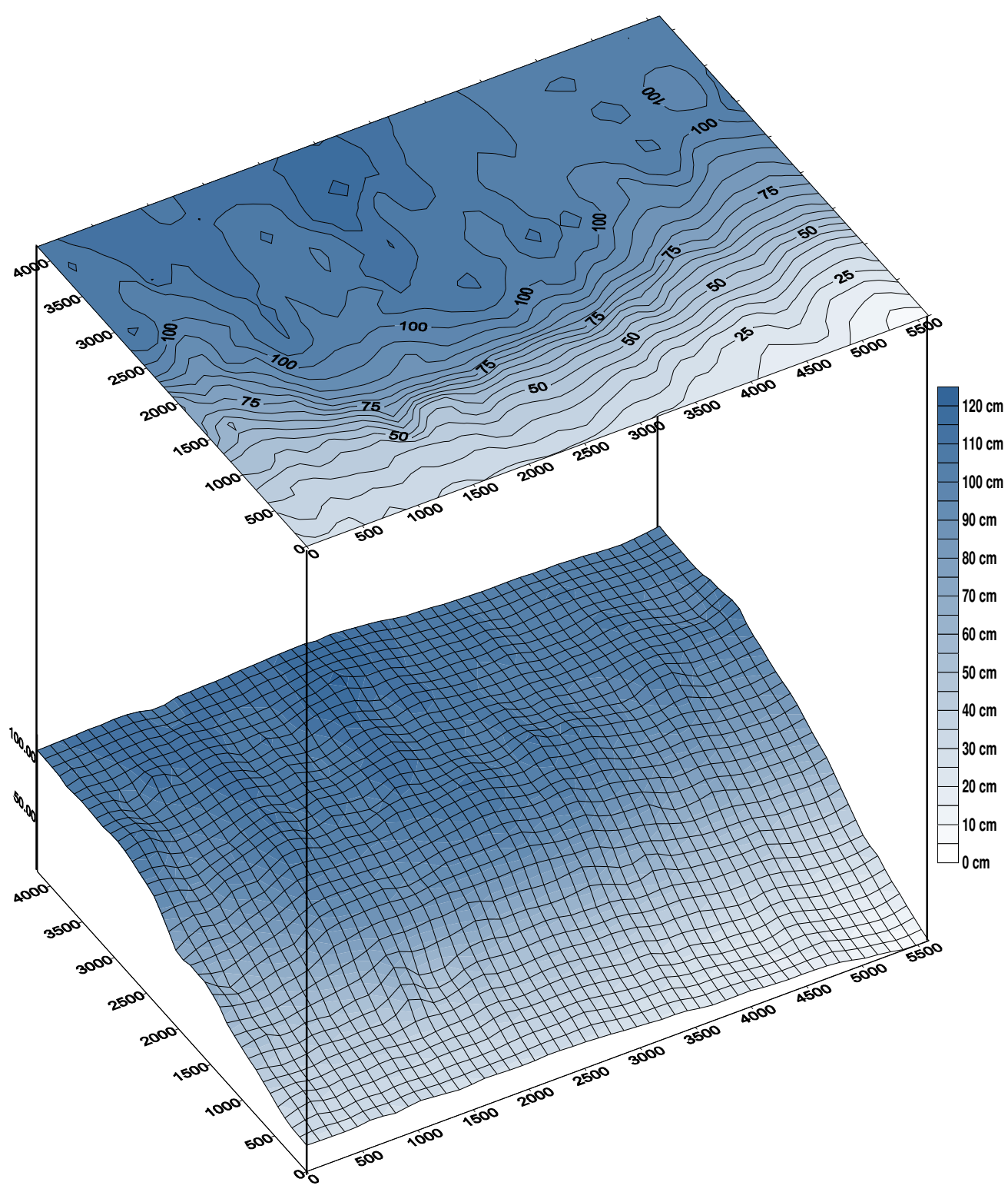

Figura 35 - Modelo de terreno com curvas de nível (superior) e modelo de superfície (inferior) para a área de estudo onde se localiza o bosque remanescente. 


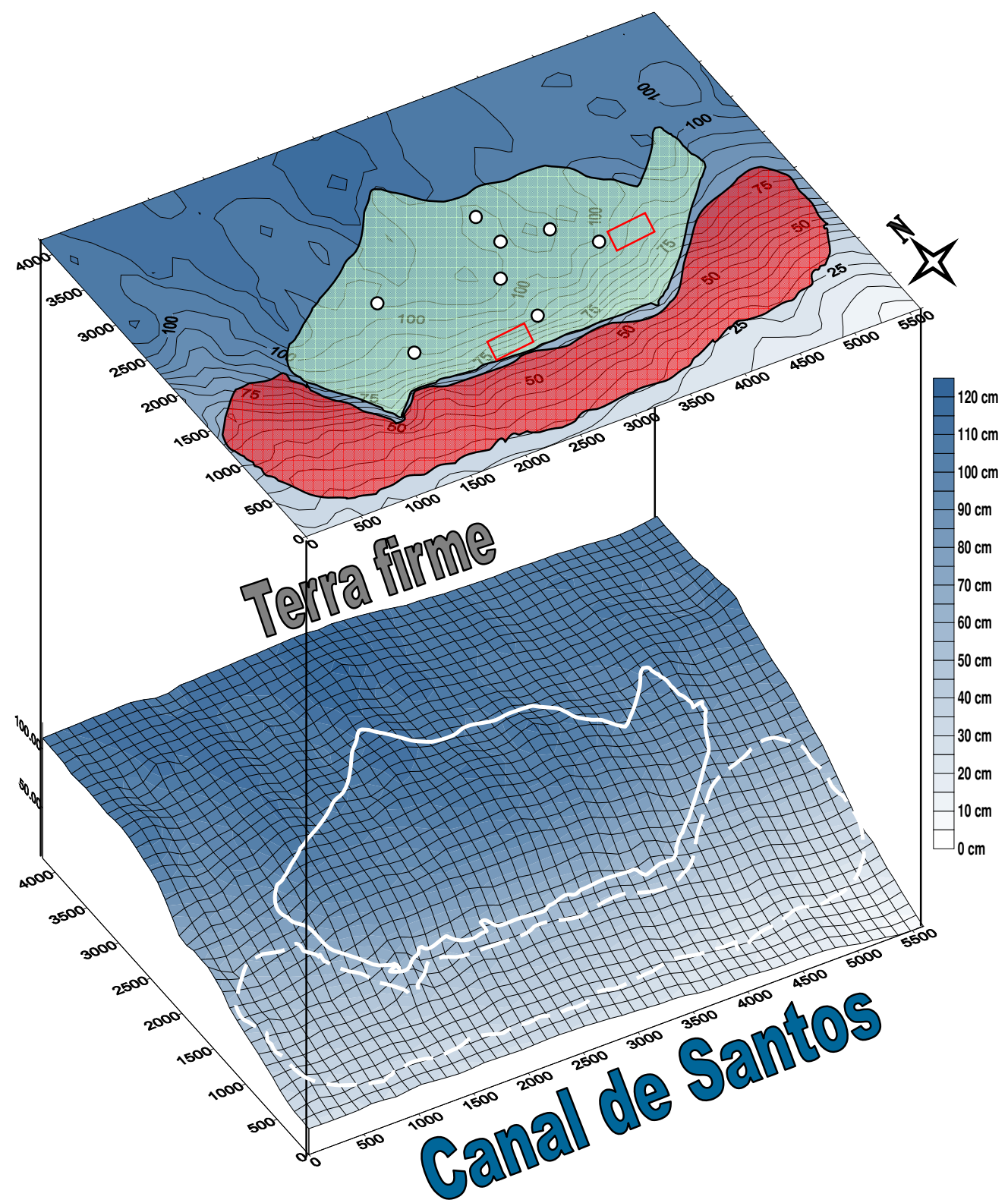

Figura 36 - Modelo de terreno com curvas de nível (superior) e modelo de superfície (inferior) para a área de estudo onde se localiza o bosque remanescente, assinalando a localização do bosque remanescente (área verde, projetada no modelo de superfície como linha contínua), área em que ocupava a antiga franja do bosque (área vermelha, projetada no modelo de superfície como linha tracejada), além das parcelas de regeneração (R2 e R3) e cestas coletoras de serapilheira (pontos brancos). 


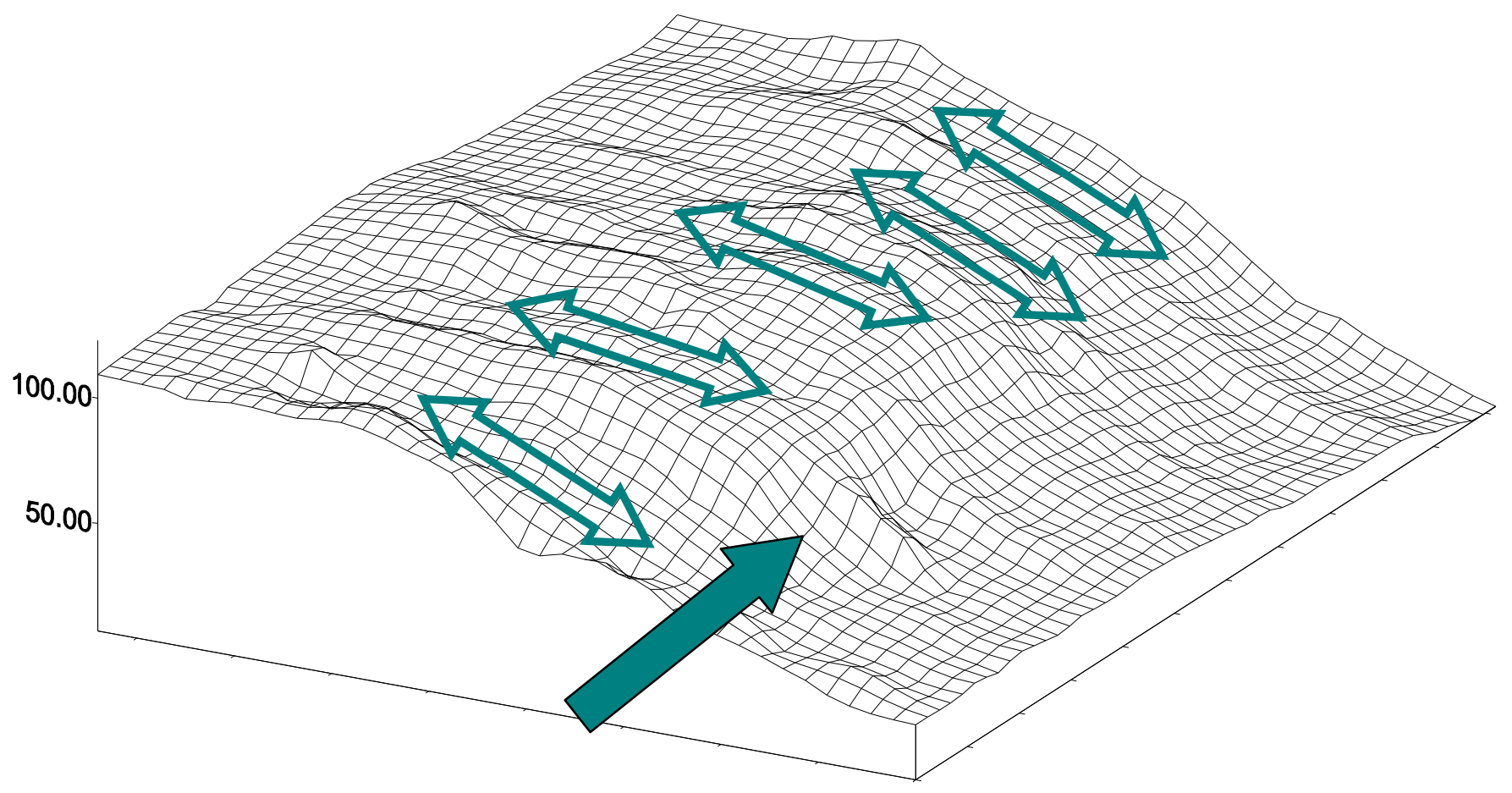

Figura 37 - Modelo de superfície para a área onde se localiza o bosque remanescente, onde as setas bidirecionais indicam as áreas com presença de "sulcos de escoamento" de drenagem terrestre e de fluxo de maré vazante e enchente no terreno. A seta direcional indica a localização do desnível no terreno. 


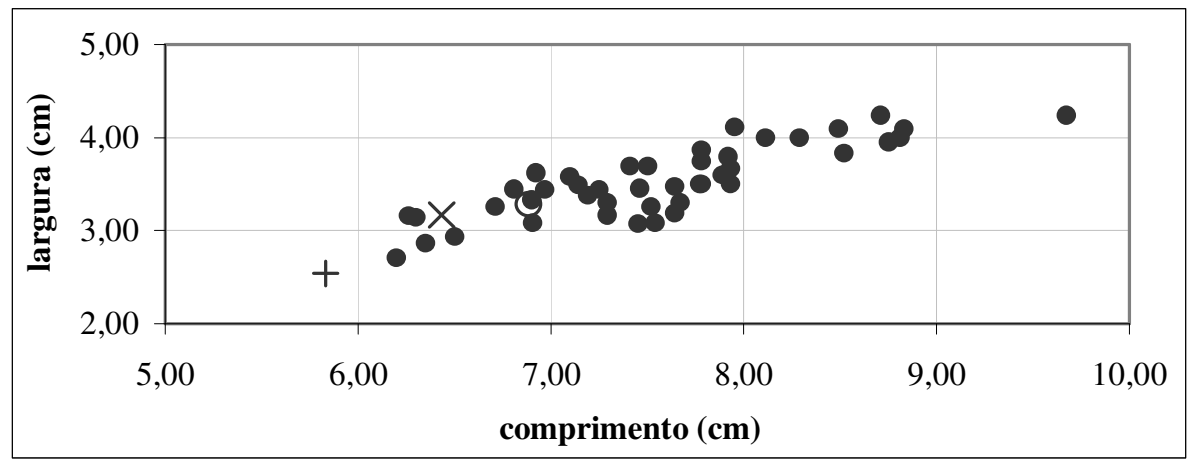

Figura 38 - Medidas foliares de Avicennia schaueriana dos bosques de mangue da Ilha Barnabé: controle $(\mathrm{O})$; remanescente $(\times)$ e regeneração $(+)$, comparados com dados de outros bosques da Baixada Santista $(\bullet$ ) (Cetesb, 1988; Rodriguez et al., 1989).

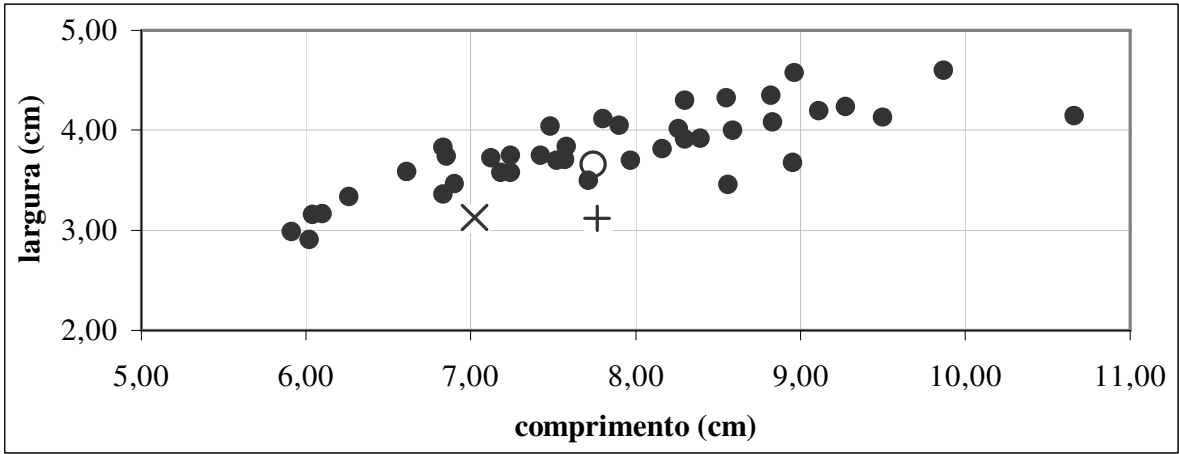

Figura 39 - Medidas foliares de Laguncularia racemosa dos bosques de mangue da Ilha Barnabé: controle $(\mathrm{O})$; remanescente $(\mathrm{X})$ e regeneração $(+)$, comparados com dados de outros bosques da Baixada Santista $(\bullet$ ) (Cetesb, 1988; Rodriguez et al., 1989).

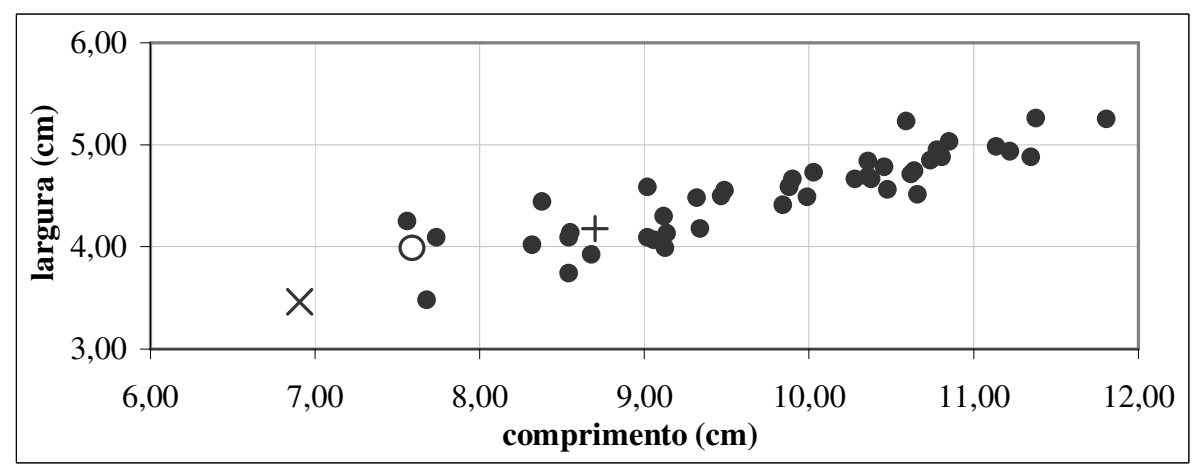

Figura 40 - Medidas foliares de Rhizophora mangle dos bosques de mangue da Ilha Barnabé: controle $(\mathrm{O})$; remanescente $(X)$ e regeneração $(+)$, comparados com dados de outros bosques da Baixada Santista $(\bullet$ ) (Cetesb, 1988; Rodriguez et al., 1989). 


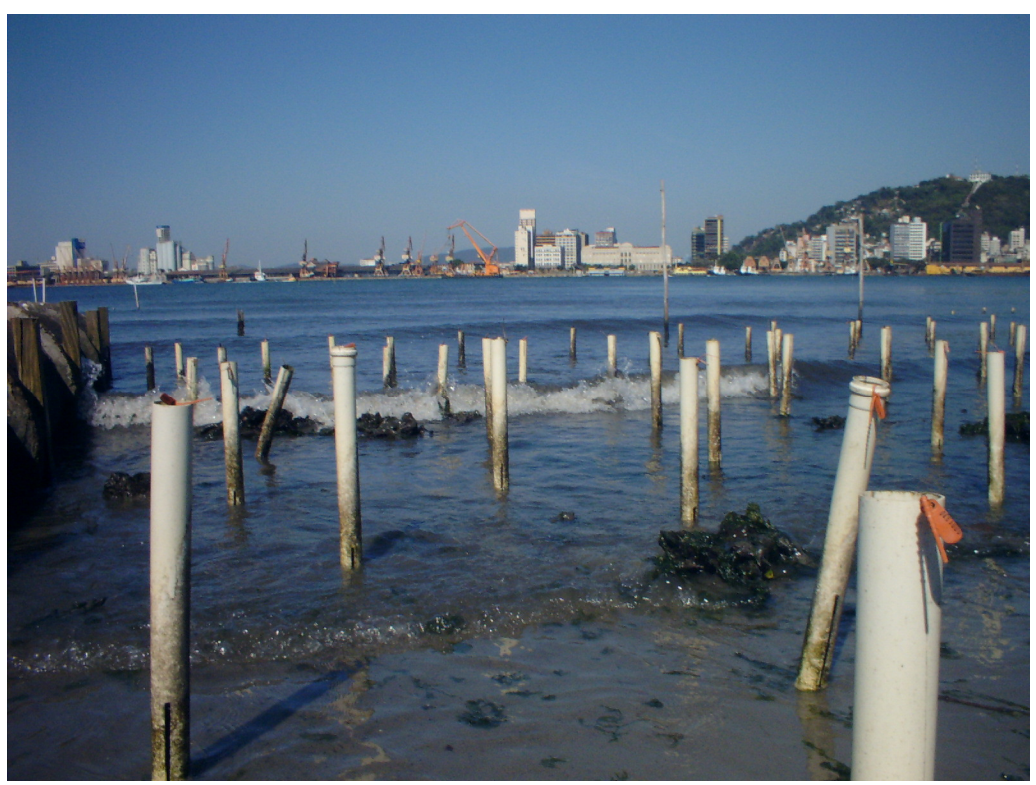

Figura 41 - Detalhe do constante embate de ondas que ocorre na franja do bosque de mangue às margens do Canal de Santos.

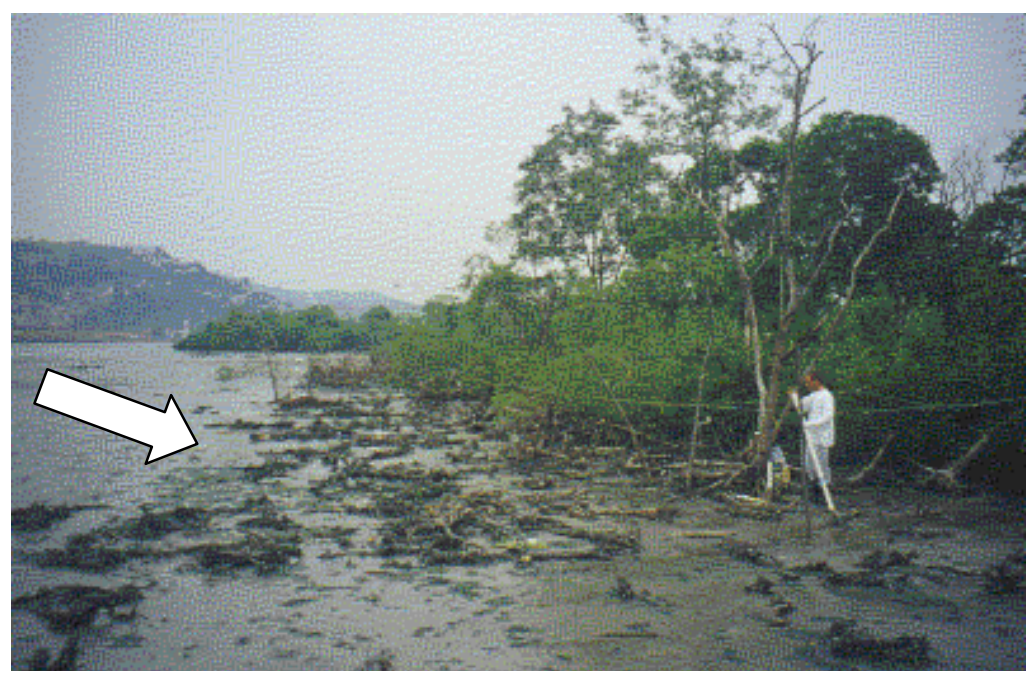

Figura 42 - Detalhe dos restos das raízes das árvores que morreram na franja do bosque no evento ocorrido em 1998. 


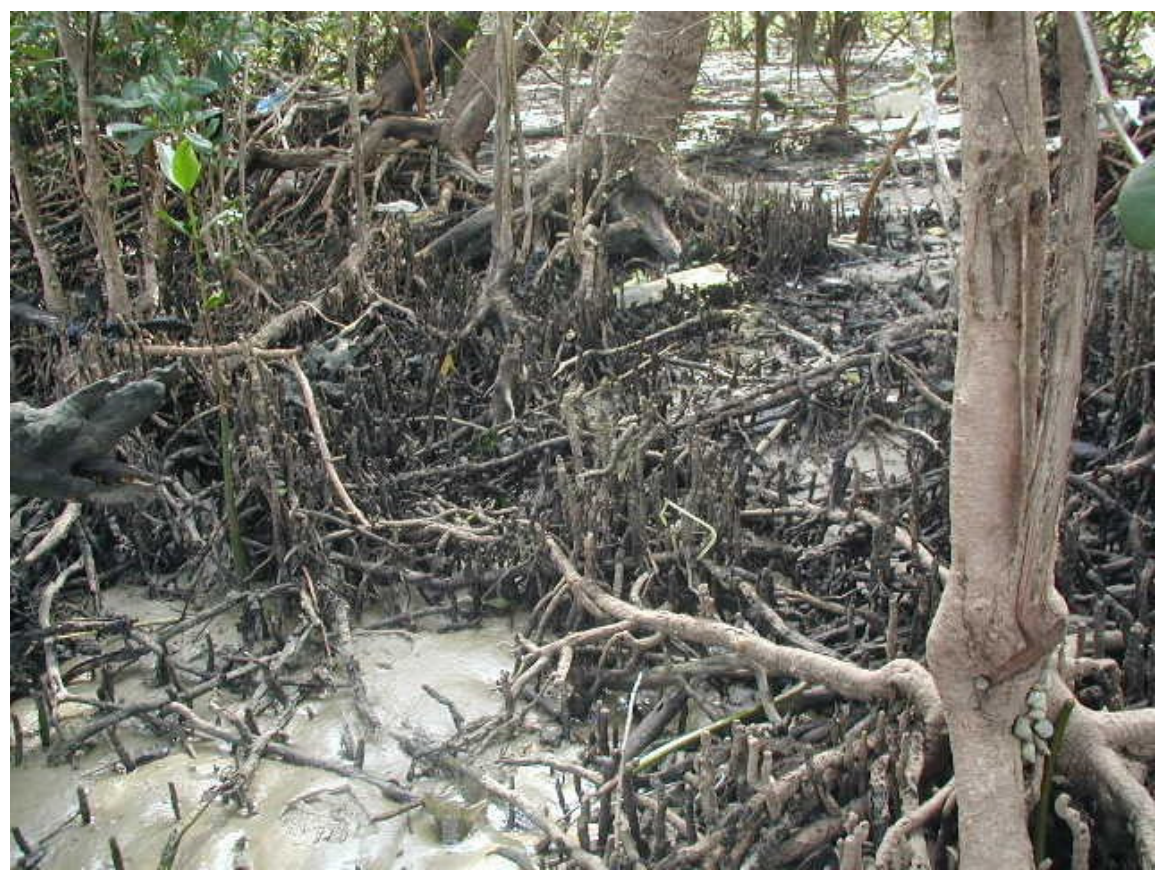

Figura 43 - Detalhe do processo erosivo expondo o sistema radicial das árvores.

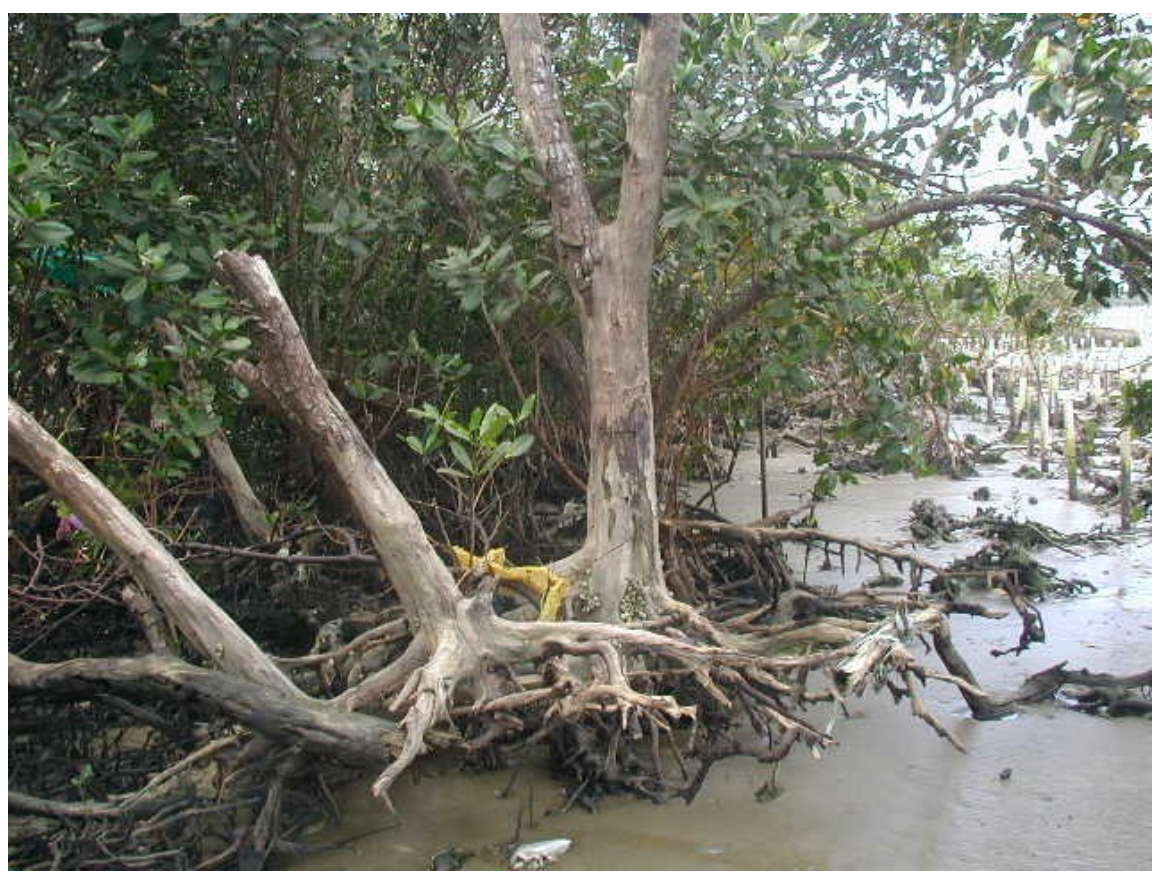

Figura 44 - Detalhe de árvores mortas ainda em pé, devido a erosão. 


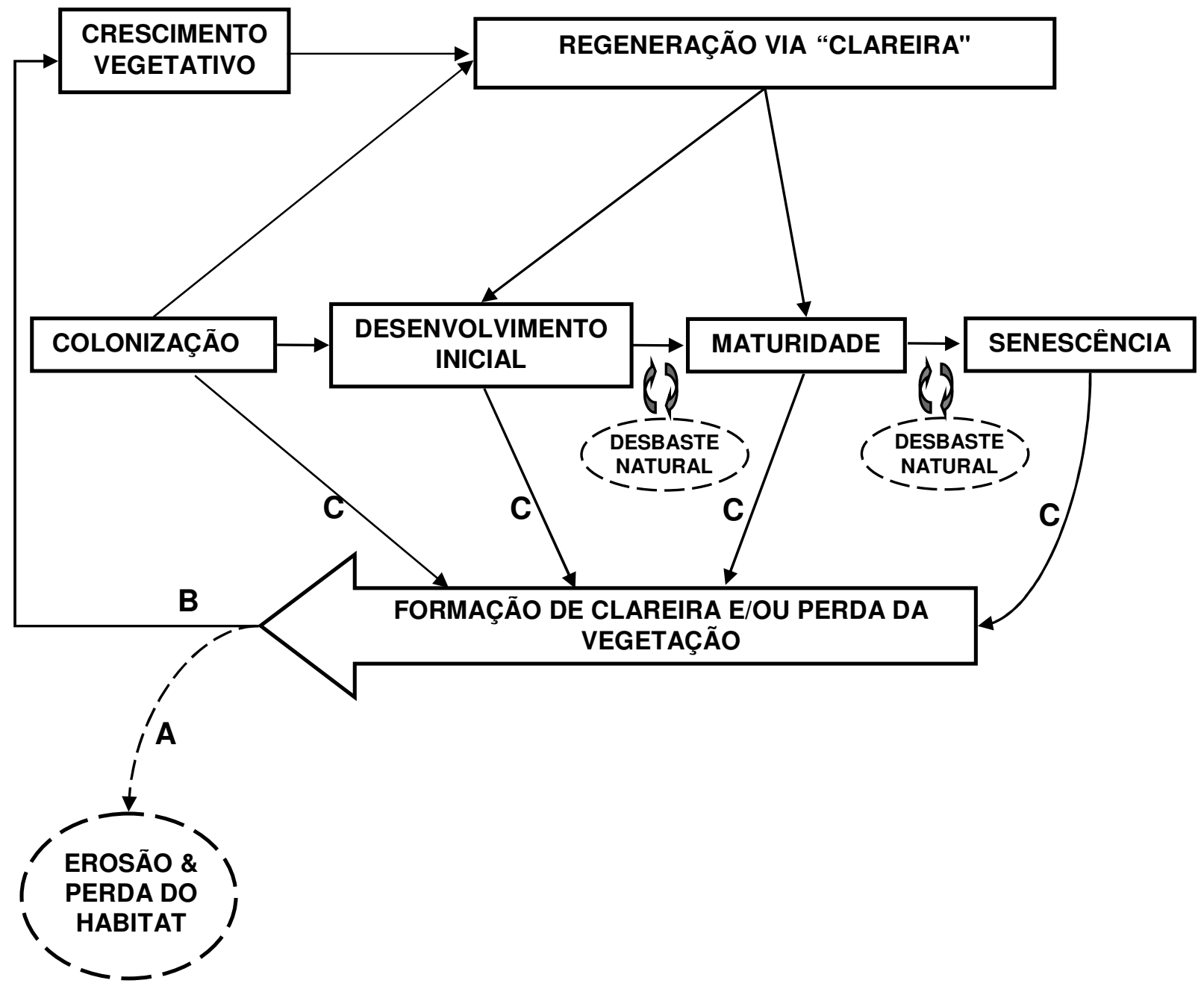

Figura 45 - Modelo modificado proposto por Duke (2001), onde A: processo ocorrido na franja do bosque, após perda da cobertura vegetal; B: processos regenerativos ocorrido nas partes internas do bosque, após abertura de clareiras no dossel e C: "vias de acesso" aos estágios iniciais de desenvolvimento. 


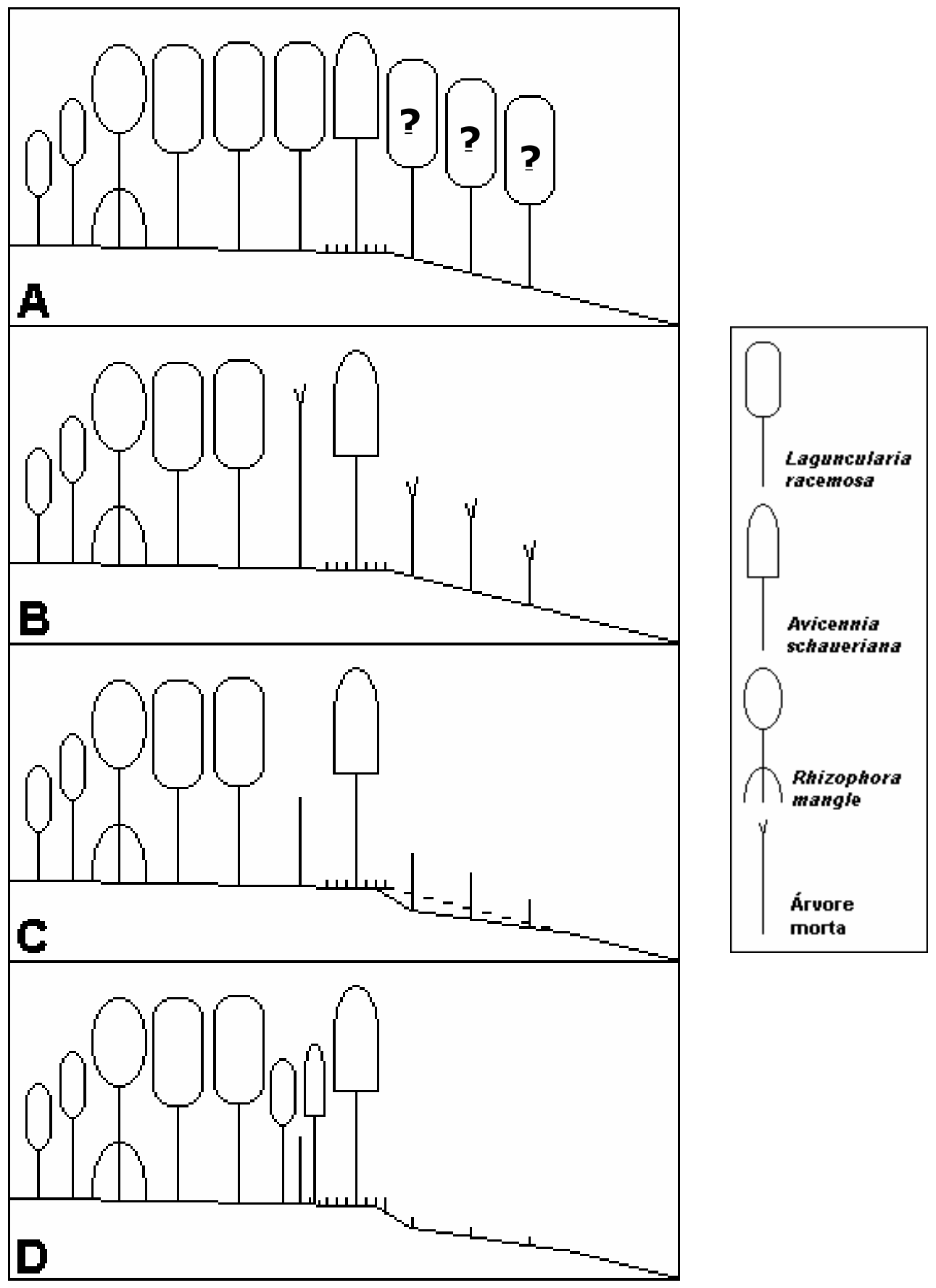

Figura 46: Perfil esquemático dos processos ocorridos no bosque de mangue da Ilha Barnabé, onde: A = bosque antes do evento em 1998 (derramamento e combustão de produto químico); $\mathbf{B}=$ bosque após o evento, com as árvores da franja e alguns indivíduos do interior do bosque queimados, decorrentes do incêndio; $\mathbf{C}=$ após a morte das árvores da franja, a erosão começou e/ou se intensificou no local; $\mathbf{D}=$ perfil do bosque atualmente, com raízes expostas decorrentes da erosão e ausência de recrutamento de novos indivíduos na franja. Nota-se que as áreas internas do bosque, onde se formaram clareiras decorrentes da morte de alguns indivíduos, ocorreu o recrutamento de novos indivíduos, possibilitando desta forma a regeneração destas áreas. 
Tabela I - Principais fontes de poluição industrial na Baixada Santista (adaptado de CETESB, 2001).

\begin{tabular}{|c|c|c|}
\hline Indústria & Produção Principal & Contaminante* \\
\hline Alba $^{(1)}$ & Resinas , formol & $\mathrm{N}$, Fenóis, $\mathrm{Cr}$ \\
\hline Carbocloro & Cloro, soda, EDC & Fenóis, Solventes halogenados, $\mathrm{Cr}, \mathrm{Hg}, \mathrm{Zn}$ \\
\hline $\mathrm{CBE}$ & Estireno & $\mathrm{N}$, Fenóis, Solventes aromáticos, $\mathrm{Cu}, \mathrm{Cr}, \mathrm{Hg}, \mathrm{Zn}$ \\
\hline $\begin{array}{l}\text { Cia Santista de } \\
\text { Papel }\end{array}$ & Papel & Fenóis, Cd, Cu, Mn, Hg, Ni, Cr, Hg, Zn \\
\hline CIEL & Coque verde & $\mathrm{Mn}, \mathrm{Ni}, \mathrm{Zn}$ \\
\hline Columbia & Negro de fumo & \\
\hline Copebrás & $\begin{array}{l}\text { Ácido fosfórico, } \\
\text { fertilizantes }\end{array}$ & $\mathrm{P}, \mathrm{N}$, Fluoreto \\
\hline Cosipa & Aços & $\begin{array}{l}\text { N, CN, Fluoreto, Fenóis, Solventes aromáticos, Ar, } \\
\text { Cd, } \\
\qquad \mathrm{Pb}, \mathrm{Cu}, \mathrm{Cr}, \mathrm{Mn}, \mathrm{Hg}, \mathrm{Ni}, \mathrm{Zn}\end{array}$ \\
\hline Dow Química & $\begin{array}{l}\text { Látex, polióis, } \\
\text { poliestireno }\end{array}$ & $\begin{array}{c}\mathrm{N}, \mathrm{CN} \text {, Fluoreto, Fenóis, Solventes aromáticos, } \\
\text { Solventes } \\
\text { halogenados, } \mathrm{Ar}, \mathrm{Cd}, \mathrm{Pb}, \mathrm{Cu}, \mathrm{Cr}, \mathrm{Mn}, \mathrm{Hg}, \mathrm{Ni}, \mathrm{Zn}\end{array}$ \\
\hline IFC & Fertilizantes & $\begin{array}{l}\mathrm{P}, \mathrm{N}, \text { Fluoreto } \\
\end{array}$ \\
\hline Liquid Química & Ácido benzóico & N, Fenóis, Solventes aromáticos, Mn, Hg, \\
\hline Manah & Fertilizantes & P, N, Fluoreto \\
\hline Petrobrás/RPBC & Derivados de petróleo & $\begin{array}{l}\text { N, CN, Fluoreto, Fenóis, Solventes aromáticos, Cd, } \\
\qquad \mathrm{Pb}, \mathrm{Cu}, \mathrm{Hg}, \mathrm{Ni}, \mathrm{Zn}\end{array}$ \\
\hline Petrocoque & Coque verde & $\mathrm{N}$, Fenóis, $\mathrm{Ar}, \mathrm{Cu}, \mathrm{Cr}, \mathrm{Ni}, \mathrm{Zn}$ \\
\hline Rhodia - Agro $^{(1)}$ & Pesticidas carbamatos & Carbamatos \\
\hline Rhodia - UQC ${ }^{(1)}$ & Organoclorados & $\begin{array}{l}\text { Fenóis, Solventes halogenados, Organoclorados } \\
\text { aromáticos, pesticidas organoclorados }\end{array}$ \\
\hline Serrana & Fertilizantes & $\begin{array}{r}\mathrm{P}, \mathrm{N}, \text { Fluoreto } \\
\end{array}$ \\
\hline Solorrico & Fertilizantes & P, N, Fluoreto, Cd \\
\hline Ultrafértil - CB & Fertilizantes & $\mathrm{P}, \mathrm{N}$, Fluoreto, Fenóis, Ar, $\mathrm{Pb}, \mathrm{Cu}, \mathrm{Cr}, \mathrm{Ni}, \mathrm{Zn}$ \\
\hline Ultrafértil - PG & Fertilizantes & $\begin{array}{l}\mathrm{P}, \mathrm{N}, \text { Fluoreto } \\
\end{array}$ \\
\hline Union Carbide & Polietileno & Fluoreto, Fenóis, Carbamatos, Mn, Zn \\
\hline
\end{tabular}

(1) - Industrias desativadas

* - O contaminante constitui matéria prima, produto ou insumo do processo produtivo, ou é resíduo obrigatório do processo produtivo, ou foi verificado em análises químicas dos efluentes entre 1979 e 1999. 
Tabela II - Principais fontes de poluição nos terminais portuários da Baixada Santista (adaptado de CETESB, 2001).

\begin{tabular}{|c|c|}
\hline Empresa & Contaminante* \\
\hline Brasterminais & $\begin{array}{c}\text { N, CN, Fluoreto, Sulfeto, Solventes aromáticos, Solventes } \\
\text { halogenados, fenóis, } \mathrm{Cd}, \mathrm{Pb}, \mathrm{Cu}, \mathrm{Mn}, \mathrm{Hg}, \mathrm{Zn}\end{array}$ \\
\hline Dibal & $\begin{array}{c}\mathrm{N}, \mathrm{CN} \text {, Fluoreto, Sulfeto, Solventes aromáticos, Solventes } \\
\text { halogenados, fenóis, } \mathrm{Cd}, \mathrm{Pb}, \mathrm{Cu}, \mathrm{Mn}, \mathrm{Hg}, \mathrm{Zn}\end{array}$ \\
\hline Granel Química & $\begin{array}{c}\mathrm{N}, \mathrm{CN} \text {, Fluoreto, Sulfeto, Solventes aromáticos, Solventes } \\
\text { halogenados, fenóis, } \mathrm{Cd}, \mathrm{Pb}, \mathrm{Cu}, \mathrm{Mn}, \mathrm{Hg}, \mathrm{Ni}, \mathrm{Zn}\end{array}$ \\
\hline Hamilton Fox ${ }^{(1)}$ & Solventes aromáticos \\
\hline Maia $^{(2)}$ & $\begin{array}{l}\mathrm{N}, \mathrm{CN} \text {, Fluoreto, Sulfeto, Solventes aromáticos, Solventes } \\
\text { halogenados, fenóis, } \mathrm{Cd}, \mathrm{Pb}, \mathrm{Cu}, \mathrm{Mn}, \mathrm{Hg}, \mathrm{Ni}, \mathrm{Zn}\end{array}$ \\
\hline Móbil & $\begin{array}{c}\mathrm{N}, \mathrm{CN} \text {, Fluoreto, Sulfeto, Solventes aromáticos, Solventes } \\
\text { halogenados, fenóis, } \mathrm{Cd}, \mathrm{Pb}, \mathrm{Cu}, \mathrm{Mn}, \mathrm{Hg}, \mathrm{Ni}, \mathrm{Zn}\end{array}$ \\
\hline Petrobrás/DTCS - Alamoa & $\begin{array}{c}\text { N, CN, Fluoreto, Sulfeto, Solventes aromáticos, fenóis, } \\
\text { Cd, } \mathrm{Pb}, \mathrm{Cu}, \mathrm{Mn}, \mathrm{Hg}, \mathrm{Zn}\end{array}$ \\
\hline Petrobrás/DTCS - Cubatão & $\mathrm{N}, \mathrm{CN}, \mathrm{S}$, Solventes halogenados, $\mathrm{Pb}$ \\
\hline Stolthaven & $\begin{array}{c}\text { N, CN, Fluoreto, Sulfeto, Solventes aromáticos, Solventes } \\
\text { halogenados, fenóis, } \mathrm{Cd}, \mathrm{Pb}, \mathrm{Cu}, \mathrm{Mn}, \mathrm{Hg}, \mathrm{Zn}\end{array}$ \\
\hline Tefer & S, Fluoreto \\
\hline Ultrafértil - Terminal Marítimo & $\mathrm{N}, \mathrm{S}$ \\
\hline Ùnião & $\begin{array}{c}\mathrm{P}, \mathrm{N}, \mathrm{CN} \text {, Fluoreto, Sulfeto, Solventes aromáticos, } \\
\text { Solventes halogenados, fenóis, } \mathrm{Cd}, \mathrm{Pb}, \mathrm{Cu}, \mathrm{Mn}, \mathrm{Hg}, \mathrm{Zn}\end{array}$ \\
\hline
\end{tabular}

(1) - Terminal de granéis líquidos paralisado

(2) - Empresa de lavagem de isocontâiners

* - O contaminante constitui matéria prima, produto ou insumo manipulado ou armazenado, ou foi verificado em análises químicas dos efluentes entre 1979 e 1999, mesmo que dentro dos padrões legais. 
Tabela III - Principais fontes de poluição relacionadas às áreas contaminadas da Baixada Santista (adaptado de CETESB, 2001).

\begin{tabular}{|c|c|c|}
\hline Empresa/Local & $\begin{array}{c}\text { Natureza da } \\
\text { área } \\
\text { contaminada \# }\end{array}$ & Contaminante* \\
\hline Aterro sanitário / Cubatão & DRSD & $\mathrm{N}, \mathrm{Cu}, \mathrm{Mn}$ e $\mathrm{Zn}$ \\
\hline Lixão de Pilões ${ }^{(1)}$ & DRSD & $\begin{array}{l}\mathrm{P}, \mathrm{N}, \mathrm{CN} \text {, Fluoreto, sulfetos, fenóis, solventes aromáticos } \\
\text { solventes halogenados, organoclorados aromáticos, } \\
\text { pesticidas organoclorados, } \mathrm{Ar}, \mathrm{Cd}, \mathrm{Pb}, \mathrm{Cu}, \mathrm{Cr}, \mathrm{Mn}, \mathrm{Hg} \text {, Ni e Zn }\end{array}$ \\
\hline Carbocloro & AIC & $\mathrm{Hg}$ \\
\hline Dow Química & AIC & Solventes halogenados \\
\hline $\mathrm{CBE}$ & AIC & Fenóis e solventes aromáticos \\
\hline Cosipa (Carboquímica) & AIC & $\mathrm{N}, \mathrm{CN}$, fenóis e solventes aromáticos \\
\hline Petrobrás / RPBC & AIC & Fenóis, solventes aromáticos e $\mathrm{Cd}$ \\
\hline Profundir ${ }^{(2)}$ & AIC & $\mathrm{Ar}, \mathrm{Cd}, \mathrm{Pb}, \mathrm{Hg}$ e $\mathrm{Zn}$ \\
\hline Petrobrás / DTCS / Cubatão & DIRSI & $\mathrm{Pb}$ \\
\hline Rhodia - UQC & DIRSI & $\begin{array}{c}\text { Solventes halogenados, organoclorados aromáticos e } \\
\text { pesticidas organoclorados }\end{array}$ \\
\hline Rhodia - Perequê & DIRSI & $\begin{array}{c}\text { Solventes halogenados, organoclorados aromáticos e } \\
\text { pesticidas organoclorados }\end{array}$ \\
\hline Rhodia - Km 67 & DIRSI & $\begin{array}{c}\text { Solventes halogenados, organoclorados aromáticos e } \\
\text { pesticidas organoclorados }\end{array}$ \\
\hline Rhodia - Km 69 & DIRSI & $\begin{array}{c}\text { Solventes halogenados, organoclorados aromáticos e } \\
\text { pesticidas organoclorados }\end{array}$ \\
\hline Rhodia Quarentenário & DIRSI & $\begin{array}{l}\text { Solventes halogenados, organoclorados aromáticos e } \\
\text { pesticidas organoclorados }\end{array}$ \\
\hline Rhodia PI - 05 & DIRSI & $\begin{array}{c}\text { Solventes halogenados, organoclorados aromáticos e } \\
\text { pesticidas organoclorados }\end{array}$ \\
\hline Rhodia PI - 06 & DIRSI & $\begin{array}{l}\text { Solventes halogenados, organoclorados aromáticos e } \\
\text { pesticidas organoclorados }\end{array}$ \\
\hline $\begin{array}{l}\text { Cosipa - Dique do } \\
\text { Furadinho }\end{array}$ & DSC & $\begin{array}{l}\text { N, sulfetos, solventes aromáticos, } \mathrm{Ar}, \mathrm{Cd}, \mathrm{Pb}, \mathrm{Cu}, \mathrm{Cr}, \mathrm{Mn}, \mathrm{Hg}, \mathrm{Ni} \\
\text { e } \mathrm{Zn}\end{array}$ \\
\hline Polígono 1 (até 1974) & DSC & $\mathrm{P}, \mathrm{N}$, organoclorados aromáticos, $\mathrm{Cd}, \mathrm{Pb}, \mathrm{Cu}, \mathrm{Cr}, \mathrm{Mn}, \mathrm{Hg}, \mathrm{Ni}$ e $\mathrm{Zn}$ \\
\hline Polígono 2 (1974 - 1996) & DSC & $\mathrm{P}, \mathrm{N}$, organoclorados aromáticos, $\mathrm{Cd}, \mathrm{Pb}, \mathrm{Cu}, \mathrm{Cr}, \mathrm{Mn}, \mathrm{Hg}, \mathrm{Ni}$ e $\mathrm{Zn}$ \\
\hline Polígono 3 (após 1996) & DSC & $\mathrm{P}, \mathrm{N}$, organoclorados aromáticos, $\mathrm{Cd}, \mathrm{Pb}, \mathrm{Cu}, \mathrm{Cr}, \mathrm{Mn}, \mathrm{Hg}, \mathrm{Ni}$ e $\mathrm{Zn}$ \\
\hline Copebrás & PG & $\begin{array}{l}\text { P e fluoreto } \\
\end{array}$ \\
\hline Ultrafértil & PG & P e fluoreto \\
\hline
\end{tabular}

(1) -indica a disposição conjunta de resíduos industriais perigosos

(2) - industrias desativadas

\# - DRSD = Disposição de resíduos sólidos domésticos; AIC = Áreas industriais contaminadas; DIRSI = Disposição irregular de resíduos sólidos industriais; DSC = Disposição de sedimentos contaminados; $\mathrm{PG}=$ Pilhas de gesso.

*- indica contaminação do poluente na área. 
Tabela IV - Dados populacionais dos municípios da Baixada Santista para os anos de 1996 e 2003.

\begin{tabular}{l|c|c|c|c|c|c|c}
\hline Cidade & Santos & $\begin{array}{c}\text { São } \\
\text { Vicente }\end{array}$ & Guarujá & Cubatão & Bertioga & $\begin{array}{c}\text { Praia } \\
\text { Grande }\end{array}$ & Total \\
\hline $\begin{array}{l}\text { População } \\
\text { (1996) }\end{array}$ & 412.243 & 279.528 & 226.365 & 97.257 & 17.002 & 150.388 & 1.182 .783 \\
\hline $\begin{array}{l}\text { População } \\
\text { (2003) }\end{array}$ & 418.147 & 314.312 & 281.634 & 113.599 & 35.759 & 215.174 & 1.378 .625 \\
\hline
\end{tabular}

Fonte: IBGE, 2003.

Tabela V - Movimentação anual de cargas do Porto de Santos (em toneladas).

\begin{tabular}{l|c|c|c|c|c|c}
\hline & $\mathbf{1 9 9 7}$ & $\mathbf{1 9 9 8}$ & $\mathbf{1 9 9 9}$ & $\mathbf{2 0 0 0}$ & $\mathbf{2 0 0 1}$ & $\mathbf{2 0 0 2}$ \\
\hline Total & 38.472 .130 & 39.940 .386 & 42.675 .507 & 43.084 .383 & 48.161 .593 & 53.474 .268 \\
\hline Exportação & 17.791 .815 & 19.401 .126 & 24.264 .690 & 22.353 .811 & 28.030 .470 & 33.822 .484 \\
\hline Importação & 20.670 .315 & 20.539 .260 & 18.410 .817 & 20.730 .572 & 20.131 .123 & 19.651 .784 \\
\hline
\end{tabular}


Tabela VI - Número de troncos vivos amostrados $(\mathrm{N})$, altura média e DAP médio dos bosques de mangue da Ilha Barnabé.

\begin{tabular}{c|c|c|c|c|c}
\hline \multirow{2}{*}{ Parcela } & \multirow{2}{*}{$\mathbf{N}$} & \multicolumn{3}{|c|}{ Altura média do bosque (m) } & \multirow{2}{*}{$\begin{array}{c}\text { DAP médio } \\
(\mathbf{c m})\end{array}$} \\
\cline { 3 - 5 } IB1 & 17 & Inferior & Superior & Total & 8,74 \\
\hline IB2 & 62 & 1,78 & 7,80 & 5,13 & 5,83 \\
\hline IB3 & 41 & 1,08 & 8,00 & 4,23 & 6,49 \\
\hline R1 & 60 & 1,00 & 7,55 & 4,59 & 1,31 \\
\hline R2 & 58 & 1,02 & 2,00 & 1,37 & 1,59 \\
\hline R3 & 54 & 1,15 & 2,80 & 1,59 & 0,88 \\
\hline C1 & 89 & 1,05 & 3,85 & 1,93 & 4,48 \\
\hline
\end{tabular}

Tabela VII - Densidade relativa (\%) de troncos vivos e mortos, por espécie e por classe de DAP, nos bosques de mangue da Ilha Barnabé.

\begin{tabular}{|c|c|c|c|c|c|c|c|c|c|c|}
\hline \multicolumn{11}{|c|}{ TRONCOS VIVOS } \\
\hline \multirow[b]{2}{*}{ Parcela } & \multicolumn{3}{|c|}{$<2,5 \mathrm{~cm}$} & \multicolumn{3}{|c|}{$>2,5 \mathrm{~cm}$} & \multicolumn{3}{|c|}{$>10,0 \mathrm{~cm}$} & \multirow{2}{*}{$\begin{array}{c}\text { Total } \\
\text { (tronco/ha) }\end{array}$} \\
\hline & $\mathbf{R m}$ & $\mathbf{L r}$ & As & $\mathbf{R m}$ & $\mathbf{L r}$ & As & $\mathbf{R m}$ & $\mathbf{L r}$ & As & \\
\hline IB1 & 0,00 & 1,92 & 0,00 & 0,00 & 19,23 & 0,00 & 0,00 & 7,69 & 3,85 & 32,69 \\
\hline IB2 & 0,00 & 11,11 & 0,00 & 11,11 & 51,11 & 0,00 & 0,00 & 2,22 & 0,00 & 75,56 \\
\hline IB3 & 0,00 & 0,00 & 0,00 & 4,08 & 28,57 & 12,24 & 2,04 & 2,04 & 0,00 & 48,98 \\
\hline R1 & 0,00 & 85,00 & 15,00 & 0,00 & 0,00 & 0,00 & 0,00 & 0,00 & 0,00 & 100,00 \\
\hline $\mathbf{R 2}$ & 5,17 & 51,72 & 43,10 & 0,00 & 0,00 & 0,00 & 0,00 & 0,00 & 0,00 & 100,00 \\
\hline $\mathbf{R 3}$ & 1,82 & 7,27 & 87,27 & 0,00 & 0,00 & 1,82 & 0,00 & 0,00 & 0,00 & 98,18 \\
\hline C1 & 2,88 & 24,04 & 16,35 & 3,85 & 23,08 & 11,54 & 0,00 & 2,88 & 0,96 & 85,58 \\
\hline \multicolumn{11}{|c|}{ TRONCOS MORTOS } \\
\hline \multirow[b]{2}{*}{ Parcela } & \multicolumn{3}{|c|}{$<2,5 \mathrm{~cm}$} & \multicolumn{3}{|c|}{$>2,5 \mathrm{~cm}$} & \multicolumn{3}{|c|}{$>10,0 \mathrm{~cm}$} & \multirow{2}{*}{$\begin{array}{c}\text { Total } \\
\text { (tronco/ha) }\end{array}$} \\
\hline & $\mathbf{R m}$ & $\mathbf{L r}$ & As & $\mathbf{R m}$ & Lr & As & $\mathbf{R m}$ & $\mathbf{L r}$ & As & \\
\hline IB1 & 0,00 & 1,92 & 0,00 & 0,00 & 53,85 & 1,92 & 0,00 & 9,62 & 0,00 & 67,31 \\
\hline IB2 & 0,00 & 2,22 & 0,00 & 2,22 & 15,56 & 0,00 & 0,00 & 4,44 & 0,00 & 24,44 \\
\hline IB3 & 0,00 & 2,04 & 0,00 & 0,00 & 36,73 & 2,04 & 0,00 & 10,20 & 0,00 & 51,02 \\
\hline $\mathbf{R 1}$ & 0,00 & 0,00 & 0,00 & 0,00 & 0,00 & 0,00 & 0,00 & 0,00 & 0,00 & 0,00 \\
\hline $\mathbf{R 2}$ & 0,00 & 0,00 & 0,00 & 0,00 & 0,00 & 0,00 & 0,00 & 0,00 & 0,00 & 0,00 \\
\hline $\mathbf{R 3}$ & 0,00 & 0,00 & 1,82 & 0,00 & 0,00 & 0,00 & 0,00 & 0,00 & 0,00 & 1,82 \\
\hline C1 & 0,00 & 0,00 & 5,77 & 0,00 & 5,77 & 1,92 & 0,00 & 0,96 & 0,00 & 14,42 \\
\hline
\end{tabular}


Tabela VIII - Área basal $\left(\mathrm{m}^{2} / \mathrm{ha}\right)$ viva e morta, por classe de DAP dos bosques de mangue da Ilha Barnabé.

\begin{tabular}{|c|c|c|c|c|c|c|c|c|c|}
\hline \multirow{2}{*}{ Parcela } & \multicolumn{4}{|c|}{ Área basal viva $\left(\mathrm{m}^{2} / \mathrm{ha}\right)$} & \multicolumn{4}{|c|}{ Área basal morta $\left(\mathrm{m}^{2} / \mathrm{ha}\right)$} & \multirow{2}{*}{ Total geral } \\
\hline & $<2.5$ & $>2.5$ & $>10.0$ & Total & $<2.5$ & $>2.5$ & $>10.0$ & Total & \\
\hline IB1 & 0,01 & 2,00 & 4,80 & 6,80 & 0,03 & 6,18 & 3,67 & 9,88 & 16,68 \\
\hline IB2 & 0,12 & 8,14 & 0,83 & 9,10 & 0,03 & 1,55 & 2,04 & 3,62 & 12,72 \\
\hline IB3 & 0,00 & 4,05 & 1,24 & 5,30 & 0,02 & 5,14 & 3,23 & 8,39 & 13,68 \\
\hline R1 & 9,07 & 0,00 & 0,00 & 9,07 & 0,00 & 0,00 & 0,00 & 0,00 & 9,07 \\
\hline $\mathbf{R 2}$ & 9,60 & 0,00 & 0,00 & 9,60 & 0,00 & 0,00 & 0,00 & 0,00 & 9,60 \\
\hline $\mathbf{R 3}$ & 4,67 & 0,88 & 0,00 & 5,56 & 0,00 & 0,00 & 0,00 & 0,01 & 5,57 \\
\hline C1 & 1,18 & 7,37 & 5,48 & 14,02 & 0,31 & 1,87 & 0,90 & 2,88 & 16,90 \\
\hline
\end{tabular}

Tabela IX - Dominância em área basal (\%) viva e morta, por espécie, nos bosques de mangue da Ilha Barnabé.

\begin{tabular}{|c|c|c|c|c|c|c|c|c|}
\hline \multirow[b]{2}{*}{ Parcela } & \multicolumn{4}{|c|}{ Área basal viva (\%) } & \multicolumn{4}{|c|}{ Área basal morta (\%) } \\
\hline & $\mathbf{R m}$ & $\mathbf{L r}$ & As & Total & $\mathbf{R m}$ & $\mathbf{L r}$ & As & Total \\
\hline IB1 & 0,00 & 27,30 & 13,48 & 40,78 & 0,00 & 58,94 & 0,28 & 59,22 \\
\hline IB2 & 11,50 & 60,03 & 0,00 & 71,53 & 0,45 & 28,02 & 0,00 & 28,47 \\
\hline IB3 & 6,06 & 27,61 & 5,03 & 38,70 & 0,00 & 60,72 & 0,58 & 61,30 \\
\hline $\mathbf{R 1}$ & 0,00 & 82,81 & 17,19 & 100,00 & 0,00 & 0,00 & 0,00 & 0,00 \\
\hline $\mathbf{R 2}$ & 7,48 & 50,59 & 41,93 & 100,00 & 0,00 & 0,00 & 0,00 & 0,00 \\
\hline $\mathbf{R 3}$ & 6,02 & 8,51 & 85,26 & 99,79 & 0,00 & 0,00 & 0,21 & 0,21 \\
\hline C1 & 7,48 & 45,65 & 29,83 & 82,97 & 0,00 & 14,70 & 2,34 & 17,03 \\
\hline
\end{tabular}


Tabela X - Número de indivíduos vivos e taxa de sobrevivência por espécie e total, altura média e taxa de crescimento da parcela em processo de regeneração (R2), do bosque de mangue da Ilha Barnabé.

\begin{tabular}{c|c|c|c|c|c|c|c}
\hline \multirow{2}{*}{ Parcela R2 } & \multicolumn{7}{c}{ Datas } \\
\cline { 2 - 8 } & $\mathbf{2 7 / 0 3 / 0 2}$ & $\mathbf{4 / 0 6 / 2 0}$ & $\mathbf{2 8 / 1 0 / 0 2}$ & $\mathbf{5 / 0 2 / 0 3}$ & $\mathbf{2 5 / 0 6 / 0 3}$ & $\mathbf{9 / 1 0 / 0 3}$ & $\mathbf{1 8 / 0 2 / 0 4}$ \\
\hline $\mathbf{n}^{\mathbf{0}}$ de indivíduos vivos Lg & 53 & 51 & 44 & 37 & 24 & 18 & 15 \\
\hline taxa de sobrevivência (\%) & 100,00 & 96,23 & 83,02 & 69,81 & 45,28 & 33,96 & 28,30 \\
\hline $\mathbf{n}^{\mathbf{0}}$ de indivíduos vivos Av & 14 & 14 & 12 & 11 & 11 & 11 & 11 \\
\hline taxa de sobrevivência (\%) & 100,00 & 100,00 & 85,71 & 78,57 & 78,57 & 78,57 & 78,57 \\
\hline $\mathbf{n}^{\mathbf{0}}$ total de indivíduos vivos & 67 & 65 & 58 & 49 & 35 & 29 & 26 \\
\hline taxa de sobrevivência (\%) & 100,00 & 97,01 & 86,57 & 73,13 & 52,24 & 43,28 & 38,81 \\
\hline Altura média & 1,56 & 1,62 & 1,88 & 2,25 & 2,47 & 2,48 & 2,51 \\
\hline Taxa de crescimento (mm/dia) & & 0,89 & 2,30 & 3,70 & 1,50 & 0,19 & 0,22 \\
\hline
\end{tabular}

Tabela XI - Número de indivíduos vivos e taxa de sobrevivência por espécie e total, altura média e taxa de crescimento da parcela em processo de regeneração (R3), do bosque de mangue da Ilha Barnabé.

\begin{tabular}{c|c|c|c|c|c|c|c}
\hline \multirow{2}{*}{ Parcela R3 } & \multicolumn{7}{|c}{ Datas } \\
\cline { 2 - 8 } & $\mathbf{2 8 / 0 2 / 0 2}$ & $\mathbf{4 / 0 6 / 0 2}$ & $\mathbf{2 8 / 1 0 / 0 2}$ & $\mathbf{5 / 0 2 / 0 3}$ & $\mathbf{2 5 / 0 6 / 0 3}$ & $\mathbf{9 / 1 0 / 0 3}$ & $\mathbf{1 8 / 0 2 / 0 4}$ \\
\hline $\mathbf{n}^{\mathbf{0}}$ de indivíduos vivos Lg & 5 & 5 & 5 & 5 & 2 & 2 & 2 \\
\hline taxa de sobrevivência (\%) & 100,00 & 100,00 & 100,00 & 100,00 & 40,00 & 40,00 & 40,00 \\
\hline $\mathbf{n}^{\mathbf{0}}$ de indivíduos vivos Av & 37 & 37 & 37 & 37 & 34 & 33 & 33 \\
\hline taxa de sobrevivência (\%) & 100,00 & 100,00 & 100,00 & 100,00 & 91,89 & 89,19 & 89,19 \\
\hline $\mathbf{n}^{\mathbf{0}}$ de indivíduos vivos Rh & 1 & 1 & 1 & 1 & 1 & 1 & 1 \\
\hline taxa de sobrevivência (\%) & 100,00 & 100,00 & 100,00 & 100,00 & 100,00 & 100,00 & 100,00 \\
\hline $\mathbf{n}^{\mathbf{0}}$ total de indivíduos vivos & 43 & 43 & 43 & 43 & 37 & 36 & 36 \\
\hline taxa de sobrevivência (\%) & 100,00 & 100,00 & 100,00 & 100,00 & 86,05 & 83,72 & 83,72 \\
\hline Altura média & 1,90 & 1,98 & 2,09 & 1,99 & 2,08 & 2,14 & 2,13 \\
\hline Taxa de crescimento (mm/dia) & 0,00 & 0,82 & 0,95 & 0,00 & 0,63 & 0,63 & 0,00 \\
\hline
\end{tabular}


Tabela XII - Número de troncos vivos amostrados $(\mathrm{N})$, altura média e DAP médio das parcelas em processo de regeneração (R2 e R3) do bosque de mangue da Ilha Barnabé, nos anos de 2002 e 2004.

\begin{tabular}{c|c|c|c|c|c}
\hline \multirow{2}{*}{ Parcela } & \multirow{N}{*}{$\mathbf{N}$} & \multicolumn{3}{|c|}{ Altura média do bosque (m) } & DAP médio \\
\cline { 3 - 5 } & & Inferior & Superior & Total & $(\mathbf{c m})$ \\
\hline R2 - 2002 & 58 & 1,02 & 2,80 & 1,59 & 1,59 \\
\hline R2 - 2004 & 61 & 0,50 & 4,30 & 2,46 & 1,36 \\
\hline R3 - 2002 & 54 & 1,15 & 3,85 & 1,93 & 0,89 \\
\hline R3 - 2004 & 59 & 0,80 & 6,60 & 2,02 & 1,57 \\
\hline
\end{tabular}

Tabela XIII - Densidade relativa (\%) de troncos vivos e mortos, por espécie e por classe de $\mathrm{DAP}$, das parcelas em processo de regeneração (R2 e R3) do bosque de mangue da Ilha Barnabé, nos anos de 2002 e 2004.

\begin{tabular}{|c|c|c|c|c|c|c|c|c|c|c|}
\hline \multicolumn{11}{|c|}{ TRONCOS VIVOS } \\
\hline \multirow[b]{2}{*}{ Parcela } & \multicolumn{3}{|c|}{$<2,5 \mathrm{~cm}$} & \multicolumn{3}{|c|}{$>2,5 \mathrm{~cm}$} & \multicolumn{3}{|c|}{$>10,0 \mathrm{~cm}$} & \multirow{2}{*}{$\begin{array}{c}\text { Total } \\
\text { (tronco/ha) }\end{array}$} \\
\hline & $\mathbf{R m}$ & Lr & As & $\mathbf{R m}$ & $\mathbf{L r}$ & As & $\mathbf{R m}$ & $\mathbf{L r}$ & As & \\
\hline R2 - 2002 & 5,17 & 51,72 & 43,10 & 0,00 & 0,00 & 0,00 & 0,00 & 0,00 & 0,00 & 100,00 \\
\hline R2 - 2004 & 0,00 & 26,98 & 46,03 & 0,00 & 4,76 & 1,59 & 0,00 & 0,00 & 0,00 & 79,37 \\
\hline R3 - 2002 & 1,82 & 7,27 & 87,27 & 0,00 & 0,00 & 1,82 & 0,00 & 0,00 & 0,00 & 98,18 \\
\hline R3 - 2004 & 3,39 & 6,78 & 81,36 & 0,00 & 0,00 & 6,78 & 0,00 & 0,00 & 0,00 & 98,31 \\
\hline \multicolumn{11}{|c|}{ TRONCOS MORTOS } \\
\hline \multirow[b]{2}{*}{ Parcela } & \multicolumn{3}{|c|}{$<2,5 \mathrm{~cm}$} & \multicolumn{3}{|c|}{$>2,5 \mathrm{~cm}$} & \multicolumn{3}{|c|}{$>10,0 \mathrm{~cm}$} & \multirow{2}{*}{$\begin{array}{c}\text { Total } \\
\text { (tronco/ha) }\end{array}$} \\
\hline & $\mathbf{R m}$ & $\mathbf{L r}$ & As & $\mathbf{R m}$ & $\mathbf{L r}$ & As & $\mathbf{R m}$ & $\mathbf{L r}$ & As & \\
\hline R2 - 2002 & 0,00 & 0,00 & 0,00 & 0,00 & 0,00 & 0,00 & 0,00 & 0,00 & 0,00 & 0,00 \\
\hline R2 - 2004 & 0,00 & 19,05 & 0,00 & 0,00 & 1,59 & 0,00 & 0,00 & 0,00 & 0,00 & 20,63 \\
\hline R3 - 2002 & 0,00 & 0,00 & 1,82 & 0,00 & 0,00 & 0,00 & 0,00 & 0,00 & 0,00 & 1,82 \\
\hline R3 - 2004 & 0,00 & 0,00 & 1,69 & 0,00 & 0,00 & 0,00 & 0,00 & 0,00 & 0,00 & 1,69 \\
\hline
\end{tabular}


Tabela XIV - Área basal $\left(\mathrm{m}^{2} / \mathrm{ha}\right)$ viva e morta, por classe de DAP das parcelas em processo de regeneração (R2 e R3) do bosque de mangue da Ilha Barnabé, nos anos de 2002 e 2004.

\begin{tabular}{c|c|c|c|c|c|c|c|c|c}
\hline \multirow{2}{*}{ Parcela } & \multicolumn{3}{|c|}{ Área basal viva $\left(\mathbf{m}^{\mathbf{2}} / \mathbf{h a}\right)$} & \multicolumn{3}{c|}{ Área basal morta $\left(\mathbf{m}^{\mathbf{2}} / \mathbf{h a}\right)$} & \multirow{2}{*}{ Total geral } \\
\cline { 2 - 10 } & $\mathbf{2 . 5}$ & $\mathbf{> 2 . 5}$ & $\mathbf{>} \mathbf{1 0 . 0}$ & Total & $\mathbf{< . 5}$ & $\mathbf{>} \mathbf{2 . 5}$ & $\mathbf{> 1 0 . 0}$ & Total & \\
\hline R2 - 2002 & 9,60 & 0,00 & 0,00 & 9,60 & 0,00 & 0,00 & 0,00 & 0,00 & 9,60 \\
\hline R2 - 2004 & 5,28 & 2,82 & 0,00 & 8,10 & 1,91 & 0,55 & 0,00 & 2,46 & 10,56 \\
\hline R3 - 2002 & 4,67 & 0,88 & 0,00 & 5,56 & 0,01 & 0,00 & 0,00 & 0,01 & 5,57 \\
\hline R3 - 2004 & 10,66 & 8,09 & 0,00 & 18,75 & 0,38 & 0,00 & 0,00 & 0,38 & 19,13 \\
\hline
\end{tabular}

Tabela XV - Dominância em área basal (\%) viva e morta, por espécie, das parcelas em processo de regeneração (R2 e R3) do bosque de mangue da Ilha Barnabé, nos anos de 2002 e 2004.

\begin{tabular}{c|c|c|c|c|c|c|c|c}
\hline \multirow{2}{*}{ Parcela } & \multicolumn{4}{|c|}{ Área basal viva (\%) } & \multicolumn{4}{c}{ Área basal morta (\%) } \\
\cline { 2 - 10 } & $\mathbf{R m}$ & $\mathbf{L r}$ & $\mathbf{A s}$ & Total & $\mathbf{R m}$ & $\mathbf{L r}$ & $\mathbf{A s}$ & Total \\
\hline R2 - 2002 & 7,48 & 50,59 & 41,93 & 100,00 & 0,00 & 0,00 & 0,00 & 0,00 \\
\hline R2 - 2004 & 0,00 & 41,81 & 34,91 & 76,72 & 0,00 & 23,28 & 0,00 & 23,28 \\
\hline R3 - 2002 & 6,02 & 8,51 & 85,26 & 99,79 & 0,00 & 0,00 & 0,21 & 0,21 \\
\hline R3 - 2004 & 4,00 & 7,30 & 86,72 & 98,02 & 0,00 & 0,00 & 1,98 & 1,98 \\
\hline
\end{tabular}




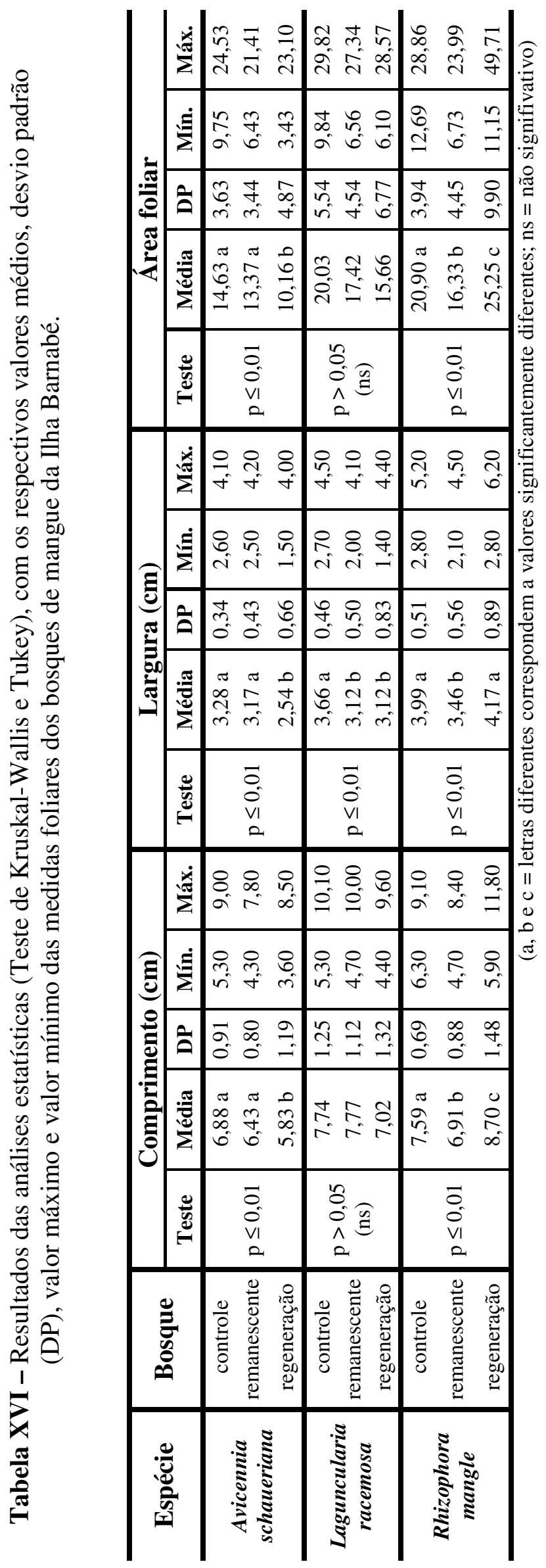




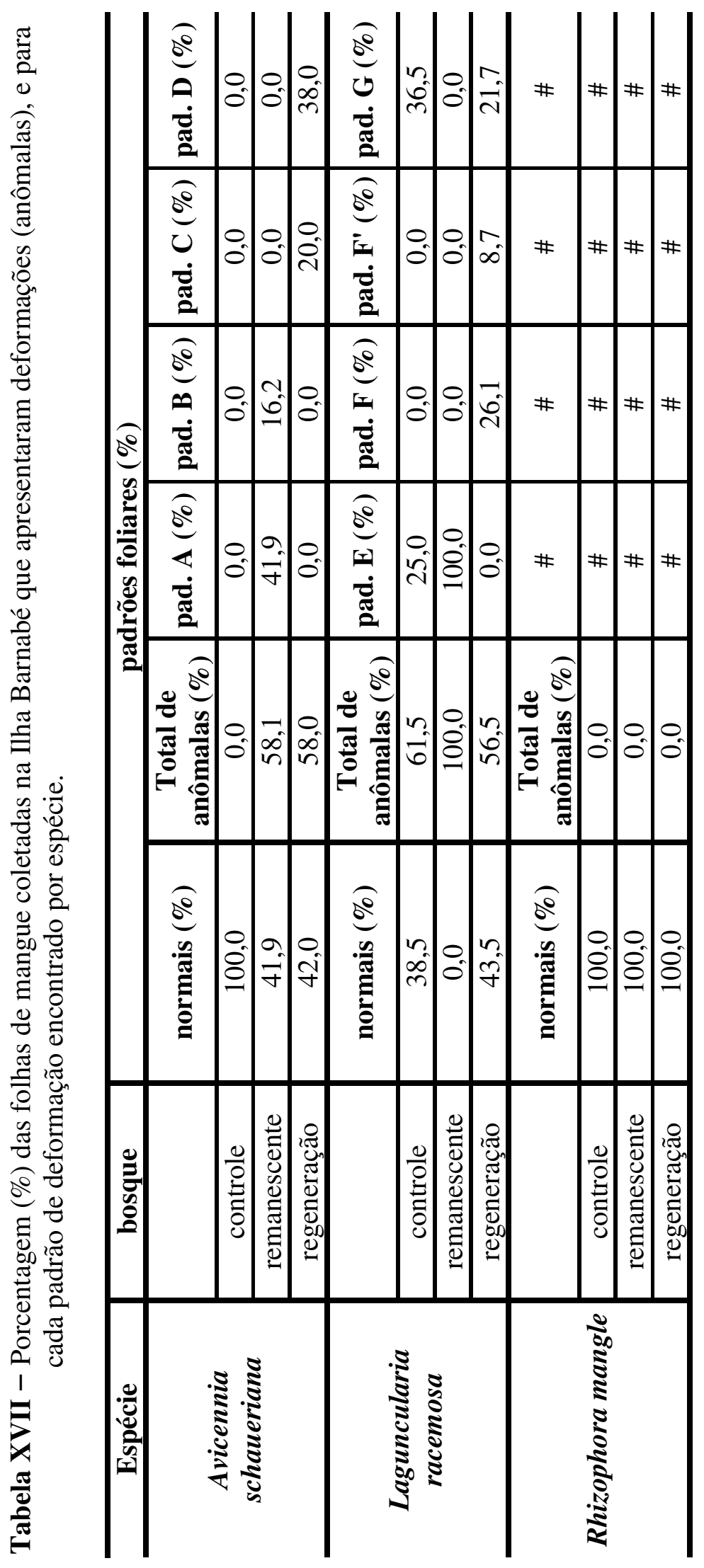


